\title{
An evaluation of the River-OSPAR method for quantifying macrolitter on Dutch riverbanks
}

Tim van Emmerik ${ }^{1}$, Paul Vriend ${ }^{1}$ and Jasper Roebroek ${ }^{1}$

1 Hydrology and Quantitative Water Management Group, Wageningen University

Correspondence: tim.vanemmerik@wur.nl

This research was funded by the Dutch Ministry of Infrastructure and Water Management, Directorate-General for Public Works and Water Management (Rijkswaterstaat) (project number 5160957973).

Wageningen University

Wageningen, January 2020

Approved for publication:

dr.ir. T.H.M. van Emmerik, Assistant Professor, Hydrology and Quantitative Water Management Group, Wageningen University 

van Emmerik, T.H.M., Vriend, P. and Roebroek, C.T.J., 2020. An evaluation of the River-OSPAR method for quantifying macrolitter on Dutch riverbanks. Wageningen, Wageningen University, Report. 86 pp., https://doi.org/10.18174/519776

Keywords: plastic pollution, anthropogenic litter, macroplastic, riverine plastic, Meuse, Rhine

This work has been commissioned by:

Ministry of Infrastructure and Water Management

Directorate-General for Public Works and Water Management

Government of the Netherlands

This work is licensed under a Creative Commons Attribution 4.0 International License (CC BY 4.0). Wageningen University does not deliver printed versions of the Wageningen University reports.

(c) 2020 T.H.M. van Emmerik, P. Vriend and C.J.T. Roebroek

Wageningen University assumes no liability for any losses resulting from the use of the research results or recommendations in this report.

Wageningen University report

ISBN 978-94-6395-379-5

https://doi.org/10.18174/519776 



\section{Contents}

$\begin{array}{lr}\text { Contents } & 5\end{array}$

$\begin{array}{ll}\text { Preface } & 7\end{array}$

$\begin{array}{lr}\text { Summary in English } & 9\end{array}$

$\begin{array}{lr}\text { Samenvatting in het Nederlands } & 11\end{array}$

$\begin{array}{ll}\text { List of abbreviations } & 13\end{array}$

$\begin{array}{llr}1 & \text { Introduction } & 15\end{array}$

$\begin{array}{lll}1.1 & \text { Background } & 15\end{array}$

1.2 Riverbank monitoring 16

1.3 Scope of this report 16

$\begin{array}{lll}1.4 & \text { Research questions } & 16\end{array}$

$\begin{array}{lll}1.5 & \text { Approach } & 17\end{array}$

$\begin{array}{lll}1.6 & \text { How to read this report } & 17\end{array}$

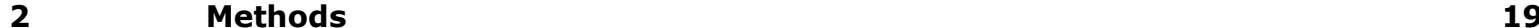

2.1 Study area $\quad 19$

2.2 Comparative literature study 19

2.3 Data analysis $\quad 20$

2.3.1 Database preprocessing 20

2.3.2 Hydrometeorological effect on litter $\quad 20$

2.3.3 Longitudinal analysis $\quad 22$

$3 \quad$ The River-OSPAR Protocol 25

3.1 Description of the River-OSPAR protocol 25

3.2 Comparison between River-OSPAR and OSPAR-Beach Litter protocols 26

3.3 Potential insights from the River-OSPAR method 29

3.3.1 Composition 29

$\begin{array}{ll}3.3 .2 \text { Sources } & 29\end{array}$

4

Comparison of the River-OSPAR with other methods $\quad 30$

4.1 Plastic Pirates $\quad 30$

4.2 NOAA Protocol $\quad 32$

4.3 Battulga Protocol 33

4.4 Overview of other citizen science projects $\quad 34$

$\begin{array}{lll}4.5 & \text { Microlitter methods } & 35\end{array}$

$5 \quad$ Analysis River-OSPAR data 2017 - $2019 \quad 37$

$\begin{array}{lll}5.1 & \text { Dataset } & 37\end{array}$

$\begin{array}{lll}5.2 & \text { Variation over time } & 37\end{array}$

5.3 Seasonality 38

$5.4 \quad$ Variation along the river $\quad 39$

5.4.1 Parent categories $\quad 39$

5.5 Litter sources $\quad 43$

5.5.1 Meuse 43 
5.5.2 Waal 45

5.5.3 Discussion litter sources $\quad 46$

$\begin{array}{lll}5.6 & \text { Governing transport mechanisms } & 46\end{array}$

$\begin{array}{ll}5.6 .1 \text { Meuse } & 46\end{array}$

5.6.2 Waal 48

$\begin{array}{lll}5.7 & \text { Data quality } & 49\end{array}$

5.8 Discussion $\quad 50$

5.9 Conclusion $\quad 50$

$6 \quad$ Outlook for future riverbank litter monitoring in the Netherlands

6.1 Alternative monitoring methods $\quad 53$

6.1.1 Learning from similar approaches $\quad 53$

6.1.2 Citizen science methods $\quad 53$

6.1.3 UAV-based methods $\quad 54$

6.1.4 Remote sensing from space $\quad 55$

6.1.5 Camera-based monitoring $\quad 55$

6.2 Including litter in other river components $\quad 55$

6.2.1 Floating Litter $\quad 55$

6.2.2 Litter in sediments $\quad 56$

6.2.3 Litter in other components of the river system 56

6.3 Link to other data sources $\quad 56$

6.3.1 Municipal waste data $\quad 56$

6.3.2 Waterboard (Waterschap) infrastructure data 56

6.3.3 Land-based litter

6.3.4 Land use data $\quad 57$

6.3.5 Riverbank cleaning efforts $\quad 57$

$\begin{array}{lll}6.4 & \text { Database and data management } & 57\end{array}$

$7 \quad$ Conclusions and recommendations $\quad 60$

$\begin{array}{lll}7.1 & \text { Answers to the research questions } & 60\end{array}$

$\begin{array}{lll}7.2 & \text { Additional recommendations } & 65\end{array}$

$\begin{array}{lr}\text { References } & 66\end{array}$

$\begin{array}{ll}\text { Annex } 1 \text { Hydrometeorological analysis } & 72\end{array}$

$\begin{array}{lr}\text { Annex } 2 \text { Extended figures } & 74\end{array}$

$\begin{array}{lr}\text { Annex } 3 \text { Item category lists } & 77\end{array}$

$\begin{array}{lr}\text { Annex } 4 \text { Item source classification } & \mathbf{8 0}\end{array}$

Annex 5 Transport mechanism classification $\quad 82$

$\begin{array}{lr}\text { Annex } 6 \text { Supporting files } & 85\end{array}$ 


\section{Preface}

This report presents the results from an evaluation of the River-OSPAR riverbank litter monitoring protocol. The River-OSPAR method has been developed by Stichting De Noordzee as an adaptation of the OSPAR Guidelines for beach litter monitoring. In our study, we compared the River-OSPAR method with the original beach protocol, and with several other protocols for quantifying riverbank litter. We also used the available two-year long dataset (2017 - 2019) for preliminary analyses of spatial and temporal variation, and identification of potential sources of the sampled litter. This study has been commissioned by the Dutch Ministry of Infrastructure and Water Management, Directorate-General for Public Works and Water Management (Rijkswaterstaat). We thank Marijke Boonsma and Winnie de Winter from Stichting De Noordzee for their contributions, making the dataset available and their feedback on earlier versions of this report. We also thank Juliane Kupfernagel and colleagues from Rijkswaterstaat for their valuable input on this report, and for giving us the opportunity to conduct this study.

Wageningen, December 2019 


\section{Summary in English}

Anthropogenic litter, plastic in particular, is an emerging ecological hazard. To effectively prevent, mitigate and reduce litter in river systems, accurate monitoring of litter in the Dutch rivers is necessary. Inspired by the OSPAR Guideline for monitoring marine litter on the beaches in the OSPAR maritime area, a riverbank litter monitoring protocol (River-OSPAR) was developed by Stichting De Noordzee. In this report, we present an evaluation of the River-OSPAR method in. We compared the River-OSPAR protocol with the original Beach-OSPAR protocol, as well as other methods for riverbank litter monitoring. Subsequently, we present the results of a data analysis based on the two years of available observations (2017 - 2019) at in total 211 unique measurement locations. We explored the variation of space and time, as well as the composition, sources and transport mechanisms. Finally, we discuss the learnings from monitoring efforts focusing on litter in other components of the river system, and potential use of additional data to study sources and pathways of litter in Dutch Rivers.

The strengths of the River-OSPAR include the extensive geographical coverage and detailed item categorization. These data allow for detailed hotspot analysis along the rivers Meuse and Waal. Both incidental and consistent hotspots were found. Incidental peaks may be related to increased input or accumulation at that location. Consistent hotspots were found to be located close to urban areas with direct access to the river, such as the cities of Nijmegen, Roermond and Maastricht. The detailed data on occurrence of specific items allowed for a correlation analysis to determine the sources of each item.

Recommendations for improvement of the method and dataset include (1) increased temporal resolution, (2) additional reference measurements, and (3) inclusion of item mass statistics. The limited temporal extent of the data causes some uncertainty. Tentative conclusions on the spatial variation and seasonality can only be supported through expansion of the dataset in time. Increasing the measurement frequency from two to four times per year will also increase the possible analysis, specifically with regard to exploring the relation between litter density and hydrometeorological conditions. Additional reference measurements will shed light on the volunteer bias. It was found that volunteers generally observe less items than the reference measurements. It is recommended to plan reference measurements at the exact same locations to determine the bias. Finally, inclusion of mass statistics will allow expressing the litter density in terms of mass rather than items. Mass can in turn be related to production, consumption and waste handling data. Furthermore, this can help optimizing strategies to mitigate and remove litter from river systems.

Additional recommendations include the application of new technology for data collection and management, and observing other components of the river system. New technological advances include the development of camera-based automated litter monitoring systems, UAVs and mobile applications. Cameras can be used for permanent monitoring of litter at specific locations. UAVs on the other hand can be used for quick scans of large areas, or follow-up monitoring of hotspots from the River-OSPAR observations. To facilitate better recording of raw data, it is recommended to use mobile apps for data collection. As samples need to be sorted in over 100 categories, apps with smart indexing may faster data collection. Also, raw data can easier be quality checked. The current monitoring effort mainly focusses on riverbank litter. A large share of litter however is mobile as floating litter. Several citizen science methods exist for rapid monitoring of floating litter in rivers. We recommend to expand the country-wide monitoring effort with floating litter observations from bridges. They can either be implemented in the current monitoring effort, or be organized as stand-alone observations with higher temporal frequency.

The current River-OSPAR method has provided an unprecedented data with high spatial frequency and detailed item categorization. These insights already provide valuable insights that can support decisionmaking in litter prevention, mitigation and reduction strategies. Several aspects can be considered to further improve the protocol, which may help answering the questions that remain open to date. 


\section{Samenvatting in het Nederlands}

Zwerfafval afkomstig van antropogene bronnen, met name plastic, is een toenemend ecologisch probleem. Het monitoren van afval in Nederlandse rivieren is essentieel voor het reduceren en/of stoppen van de instroom van nieuw zwerfafval in het aquatisch milieu. Stichting De Noordzee heeft een protocol ontwikkeld voor het monitoren van zwerfafval op rivieroevers (River-OSPAR), geïnspireerd door het protocol voor strandafvalmetingen dat is ontwikkeld door de OSPAR-commissie (Beach-OSPAR). In dit rapport presenteren wij een evaluatie van de River-OSPAR-methode. Hiervoor hebben wij vergelijkend onderzoek uitgevoerd waarin het River-OSPAR-protocol wordt vergeleken met het BeachOSPAR-protocol, en met andere protocollen die zwerfafval op rivieroevers kwantificeren. Aansluitend presenteren wij de resultaten van de data-analyse gebaseerd op de dataset van Stichting De Noordzee. Deze dataset bevat gegevens verzameld over een periode van 2 jaar (2017 - 2019) voor 211 unieke locaties op Nederlandse rivieroevers. Deze data zijn gebruikt voor het bestuderen van de variatie van zwerfaval over de ruimte en de tijd, de compositie van het afval, en mogelijke bronnen en transport mechanismes. Tot slot bespreken wij lessen die we kunnen trekken uit het monitoren van zwerfafval in andere componenten van riviersystemen, en andere potentiele databronnen die gebruikt zouden kunnen worden voor het bestuderen van de bronnen en transportmechanismes van afval in Nederlandse rivieren.

Sterke punten van het River-OSPAR-protocol zijn de grote geografische spreiding van de meetlocaties en het detail waarop het gevonden zwerfafval wordt gecategoriseerd. Deze data maken het mogelijk om een gedetailleerde hotspotanalyse uit te voeren van afval op de rivieroevers van de Maas en de Waal. Deze analyse heeft zowel tijdelijke als consistente hotspots geïdentificeerd. De tijdelijke hotspots kunnen gerelateerd zijn aan een hogere toevoer of accumulatie van zwerfafval op de specifieke locatie. De consistente hotspots zijn vaak gelegen in de omgeving van dichtbevolkte gebieden met directe toegang tot de rivieren, voorbeelden hiervan zijn de steden Nijmegen, Roermond en Maastricht. Door de getailleerde data over het voorkomen van de verschillende items konden correlaties worden gemaakt tussen de items. Deze correlaties in combinatie met indicatoritems zijn gebruikt om de items in bron categorieën onder te verdelen.

Aanbevelingen voor de verbetering van de River-OSPAR-methode en de bijbehorende dataset zijn (1) een verhoging van de meetfrequentie, (2) een vergroting van het aantal referentiemetingen, en (3) de toevoeging van massa statistieken van het gevonden zwerfafval. De voorlopige conclusies over de ruimtelijke verdeling en seizoensgebondenheid van zwerfafval in rivieren hebben verdere onderbouwing nodig. Hiervoor zal de meetfrequentie moeten worden verhoogd, bijvoorbeeld van twee naar vier keer per jaar. Deze verhoging zal ook lijden tot het verkrijgen van andere inzichten zoals het verband tussen afval dichtheid en hydrometeorologische omstandigheden. De vergroting van het aantal referentiemetingen zal meer inzicht geven in de eventuele meetonnauwkeurigheid van de vrijwilligers. Uit de huidige data blijkt dat vrijwilligers in het algemeen minder afval vinden dan de experts tijdens de referentiemetingen. We raden aan om referentiemetingen op dezelfde locaties uit te voeren als waar vrijwilligers onderzoek doen om deze meetonnauwkeurigheid beter te kunnen bestuderen. Tot slot raden wij aan om een massa-analyse toe te passen op het gevonden zwerfvuil zodat de afvaldichtheid kan worden uitgedrukt in massa in plaats van aantal voorwerpen. Dit omdat massa kan worden gerelateerd aan productie-, consumptie- en afvalverwerkingsdata. Bovendien kan massadata van pas komen met het optimaliseren van strategieën om afval te verminderen en/of te verwijderen uit de Nederlandse rivieren.

Naast verbeterpunten voor de River-OSPAR-methode hebben wij ook aanvullende aanbevelingen voor andere technologieën die gebruikt zouden kunnen worden voor het monitoren van afval op rivieroever afval. Hiervoor zouden bijvoorbeeld nieuwe ontwikkelingen zoals camera's die automatisch afval kwantificeren, unmanned aerial vehicles (UAVs, ook wel drones genoemd), en het gebruik van mobiele telefoonapplicaties. Camera's kunnen worden gebruikt om bepaalde locaties permanent en autonoom te monitoren. UAVs kunnen juist worden gebruikt om in een korte tijdspan een groter gebied te kunnen analyseren, of kunnen worden gebruikt om hotspots die zijn geïdentificeerd tijdens River-OSPARmethode makkelijker te blijven monitoren. Mobiele telefoonapplicaties kunnen twee voordelen bieden. Ten eerste kan een app het makkelijker maken voor vrijwilligers om het gevonden afval te categoriseren 
door het gebruik van een slimme indeling en/of zoekfunctie. Ten tweede wordt door het gebruik van een app de ruwe data ook beschikbaar voor analyse, hierdoor wordt het checken van de kwaliteit van de data gemakkelijker.

De huidige monitoring methode focust zich alleen op afval op rivieroevers. Een groot deel van afval in rivieren is echter drijvend afval. Wij raden daarom aan om de schaal van toekomstige nationale monitoring campagnes uit te breiden met het monitoren van drijvend afval vanaf bruggen. Dit kan bij de huidige monitoring campagne worden toegevoegd, of als losstaande campagne met een hogere meetfrequentie worden geïmplementeerd.

De huidige River-OSPAR-methode heeft een ongekend grote dataset opgeleverd met een hoge ruimtelijke frequentie en gedetailleerde itemcategorisering. Deze inzichten leveren al waardevolle inzichten op die de besluitvorming over zwerfafvalpreventie, mitigatie en reductiestrategieën kunnen ondersteunen. Verschillende aspecten kunnen worden overwogen om het protocol verder te verbeteren, wat kan helpen bij het beantwoorden van de vragen die tot op heden nog niet beantwoord zijn. 


\section{List of abbreviations}

Beach-OSPAR OSPAR Guidelines for Monitoring Marine Litter on Beaches in the OSPAR Maritime Area IVN Instituut voor natuureducatie en duurzaamheid (Institute for Nature Education and Sustainability)

KNMI Koninklijk Nederlands Meteorologisch Instituut (Royal Netherlands Meteorological Institute)

OSPAR Combination of Oslo and Paris. Refers to the Convention for the Protection of the Marine Environment of the North-East Atlantic or OSPAR Convention

PPM

Plastic Pirate Method, litter identification protocol developed by Kiessling et al. (2019)

River-OSPAR

OSPAR inspired monitoring protocol for litter on river shores, developed by SDN

SDN

Stichting De Noordzee 


\section{Introduction}

\subsection{Background}

Plastic pollution in aquatic environments is an emerging environmental risk, as it may negatively impact ecosystems, endangers aquatic species, and causes economic damage (Thompson et al., 2004; McIlgorm et al., 2011; O Conchubhair et al., 2019). Rivers are assumed to play a crucial role in transporting land-based plastic waste to the world's oceans (Schmidt et al., 2017). However, rivers and their ecosystems are also directly affected by plastic pollution (van Emmerik \& Schwarz, 2020). To better quantify global plastic pollution transport and to effectively reduce sources and risks, a thorough understanding of sources, transport, fate and effects of riverine plastic debris is crucial.

Plastic waste enter river systems through either natural transport processes or through direct dumping. Natural transport can be caused by wind or rainfall-driven surface runoff (Bruge et al., 2018). Direct dumping can include illegal dumping sites (Rech et al., 2015; Mihai, 2018) and unintentional disposal at recreational locations, such as river banks (Kiessling et al. 2019). Once in a river, plastic transport and accumulation is influenced by hydrological (water level, flow velocity, discharge) and anthropogenic factors (hydraulic infrastructure, cleanup activities, navigation).

Plastic items have been observed in all compartments of the river system. Depending on the plastic item polymer type, state of degradation and antecedent hydrological regime, items can be mobile in the water column or (temporarily) accumulated. Riverine plastic transport consists of floating items at the surface, suspended plastics along the water column and transport over the riverbed. Accumulation occurs in biota, sediment, riparian vegetation and on riverbanks (Figure 1).

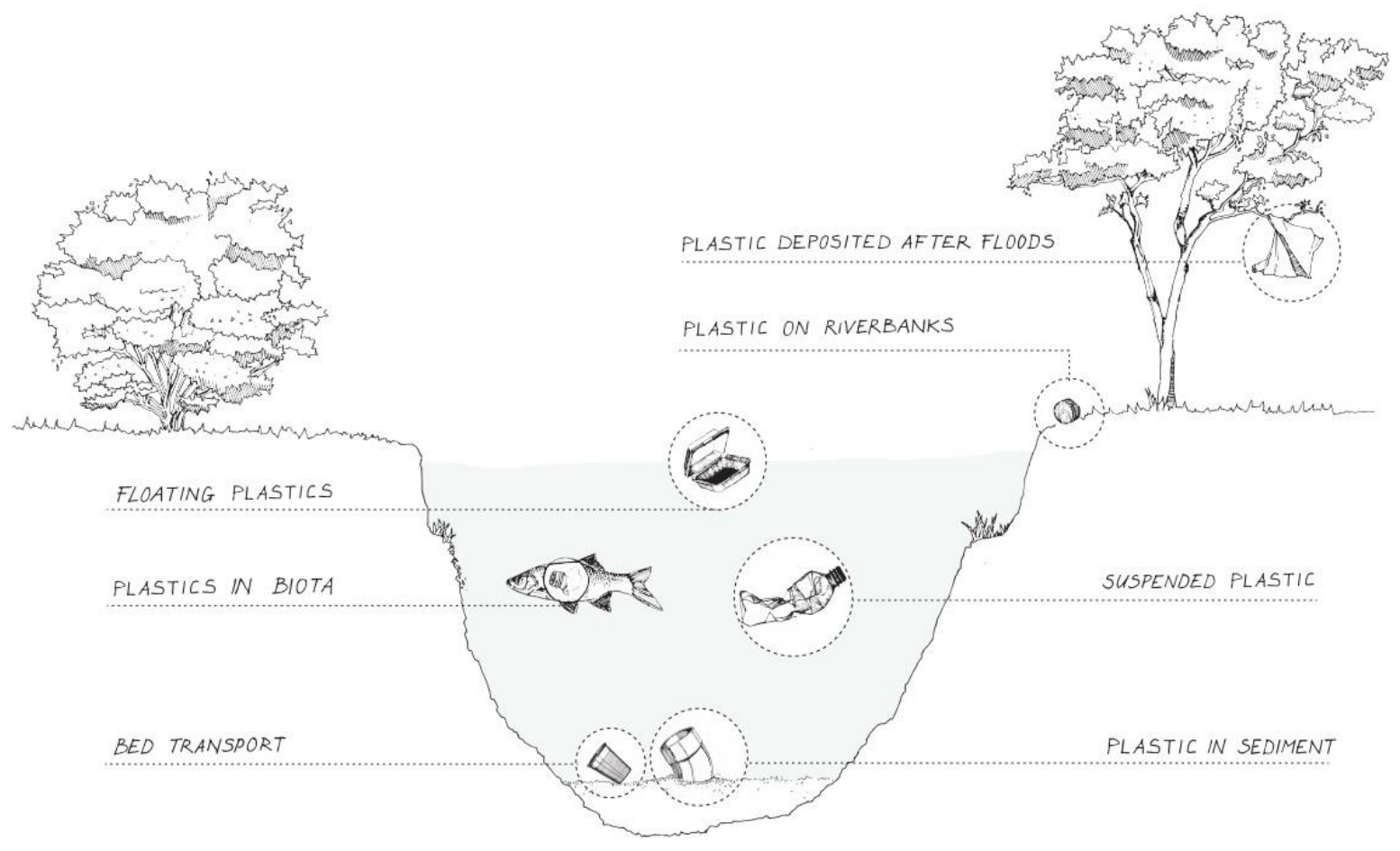

Figure 1 Overview of the abundance of plastic items in the various river system compartments (Artwork: Cher van den Eng, taken from Van Emmerik \& Schwarz, 2020).

Monitoring waste in river systems can help identifying sources of litter. Known sources include sewage outlets from wastewater treatment plants (Dris et al., 2015), recreational activities in the vicinity of riversides (Gasperi et al., 2014), and areas with high urban activities (Carson et al., 2013). 


\subsection{Riverbank monitoring}

To reduce riverine litter, it is required to identify and characterize litter items, its sources and variation over time and space. Riverbank monitoring programs can provide the data that is necessary for such insights. Most riverbank monitoring efforts are inspired by beach litter monitoring methods that have been around longer. For beach litter, monitoring has been standardized in the OSPAR guidelines for beach litter monitoring (OSPAR Commission, 2010). OSPAR refers to the Oslo and Paris conventions, which ultimately resulted in the Convention for the Protection of the Marine Environment of the NorthEast Atlantic (or OSPAR convention).

In recent years various initiatives have started to monitor litter on riverbanks, to identify sources and sinks, and quantify the spatiotemporal variation. One of the first attempts to quantify sources of riverine litter was done by Williams \& Simmons (1998), who measured litter items along the banks of the River Taff in Wales, UK. Many following efforts have been collecting data using citizen science, as that allows data collection over large areas and timespans (Kiessling et al., 2018). Chilean riverbanks have been monitored by groups of scientists and schoolchildren, and actually discovered several illegal dumping sites along the river (Rech et al., 2015). More recently, Kiessling et al. (2018) reported their firsts results of the Plastic Pirates project, covering 250 sampling spots along all German main rivers (Rhine, Danube, Weser, Elbe). We discuss this study in more detail in Chapter 4.

In the Netherlands, the Schone Rivieren riverbank litter monitoring program has been launched in 2017. This project adjusted the existing OSPAR beach litter monitoring protocol for better applicability to the Dutch rivers. Data is collected twice per year by trained volunteers. The observations are supplemented by expert observations as a reference. This report evaluates this proposed River-OSPAR protocol and the available data to date.

\subsection{Scope of this report}

This study will assess the River-OSPAR monitoring protocol and the data it has generated in Dutch rivers to date. The assessment will focus on (1) evaluating the protocol in comparison with other available riverbank monitoring protocols of efforts, (2) exploring the scientific value of the generated data, and (3) provide recommendations for future long-term monitoring strategy of riverine litter in Dutch rivers.

\subsection{Research questions}

1. To what extent is the River-OSPAR method suitable to get insights in:
a. the type and composition of waste on Dutch rivers;
b. the sources of riverbank waste;
c. what portion of this waste originates from land-based sources.

2. What is the reliability, validity and representativeness of the available River-OSPAR data? Specific aspects to consider are:
a. the number of measurement locations along the Meuse and Waal rivers;
b. the measurement frequency;
c. the training of volunteers and the practical execution of the monitoring by volunteers;
d. the data quality and reference measurements, the data processing, management and statistical analysis;
e. the categorization of waste types.

3. Can the currently available data be used for trend analyses on the composition, sources, land-based portion and quantities of the (plastic) waste? If not, what methodological changes have to be implemented to facilitate these? If yes, can the observed trends be used to design policy? 
4. What changes have been implemented in the River-OSPAR method in comparison to the international OSPAR Beach Litter monitoring protocol? What are the consequences for the intercomparison of data obtained from the two methods?

5. What changes/improvements are required to obtain a reliable, valid and representative estimation of riverbank (plastic) waste for the whole of the Netherlands? What are the costs for the realization of a national riverbank waste monitoring strategy?

6. What other data sources can be coupled with the data from the Schone Rivieren project to get more insight. For example:

a. sewerage outlets;

b. high water lines;

c. discharge of wastewater treatment plants;

d. locations of hydraulic infrastructure.

\subsection{Approach}

The research questions have been answered using a combination of comparative research and data analysis. Comparative research has been done to identify the changes of the River-OSPAR protocol compared to the Beach-OSPAR protocol, the motivation for these changes and the potential impact on the results. Second, the River-OSPAR protocol is compared to several other available protocols reported in the literature. Data analysis has been done to explore the use of the current dataset. More details on the research methods are given in Chapter 2.

\subsection{How to read this report}

In Chapter 2 we discuss the used research methods for this report. Chapter 3 introduces the RiverOSPAR protocol and provides an overview of the changes in comparison to the Beach-OSPAR protocol. Chapter 4 extends the comparison by including several other riverbank litter monitoring methods. In Chapter 5 we provide the results of the data analysis, focusing on spatial and temporal trends. In Chapter 6 we discuss potential alternative monitoring methods and data sources that can provide additional insights in river litter in Dutch rivers. Finally, Chapter 7 presents our key conclusions and recommendations. 


\section{Methods}

\subsection{Study area}

The Schone Rivieren project analyses litter on riverbanks of two rivers: the Rhine and the Meuse. The Rhine is approximately $1200 \mathrm{~km}$ long and flows though Switzerland, France, Germany Belgium, and discharges in the North Sea through the Netherlands. Its catchment area includes densely populated areas such as the Randstad in the Netherlands, and heavily industrialized areas such as the Ruhr area in Germany and the Port of Rotterdam in the Netherlands. The Meuse is approximately $900 \mathrm{~km}$ long and flows through France, Belgium, and draining in the North Sea in the Netherlands.

The study area was defined as the length of both rivers from the point of entry into the Netherlands until the Biesbosch National park (see Figure 2). A total stretch of $153 \mathrm{~km}$ of the Rhine-Waal delta was analyzed using 71 measuring locations. The uppermost measuring location was located at $22 \mathrm{~km}$ downstream from the point of entry of the Rhine in the Netherlands. The most downstream measuring location at the Rhine was located at $155 \mathrm{~km}$ away from the entry point. The IJssel was excluded from the study area, although Stichting De Noordzee is planning on including this distributary in future analysis. For the Meuse, a total stretch of $277 \mathrm{~km}$ was analyzed using 137 measuring locations. The uppermost measuring location was located at $0.1 \mathrm{~km}$ downstream from the point of entry of the Meuse in the Netherlands. The most downstream measuring location was located at $277 \mathrm{~km}$ away from point of entry of the river to the Netherlands.

\subsection{Comparative literature study}

The comparative literature study between the River-OSPAR method and other litter identification has been divided into three parts. First, we will compare the River-OSPAR and the Beach-OSPAR protocols. Information on both protocols were gathered through literature review, analysis of the training

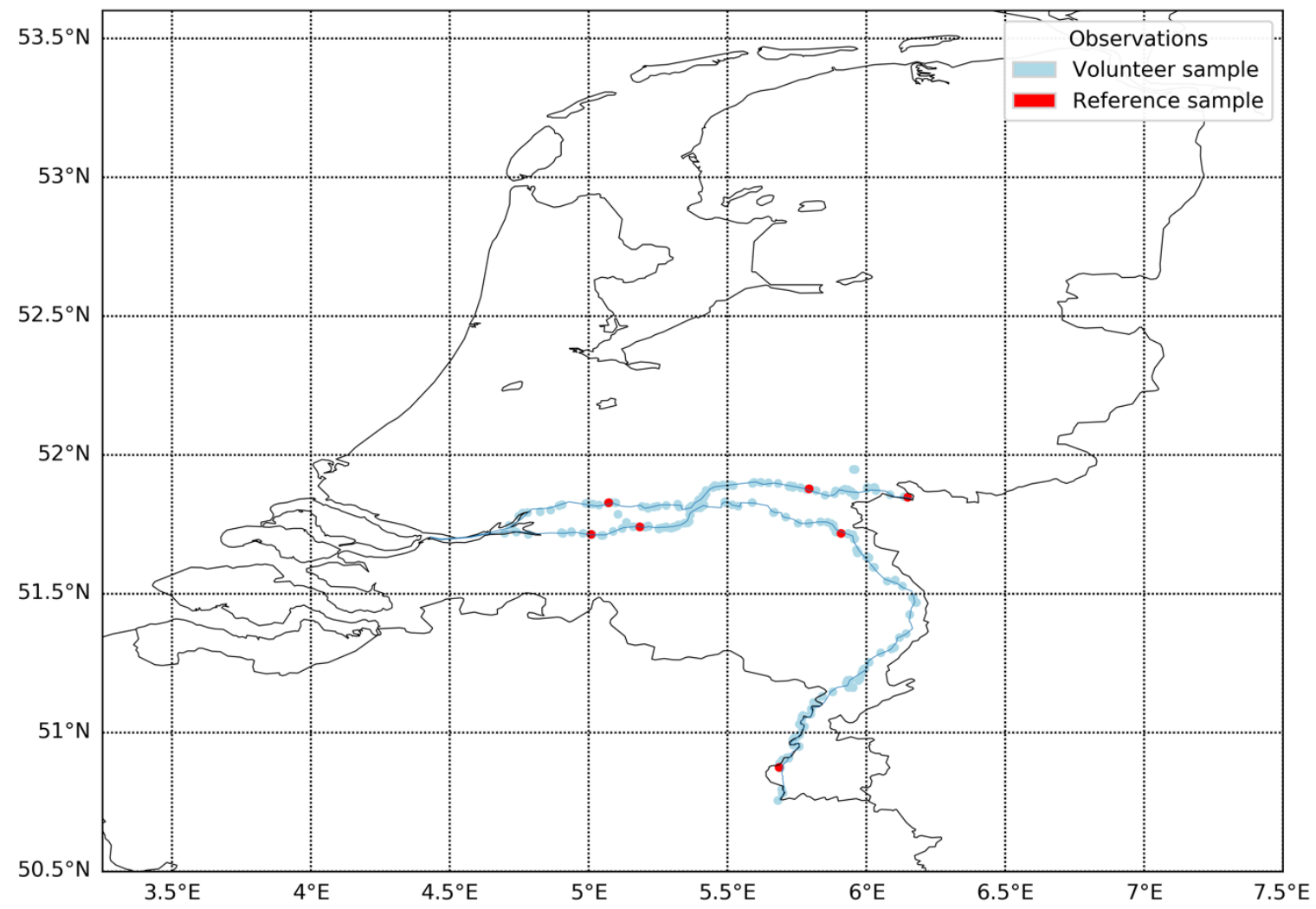

Figure 2 Overview of the study area, with measurement locations indicated along the Meuse and Waal rivers, ranging from the borders with Belgian and Germany until the Biesbosch National park. The blue dots refer to the samples made by the volunteers while the red dots are the reference samples, executed by SDN. 
information by SDN and the OSPAR committee, and personal contact with SDN. We have selected five key aspects to compare the two OSPAR methods with, these characteristics being: sampling area, sampling period, types of debris analyzed, item identification category list, and training protocol. These elements were selected because together they are the core elements of both litter identification protocols. In the comparison, we examine how these elements have been altered for the river method, why these changes were made, and what the implications of the alterations are.

In the second part of this comparative research we compare the River-OSPAR method against other riverbank litter identification protocols. For this we have performed a literature review using the Wageningen University depository and Google Scholar, using different combinations of the following keywords: plastic, litter, riverbank, river shore, lakeshore, and river. From this, protocols most similar to the River-OSPAR method were selected, these being the Plastic Pirates project, the National Oceanic and Atmospheric Administration marine debris monitoring protocol, and a litter identification protocol as proposed by Battulga et al. (2019). Selected articles were then analyzed using the same key characteristics as used for the Beach- and River-OSPAR comparison.

The last part to the comparative study is a comparison with other methods that use certain elements that the River-OSPAR method utilizes as well in order to see what can be learned from other applications. Elements that are compared include citizen science, macrolitter sampling areas, and microlitter analysis. The literature used for this comparison was identified through the literature review as performed in the second part.

\subsection{Data analysis}

\subsubsection{Database preprocessing}

The database is made ready for analysis by making the temporal information homogeneous and by filling up the gaps in the data with zeros. Some items in the River-OSPAR checklist were added or removed during the measurement campaign, because some items were never found and others were deemed to deserve their own category (around 15 percent of all items were added or removed since the beginning of the project). The gaps, of added and removed items in measurement rounds in which they were not present on the checklist are filled up with NaN-values ("not a number"). Subsequently, the data is made homogeneous by correcting the data for sampling area to a standard $2500 \mathrm{~m}^{2}$ (100 by 25 meters). This was done to compensate for both sampled beach length, as a smaller stretch was sampled in some cases with too much litter to sample in one day, and because 25 meters width was not always possible to sample due to the vegetation line being closer than 25 meters. The homogenization was performed by interpolation and rounding up to obtain integer values.

To (1) analyze the spatial variation of the data, (2) identify potential sources and sinks of litter, and (3) characterize the litter composition, the sampling locations are converted to a river coordinate system. This coordinate system denotes the distance along the river measured from the entry of the river into the country. To do this a river centerline was drawn and the River-OSPAR locations are projected on this line. Subsequently, the distance along this new coordinate system is added to the sampling locations for further analysis.

\subsubsection{Hydrometeorological effect on litter}

The influence of precipitation, windspeed and water height, in time scales ranging from 1 day to 6 months at each River-OSPAR location is analyzed to determine the depositional environment and the circumstances in which litter is removed from the riverbanks. For each River-OSPAR location, at each measurement round, time-lags of 1, 2, 7 and 14 days and 1 and 6 months are determined. Within these time-intervals, precipitations and windspeed data are extracted from the Koninklijk Nederlands Meterologisch Instituut (KNMI; Royal Netherlands Meteorological Institute) archive $^{1}$ at their observational sites throughout the country. Subsequently, the sum and maximum are calculated for the precipitation series and the mean and maximum for windspeed at each KNMI site for each time-lag.

\footnotetext{
${ }^{1}$ http://projects.knmi.nl/klimatologie/daggegevens/selectie.cgi
} 
Ultimately, this spatial information is interpolated with IDW (inverse distance weighting) to the RiverOSPAR locations. A similar strategy is applied to the river water height measurements, obtained from the Rijkswaterstaat archives ${ }^{2}$. Only interpolation for this data is different as it is casted to the 1D coordinate space as described above.

To describe the influence of the hydrometeorological events, the accuracy of volunteers and trends in time on the distribution of the items counted on the River-OSPAR checklist, the data obtained as described above are used as explanatory variables in a negative binomial regression model. This is an adapted form of a multiple linear regression model, using the negative binomial distribution as linkage function (instead of a Gaussian distribution, as is it the case in the standard regression models). This distribution is suited for integer data with a lot of 0 s. The exact model structure is set as follows with the parameters explained in Table 1:

Item P_1d_sum + P_1m_sum + U_1d_max + U_1m_max + h_2d_max_above_current + h_1m_max_above_current + dop + doy $+\mathrm{C}($ river $)+\mathrm{C}($ sampling $)$

Table 1 Parameters of the model structure explained.

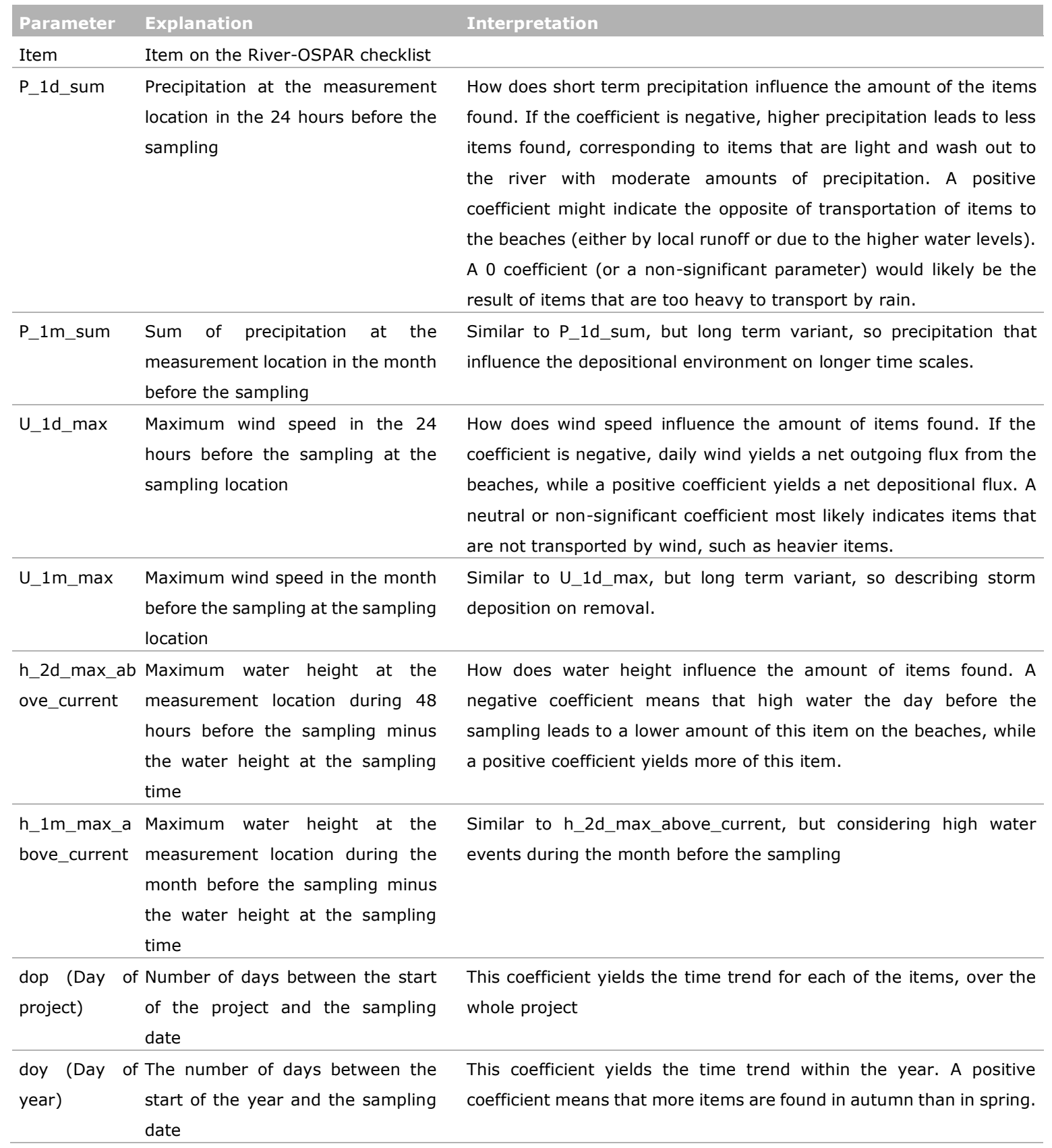

\footnotetext{
${ }^{2}$ http://waterinfo.rws.nl
} 


\begin{tabular}{ll} 
C(river) & $\begin{array}{l}\text { Categorical value, separating the Factor that is used to compare rivers } \\
\text { Meuse and Waal }\end{array}$ \\
\hline C(sampling) & $\begin{array}{l}\text { Categorical value, separating the Factor to compare the difference between reference samples and the } \\
\text { reference samples and volunteer samples made by the volunteers. } \\
\text { samples }\end{array}$
\end{tabular}

The resulting coefficients are reported in a separate excel file (see Annex 6) together with their respective significance.

\subsubsection{Longitudinal analysis}

In this report we present the data on longitudinal plots (distance along the river as described above). To better understand and visualize the spatial trends, the different items, as sampled in the River-OSPAR methodology, have been combined in three different ways; (1) material type, (2) main litter source and (3) main transport mechanism. The data, before plotting, has been condensed in 15-kilometre bins by taking the median value of the samples. This has been done to remove outliers and focus more on spatial and temporal trends. The number of measurements per bin and per measurement round are shown in Table 2 and Table 3. 15 kilometers per bin seemed the best trade-off between spatial accuracy and data availability.

Table 2 Number of sampling locations per $15 \mathrm{~km}$ bin per measurement round at the river Waal.

\begin{tabular}{lllll} 
& 1 & 2 & 3 & 4 \\
\hline$(0,15]$ & 1 & 2 & 2 & 4 \\
\hline$(15,30]$ & 1 & 4 & 5 & 10 \\
\hline$(30,45]$ & 1 & 4 & 3 & 4 \\
\hline$(65,60]$ & 1 & 3 & 3 & 7 \\
\hline$(75,90]$ & 4 & 5 & 2 & 6 \\
\hline$(90,105]$ & 3 & 4 & 5 & 7 \\
\hline$(105,120]$ & 1 & 4 & 1 & 6 \\
\hline$(120,135]$ & 1 & 3 & 4 & 2 \\
\hline$(135,150]$ & 0 & 3 & 4 & 4 \\
\hline$(150,165]$ & 0 & 3 & 0 & 2 \\
\hline
\end{tabular}

Table 3 Number of sampling locations per $15 \mathrm{~km}$ bin per measurement round at the river Meuse.

\begin{tabular}{lllll} 
& 1 & 2 & 3 & 4 \\
$(0,15]$ & 1 & 5 & 1 & 7 \\
$(15,30]$ & 0 & 7 & 5 & 7 \\
\hline$(30,45]$ & 0 & 7 & 3 & 7 \\
$(45,60]$ & 0 & 3 & 2 & 4 \\
\hline$(60,75]$ & 0 & 9 & 5 & 10 \\
\hline$(75,90]$ & 0 & 2 & 2 & 3 \\
\hline$(90,105]$ & 0 & 2 & 1 & 1 \\
\hline$(105,120]$ & 0 & 7 & 2 & 10 \\
\hline$(120,135]$ & 0 & 5 & 5 & 6 \\
\hline$(135,150]$ & 1 & 9 & 5 & 8 \\
\hline$(150,165]$ & 0 & 1 & 0 & 5 \\
\hline$(165,180]$ & 0 & 3 & 2 & 1 \\
\hline$(180,195]$ & 0 & 2 & 1 & 5 \\
\hline$(195,210]$ & 1 & 4 & 6 & 6 \\
\hline$(210,225]$ & 0 & 7 & 2 & 9 \\
\hline$(225,240]$ & 0 & 6 & 4 & 5 \\
\hline$(240,255]$ & 0 & 4 & 3 & 6 \\
\hline$(255,270]$ & 0 & 1 & 1 & 3 \\
\hline & & & &
\end{tabular}




\subsubsection{Litter category}

The first visualization combines the litter categories in their parent category; plastic, rubber, textile, paper, wood, metal, glass, sanitary and medical items. This method was chosen in many studies and can therefore be used to compare this study to similar projects, which will be discussed further in Chapter 3 and 4.

\subsubsection{Litter sources}

The second visualization describes the longitudinal distribution of litter coming from four major sources; industry, recreation, sewage storm drains and litter disposal (as proposed by SDN). To divide the sampled items in these four source categories, indicator items are used (based on export knowledge of SDN). Each of these indicator items, as showed in Table 4, is assumed to come from a single source. The other items are correlated with these indicator items and subsequently categorized with the source of the indicator item yielding the highest correlation value. If none if of the indicator items gave a correlation value higher than 0.35, the item was not categorized. See Annex 4 for table with categorization.

Table 4 Overview of litter items associated with one of the four source categories.

\begin{tabular}{ll} 
Source category & Items \\
\hline Industry & Industrial packaging \\
& Rope with diameter bigger than $1 \mathrm{~cm}$ \\
& Fuel packaging \\
& Working gloves \\
\hline Recreation & Cigarette packaging \\
& Crown caps \\
& Lolly sticks \\
& Packaging of crisps and candy \\
\hline Sewage storm drain & Toilet freshener \\
\hline Litter disposal (dumping) & Sanitary napkins \\
& Tires \\
\hline
\end{tabular}

\subsubsection{Litter transport mechanisms}

The third visualization bins the data in the three main litter transport mechanisms: constant flushing, constant deposition, high water deposition and other. To divide the River-OSPAR items in these four categories, the regression models described in paragraph 2.3.2 are used. The two model coefficients for water height are used: short term water height (h_2d_max_above_current) and long term water height (h_1m_max_above_current). Negative coefficients correspond to less items found with higher water while positive coefficients report an increase in item count with higher water height. The categorization and discussion of the thresholds is presented in Table $\mathbf{5}$ and Figure 3. The classification of all items is presented in appendix 5 . 
Table 5 Transport mechanism categorization and discussion

\begin{tabular}{|c|c|c|c|}
\hline $\begin{array}{l}\text { Transport } \\
\text { mechanism }\end{array}$ & $\begin{array}{l}\text { Short } \\
\text { term } \\
\text { water } \\
\text { height }\end{array}$ & $\begin{array}{l}\text { Long } \\
\text { term } \\
\text { water } \\
\text { height }\end{array}$ & Rational \\
\hline Constant flushing & $<0$ & $<0$ & $\begin{array}{l}\text { If both coefficients are negative, both long term and short term high water } \\
\text { cause less items to be found during the sampling. This indicates that items } \\
\text { are locally deposited (either dumped on the beach itself or in the water in } \\
\text { front of the beach). }\end{array}$ \\
\hline $\begin{array}{l}\text { Constant } \\
\text { deposition }\end{array}$ & $>0$ & $>0$ & $\begin{array}{l}\text { If both coefficients are positive, high water at short and long term cause } \\
\text { more items to be found at the beaches, meaning that the litter is } \\
\text { transported in the river and deposited on the banks. }\end{array}$ \\
\hline $\begin{array}{l}\text { High water } \\
\text { deposition }\end{array}$ & $<0$ & $>0$ & $\begin{array}{l}\text { If short term water height has a negative coefficient (items removed) and } \\
\text { a long term positive coefficient (items deposited) the transport } \\
\text { mechanisms of these items are high waters with a longer return period. }\end{array}$ \\
\hline Other & $>0$ & $<0$ & Other category \\
\hline
\end{tabular}
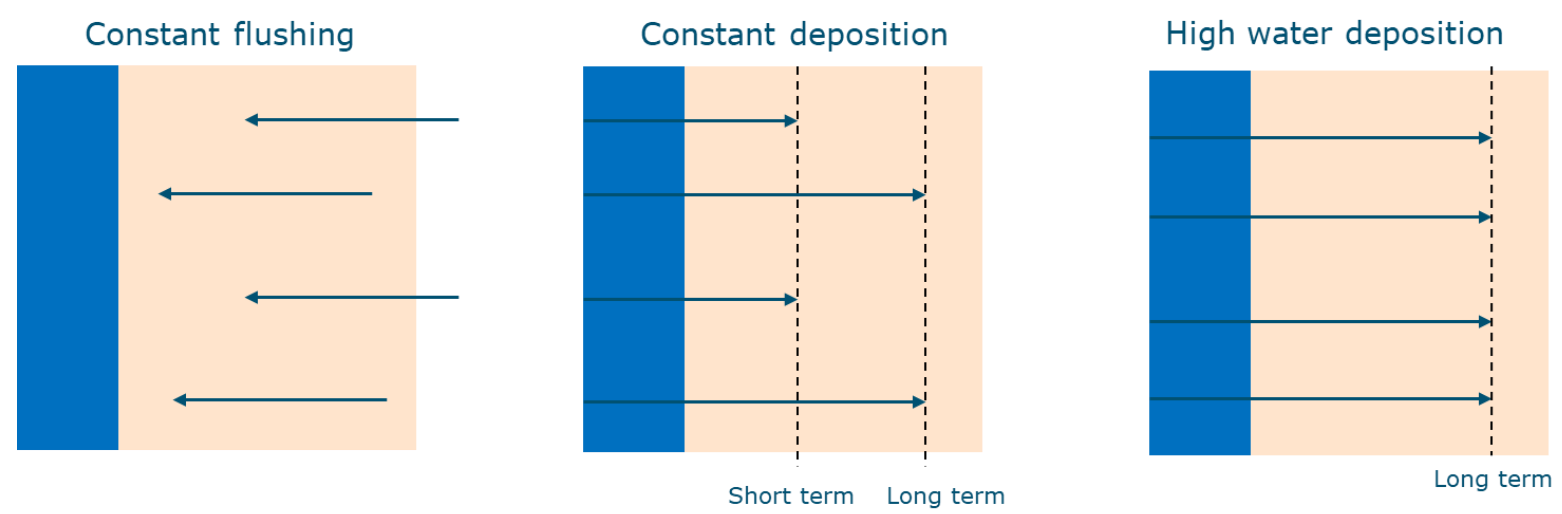

Figure 3 Conceptual sketches of the transport mechanisms. 


\section{The River-OSPAR Protocol}

\subsection{Description of the River-OSPAR protocol}

The River-OSPAR protocol was developed by Stichting De Noordzee (SDN) as a way to utilize citizen science to gather data on litter that is deposited on the banks of Dutch rivers. It is based on the protocol for beach litter identification developed by OSPAR commission. SDN has adapted the protocol so it is applicable on riverbanks. This method is currently being applied at 211 unique locations spread along the Meuse and Waal rivers in the Netherlands since 2017 and will be continued until at least 2021 (Table 6). Each monitoring location is analyzed twice per year, once in spring and once in fall.

Table 6 Number of samples per river per measurement round.

\begin{tabular}{llll} 
Measurement round & Meuse & Waal & Rhine \\
\hline 1 & 3 & 14 & 0 \\
\hline 2 & 84 & 37 & 1 \\
\hline 3 & 51 & 31 & 1 \\
\hline 4 & 107 & 56 & 5 \\
\hline
\end{tabular}

The River-OSPAR protocol consists of two main parts and a third optional part. The two main parts being the 100-meter count and the detailed measurement, with the optional part being a brand registration section. The 100-meter count analyzes macro litter (>5 mm), the detailed measurements examines microlitter (1-5 mm). Volunteers are trained by the Institute for Nature Education and Sustainability (IVN) and the North Sea Foundation to effectively apply the River-OSPAR protocol. Once they have received this training, they will be assigned a measuring location where they will have to apply the following steps.

\section{100-meter count}

- Stake out a transect parallel to the river of $100 \mathrm{~m}$ long, and a width from the waterline until the highwater line or the first vegetation. Important to note is that the width cannot exceed $25 \mathrm{~m}$.

- Analyze the transect in strips of $1-3 m$ wide parallel to the water, pick up all the litter you can see while standing up.

- Identify what litter category the litter belongs to using the litter photo guide and mark it on the tally sheet. Store all identified litter in a garbage bag for proper disposal after the analysis.

- $\quad$ Fill in the raw data on the online data form after which it is automatically sent to SDN for further analysis.

\section{Detailed measurement}

- Identify the highwater line, characterized by loose washed up organic material.

- Mark a quadrant of $50 \times 50 \mathrm{~cm}$ on the highwater line.

- Using a metal spoon, scoop up the top $3 \mathrm{~cm}$ layer of sediment within this quadrant and fill a bag with it.

- Spread out the sample and count the microplastic pellets (either on location or at home)

- $\quad$ Fill in the data on the online form and send the sample to SDN

3. Brand registration (optional)

- Download the Litterati app ${ }^{3}$

- Use the app to take pictures of the brands of each litter item (when applicable)

\footnotetext{
${ }^{3}$ https://www.litterati.org/
} 


\subsection{Comparison between River-OSPAR and OSPAR-Beach Litter protocols}

We have selected five key elements to compare the two OSPAR methods with, these characteristics being: sampling area, sampling period, types of debris analyzed, item identification category list, and training protocol. In this comparison, we examine how these elements have been altered for the river methods, why these changes were made, and what the implications of the alterations are.

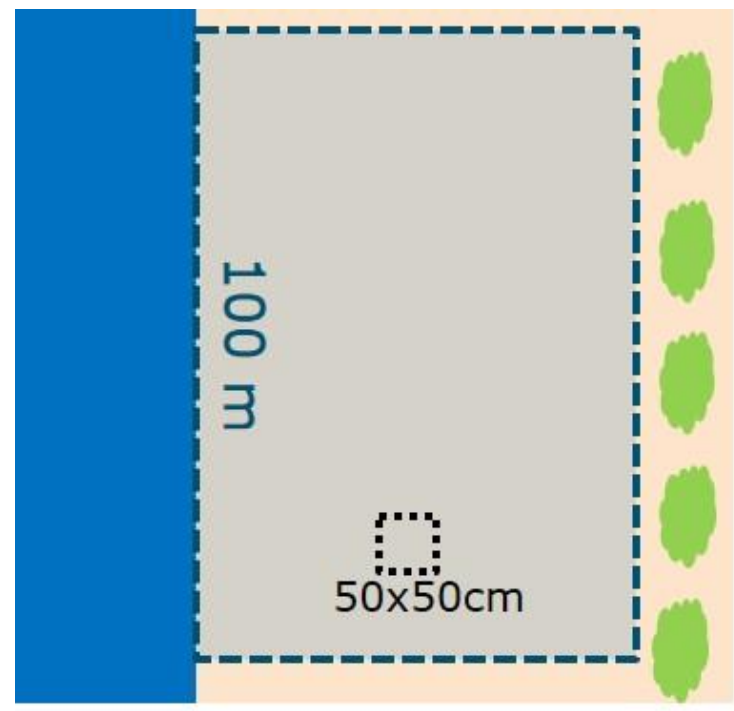

River-OSPAR

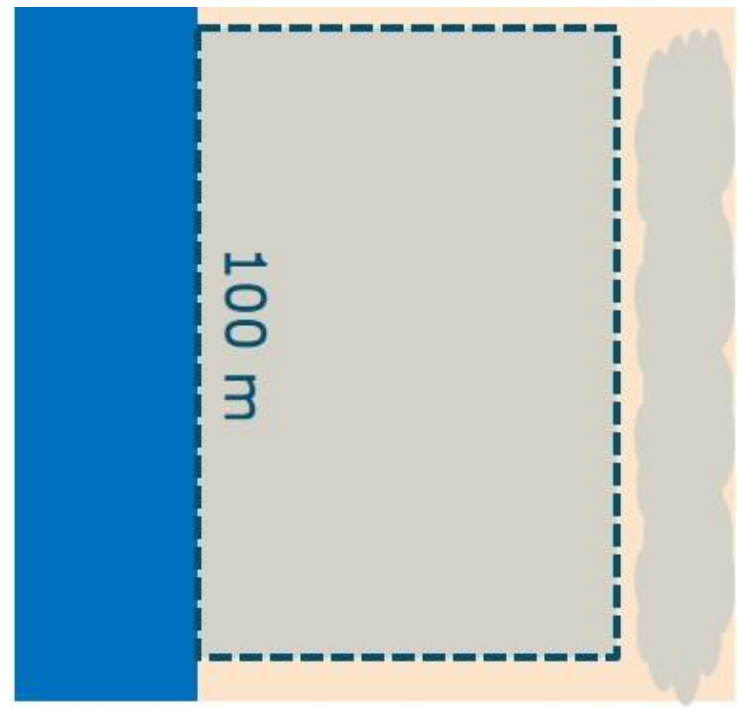

Beach-OSPAR

Figure 4 Differences in sampling area between River-OSPAR and Beach-OSPAR protocols.

\section{Sampling area}

The Beach-OSPAR method has one sampling area. The analysis (litter of all sizes) is performed using a 100-meter-long stretch of beach parallel to the waterline. The width of this sampling area is determined by the characteristics of the beach: the transect stretches from the water line to the beginning of the dunes or other characteristics that mark the end of the beach (e.g. fences).

The River-OSPAR method consists of two parts. The first part, which examines macro debris, uses a sampling unit of $100 \mathrm{~m}$ parallel to the river. The width of the transect is determined by the characteristics of the riverbank: it reaches from the water line to the first dense vegetation or the highwater line. For wide riverbanks the protocol dictates that the width of the transect should be limited at $25 \mathrm{~m}$ in order to reduce the time it takes to perform the analysis. The second part to the River-OSPAR method uses a quadrat to examine the presence of plastic pellets/nurdles. This quadrat, with an area of $50 \times 50 \mathrm{~cm}$, is used to scoop up the top $3 \mathrm{~cm}$ of sediment on the river shore. This sample is then used to determine the presence and abundance of pellets/nurdles through counting by eye.

The locations of the River-OSPAR analysis are decided based on four criteria. First, the measuring location should have a stretch of riverbank or a sandy beach that can be submerged with higher water levels. Second, the location should be legally accessible by the volunteers (e.g. no fences or private property). Third, the locations should be well distributed along the length of the river and should be representative for the land uses along the river (e.g. locations should be in natural, industrial, and urban areas etc.). Last, sluices, weirs and pumping stations in the vicinity of the location should be considered since those can influence the litter present in the riverine environment.

The sampling areas of both OSPAR methods differ on two main points. First, the analysis of plastic pellets is added to the River-OSPAR method. By doing so, the River-OSPAR method also allows for the analysis of this smaller type of litter (see Figure 4). Second, the width of the sampling area is determined differently with the river method. Instead of using the dunes as the end of the transect, the river method uses other natural characteristics of riverbanks, namely the highwater line or the vegetation line. A drawback to using these characteristics is that they are more sensitive to changes 
over time. Changes of these characteristics could lead to sampling units being different between measuring periods.

\section{Sampling period}

The sampling periods of the two methods have the same length but differ in measuring frequency. First, both methods prescribe a 4-week period in which all measuring locations have to be analyzed. SDN implemented this 4-week period since the research is performed by volunteers whom perform the research in their free time. The 4-week period allows the volunteers to be more flexible on when they execute the research. Ideally, the measuring period is as short as possible in order to reduce the risk of external factors influencing the results.

Second, the frequency of analysis has been altered for the river method from 4 to 2 times per year, in spring and fall (the exact periods being 15 September - 15 October 2017, 15 February - 15 March 2018, 15 October - 15 November 2018, 15 February - 15 March 2019). The reasoning behind performing measurements in this period is that vegetation growth hinders analysis at other times of the year. Moreover, these measuring periods were chosen because SDN aims for the analysis to be performed after a peak discharge moment in the river, since these are the moments in which most litter is deposited on riverbanks. Additionally, these measuring periods were chosen in order to avoid disturbance of breeding sites of birds. The reduction of measuring frequency leads to lower temporal resolution data for the analysis of litter trends. The frequency of analysis could be increased through the clearing of vegetation at the sampling site. However, this would both increase the required equipment (for clearing the vegetation) and labor required for proper analysis. Moreover, this could be harmful for birds breeding in the area, and the clearing itself could influence the results by moving litter.

\section{Types of debris}

The Beach-OSPAR method prescribes that only litter that can be seen while standing up straight should be considered for analysis. With this, no direct lower boundary for the size of litter to be analyzed is set. However, it does mean that this method predominantly considers macro litter, though the presence of plastic pellets is noted. Hanke et al. (2019) do note that meso-sized litter ( $5-25 \mathrm{~mm}$ ) is difficult to monitor using this method. Meso-sized litter is therefore excluded from the current Beach-OSPAR analysis. The River-OSPAR method uses the same approach for the 100-meter analysis. However, due to the added quadrat sampling unit, the method also considers plastic pellets. This analysis is performed by eye, which means that smaller particles, which for more elaborate microplastic analysis are normally counted using a microscope, are not counted within the River-OSPAR method (Klein et al., 2015). These particles, which are primary raw plastic materials, are counted, whereas non virgin plastics (e.g. microplastics stemming from degradation of macro plastic) are not considered. Still it is useful to add this analysis since previous research has shown that microplastics are present in Dutch river systems (e.g. Klein et al., 2015). Furthermore, current methods for microplastic analysis in river shore sediment are laborious, using citizen science to gather data can, therefore, speed up the data collection process significantly.

\section{Item identification category list}

The Beach-OSPAR method distinguishes 121 identification item categories, with an option at the end of the turf list to write down unlisted items. These items are grouped by material type of the item to make it easier for volunteers to find the item on the list. The Beach-OSPAR method supplies the people performing the analysis with a photo guide with pictures of the most frequently found items. This to aid the item categorization process. The River-OSPAR method identifies 110 items on its item list and also offers an option to write down unlisted items. Unlisted items that have been found frequently ( $>30$ times) are added to the item list. Several item categories were omitted since they were beach specific (e.g. items related to sea-based fishing). The River-OSPAR item identification list was further altered by rearranging some of the item categories to have more frequently found items at the top of each material type. Moreover, some item categories were added for a more detailed analysis. For example, the item category for plastic bottles was subdivided in bottles smaller than $0.5 \mathrm{l}$, and bottles larger than $0.5 \mathrm{I}$. This was done in order to analyze the effects of bottle deposits on litter. Lastly, the item category 'labels' of bottles was added because this these were found frequently on riverbanks. The effects of these changes are twofold. Firstly, the rearranging of the item categories on the item category list safes time for the volunteer carrying out the analysis. Secondly, the alterations made to item categories such as the omission of beach specific items, the addition of riverbank specific items, and the splitting up existing 
item categories, makes it easier for the volunteer to utilize the list while also tailoring the list to specific the specific conditions on the river bank.

Table 7 Summary of the differences between the original Beach-OSPAR and adjusted River-OSPAR methods.

\begin{tabular}{|c|c|c|c|c|}
\hline Element & Beach-OSPAR & River-OSPAR & $\begin{array}{l}\text { Reasoning behind } \\
\text { change }\end{array}$ & $\begin{array}{l}\text { Implications of } \\
\text { change }\end{array}$ \\
\hline $\begin{array}{l}\text { Sampling } \\
\text { area }\end{array}$ & $\begin{array}{l}100 \mathrm{~m} \text { wide stretch of } \\
\text { beach, from water to } \\
\text { dunes (all litter) }\end{array}$ & $\begin{array}{l}100 \text { m stretch along } \\
\text { river, from water to } \\
\text { dense vegetation or } \\
\text { high waterline - } 50 \times 50 \\
\text { cm quadrat, } 3 \mathrm{~cm} \text { deep } \\
\text { (micro) }\end{array}$ & $\begin{array}{l}\text { No dunes available to } \\
\text { mark side of transect - } \\
\text { To add micro plastic } \\
\text { analysis to the method }\end{array}$ & $\begin{array}{l}\text { Ability to analyze } \\
\text { abundance of } \\
\text { pellets/nurdles on } \\
\text { riverbanks }\end{array}$ \\
\hline $\begin{array}{l}\text { Sampling } \\
\text { period }\end{array}$ & $\begin{array}{l}4 \text { times per year in a } 4 \\
\text { week period for all } \\
\text { locations }\end{array}$ & $\begin{array}{l}2 \text { times per year, in a } 4 \\
\text { week time period for all } \\
\text { locations }\end{array}$ & $\begin{array}{l}\text { Too much vegetation } \\
\text { on riverbanks for } \\
\text { proper analysis, after } \\
\text { period of high discharge } \\
\text { of river, and to avoid } \\
\text { disturbance of breeding } \\
\text { birds }\end{array}$ & $\begin{array}{l}\text { Lower resolution } \\
\text { temporal analysis of } \\
\text { litter trends - Higher } \\
\text { risk of influence by } \\
\text { external factors }\end{array}$ \\
\hline $\begin{array}{l}\text { Types of } \\
\text { debris }\end{array}$ & Macro & $\begin{array}{l}\text { Macro and } \\
\text { pellets/nurdles }\end{array}$ & To expand analysis & $\begin{array}{l}\text { Ability to analyze } \\
\text { pellet/nurdle } \\
\text { abundance on } \\
\text { riverbanks }\end{array}$ \\
\hline $\begin{array}{l}\text { Item } \\
\text { identification } \\
\text { category list }\end{array}$ & $\begin{array}{l}\text { List of } 121 \text { items, } \\
\text { grouped per material } \\
\text { type. Extra items added } \\
\text { after evaluation }\end{array}$ & List of 110 items, & $\begin{array}{l}\text { Some items that only } \\
\text { occur on beaches were } \\
\text { removed (e.g. fishing } \\
\text { industry related) and } \\
\text { some categories split } \\
\text { up for more detailed } \\
\text { analysis (e.g. plastic } \\
\text { bottles) }\end{array}$ & $\begin{array}{l}\text { Easier to use for } \\
\text { volunteers, more } \\
\text { tailored to riverine } \\
\text { environment, ability to } \\
\text { analyze specific } \\
\text { categories more in } \\
\text { depth }\end{array}$ \\
\hline $\begin{array}{l}\text { Training } \\
\text { method for } \\
\text { observers }\end{array}$ & $\begin{array}{l}\text { Organizations chosen } \\
\text { by OSPAR member } \\
\text { states, SDN performs } \\
\text { analysis on Dutch }\end{array}$ & $\begin{array}{l}\text { In person training by } \\
\text { IVN for volunteers }\end{array}$ & $\begin{array}{l}\text { Due to the small spatial } \\
\text { scale of the river } \\
\text { project, personal } \\
\text { training is possible }\end{array}$ & $\begin{array}{l}\text { Possibility to analyze } \\
\text { more locations, possibly } \\
\text { lower data quality } \\
\text { compared to experts }\end{array}$ \\
\hline
\end{tabular}

\section{Training protocol}

The training protocol differs between the two OSPAR methods, which is mainly caused by the fact that the River-OSPAR analysis is performed by volunteers. The small and localized character of the RiverOSPAR method allows for all volunteers to be trained personally by IVN and SDN. The Beach-OSPAR is performed by local representatives. This team of representatives received training by the OSPAR ICG$M L$ on how to organize and perform the Beach-OSPAR analysis in their region and how to perform data quality control and assessments. Representatives include municipalities, national environmental institutes, and non-governmental organizations with interest in the marine environment. SDN was selected by the Dutch government to perform the Beach-OSPAR analysis in the Netherlands because of their long national experience in beach monitoring and their participation in OSPAR ICGML.

SDN performs reference measurements, validates the data, conducts data-analysis, and reports on the results. These measurements, performed by experts who also perform the Beach-OSPAR surveys in the Netherlands, are used to determine the accuracy of the volunteers. The personal training and the reference measurements allow for quality control of the volunteers and the data they gather. Both of 
these factors lead to higher quality data. Reference measurements could further be used to determine the most effective monitoring strategy once they are available over a longer period of time.

\subsection{Potential insights from the River-OSPAR method}

Here we discuss the potential of the River-OSPAR monitoring method for gaining insights in (a) The composition of the litter on Dutch riverbanks, (b) the sources of this litter, and (c) whether this litter is land-based. Certain terms within the formulated research questions have a different meaning depending on the user. Therefore, this chapter first sets out to give more context to these terms. To do this, we will compare the definitions given to these terms in scientific literature. For this comparison we have performed a small-scale literature review within the Wageningen University Depository and Google Scholar database, using the following keywords: sources, litter, plastic, river, beach. Further literature of interest was identified using the snowball sampling method.

\subsubsection{Composition}

Methods to classify the composition of litter in the literature can be roughly subdivided in three categories: classification based on identity, function, or material type of the item (Hoellein et al., 2014). Item identity-based classification methods (e.g. Beach-OSPAR method) rely on the researcher identifying what the item is (e.g. cigarette, plastic bag, etc.) and counting the specific items found in the research area. The advantages to using this system is that the litter is characterized on a detailed level, which allows for more detailed analysis. However, identity-based classification methods are at risk of having too many classification categories. This could make it more difficult for volunteers to do the research, which leads to some methods reducing the amount of item categories (Kiessling et al., 2019).

Function-based composition classification methods categorize litter based on what the item is used for (e.g. fishing, food related, construction) (Schwarz et al., 2019). This method of determining litter composition is less time consuming compared to the identity-based system, but also offers less details for further data analysis. Last, material-based composition classification methods characterize litter based on the material it is (predominantly) made off (e.g. plastic, metal, glass). Each of these material types can be subdivided further in types of the material (e.g. different plastic polymers, metal types) (Van Emmerik et al., 2018). Material-based composition methods are useful when it is difficult to identify the identity or function of litter, or when research is only focused on one material type (e.g. plastic). However, it is more difficult to identify possible sources of litter using this system.

\subsubsection{Sources}

Most studies identifying sources examine two types: point sources and diffused sources. Point sources are places where litter input into the environment is concentrated in one place. Well studied point sources include sewage outlets of wastewater treatment plants, which emit mostly microplastics (Browne et al., 2011; McCormick et al., 2014), but can also be a source for larger sanitary items (Morrit et al., 2014). Diffused sources are those where the point of entry of litter cannot be pinpointed down to one place, but where litter enters the (riverine) environment over a larger area. Documented diffused sources of litter in the riverine environment include recreational activity near the river (Gaspari et al., 2014), areas with high urban activity (Carson et al., 2013; Van Emmerik et al., 2019a), or items intentionally disposed of at riverbanks (Rech et al., 2015). 


\section{Comparison of the River-OSPAR with other methods}

A literature review was performed using both the WUR depository and Google Scholar using combinations of the following keywords: plastic, litter, riverbank, rivershore, lakeshore, and river. A total of 15 papers (see Table 8) were selected for an in-depth analysis. Three categories can be identified in these papers. The first category are litter identification protocols that examine microlitter in the riverbank sediment (e.g. Klein et al., 2015; Naido et al., 2016). The second category covers protocols that only characterize macro sized litter (e.g. Kiessling et al., 2019). And last, the protocols that examine both macro and micro sized litter (e.g. Blettler et al., 2017). It must be noted that not all papers that characterized microplastics were taken into consideration for analysis. This was done because papers that quantified microplastic all have a relatively similar, already established methods. Moreover, these papers clearly outnumbered papers characterizing macrolitter, a problem which was also identified by Blettler et al. (2018).

Table $8 \quad$ Overview of studies considered in our assessment.

\begin{tabular}{lll} 
Macro & Micro & Macro + Micro \\
Beach-OSPAR & Klein et al. (2015, 2019) & Schone Rivieren \\
\hline Dalu et al. (2019) & Sarkar et al. (2019) & Battulga et al. (2019) \\
\hline Cowger, Gray \& Schultz (2019) & Jiang (2018) & Blettler et al. (2017) \\
\hline Honorato-Zimmer et al. (2019) & Cheung, Cheung \& Fok (2016) & NOAA Protocol (Lippiatt et al., 2013) \\
\hline & Browne et al. (2011) & Plastic Pirates (Kiessling et al., 2019) \\
\hline & Naido, Glassom and Smith (2016) & \\
\hline
\end{tabular}

\subsection{Plastic Pirates}

We will first make a comparison between methods that are most similar to the River-OSPAR method. For this, we first chose the Plastic Pirates project developed and reported by Kiessling et al. (2019). This method is similar since it also characterizes both macro- and microlitter on riverbanks with the use of citizen science. The two methods will be compared based on similar elements as used in the comparison between the two OSPAR methods.

The Plastic Pirates project is based on the premise to train schoolchildren to do the litter characterization. For this, Kiessling et al. (2019) have developed an elaborate program to be taught in schools ${ }^{4}$. The teaching materials include classes to be taught to the children on the effects of litter on the environment, how to gather field data, and the program ends with a day where all participating school characterize litter at a designated riverbank. The sampling method used by Kiessling et al. (2019) is based on the method developed by Rech et al. (2015). Using this method, a total of 250 sampling spots along German rivers were analyzed during both autumn 2016 and spring 2017 (Kiessling et al., 2019). The analysis has continued biannually since this period, but these results have not been published yet (personal communication).

\section{Sampling area}

The Plastic Pirates method (PPM) utilizes a different sampling technique compared to the River-OSPAR method. First, the PPM requires the volunteers to identify a stretch of riverbank approximately $20 \mathrm{~m}$ wide and $50 \mathrm{~m}$ long. Within this area three zones are identified: the zone that is in daily contact with the river (water - 5m), the zone that is in irregular contact with the river (5-15 m away from water), and last, the zone that has no contact with the river (15 $\mathrm{m}$ onwards). Then, random transects perpendicular to the water, crossing each zone, are staked out. These transects are used to determine points to take samples; each zone should have one point, and the points should be evenly spaced apart. At each sampling point, a stick with a $1.5 \mathrm{~m}$ rope attached to the bottom is used to draw out circles. All litter within these circles is analyzed by the volunteers. This process is repeated for several transects.

\footnotetext{
${ }^{4}$ https://www.wissenschaftsjahr.de/2016-17/weiterfuehrende-informationen/englisch/plastic-pirates/downloads.html
} 
The PPM consists of two more parts. The first part being a rubbish patch examination. For this, a stretch of river of between 200 - $300 \mathrm{~m}$ long and $20 \mathrm{~m}$ wide is identified and analyzed for clusters of rubbish. A third sampling unit is used for the characterization of microlitter. For this, a $20 \mathrm{~m}$ long rope is used to mark out a transect on the high-water line. Microlitter is sampled at the beginning, halfway point and endpoint of this line using $50 \times 50 \mathrm{~cm}$ quadrats. The top $2 \mathrm{~cm}$ of this layer within the quadrat is scooped up using a metal spoon or shovel.

The sampling area for macrolitter used in the PPM differs from the River-OSPAR method in two major ways. First, instead of analyzing the complete stretch of river, subsamples are taken in strategic places. This reduces the total sampling time and allows the volunteers carrying out the research to go into more detail with their analysis. The second alteration is that this method uses circles instead of quadrats as a sampling unit. This was done because is easier to apply on complex substrata and at sites with abundant vegetation cover (Kiessling et al., 2019). The microlitter sample unit differs slightly from the RiverOSPAR method. Instead of using one $50 \times 50 \mathrm{~cm}$ quadrant, the PPM uses three quadrats to gather the sediment sample. Moreover, the PPM prescribes to only gather the top $2 \mathrm{~cm}$ of the sediment, while the River-OSPAR prescribes the top $3 \mathrm{~cm}$. However, we believe that this accuracy is hard to achieve in the field, therefore the thickness of the sediment sample could be assumed as being similar.

\section{Sampling period}

Similar to the River-OSPAR method, the PPM uses a di-annual pattern to gather samples, once in spring and once in fall. Since the PPM is part of a school project, the method allows for a very short sampling period of one day. Because all samples are taken on the same day, the influence of external events (e.g. rainfall, high discharge events) on the data is minimized.

\section{Types of debris analyzed}

Although the sample units differ significantly between the two methods, the types of debris that is analyzed are the same: both macro-sized and micro-sized debris are considered in the two methods.

\section{Item identification category list}

The identification categories used within the PPM are the major downgrade compared to the RiverOSPAR method. To make identification easier for school children, Kiessling et al. (2019) reduced the number of categories to nine material types: paper, cigarettes, plastic, metal, glass, food leftovers and other items. The effects of these changes are a reduction the level of detail of the data. For example, these categories can give insights in the litter composition but make further analysis, such as identification of the sources of the litter, difficult.

\section{Training protocol}

The training protocol used within the PPM differs from the personal training of the River-OSPAR method. Instead of personally training the volunteers, the PPM provides teachers with an elaborate guide on how to apply the method. These teachers can then explain the method to the schoolchildren and supervise them while they are gathering the data. This supervision combined with the previously discussed reduced item identification categories and reference measurements performed by the research team ensure high quality data.

\section{Summary}

Although the River-OSPAR method and PPM seem similar at first glance, they differentiate on several key elements. Most of these differences are caused by the fact the PPM uses schoolchildren to gather data (e.g. the simplification of identification categories). We see elements that could be used to improve the River-OSPAR method. An interesting avenue for SDN to explore would be adopting the PPM sampling unit. This could reduce the total time required for the analysis, and also give an indication of the location of litter on riverbanks. Moreover, the use of a circle instead of a quadrat could also be of interest for the River-OSPAR method since it would allow for microplastic analysis at sites with higher vegetation cover. 


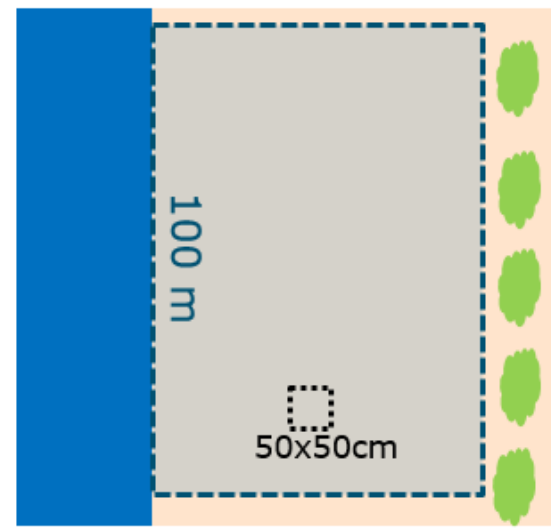

River OSPAR

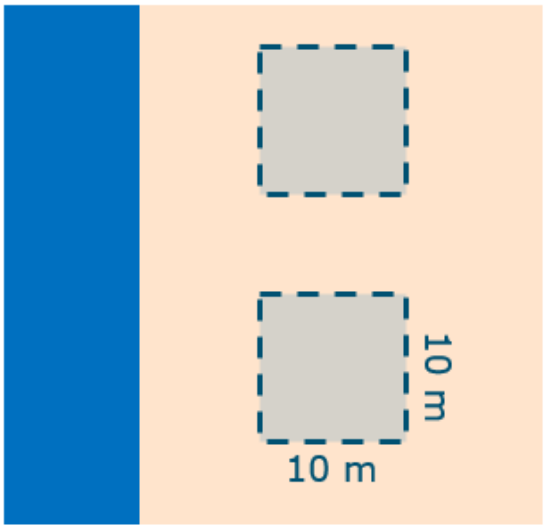

Battulga et al. (2019)

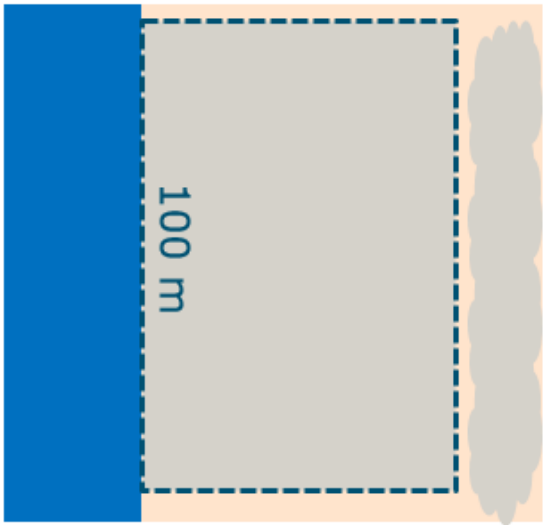

Beach OSPAR

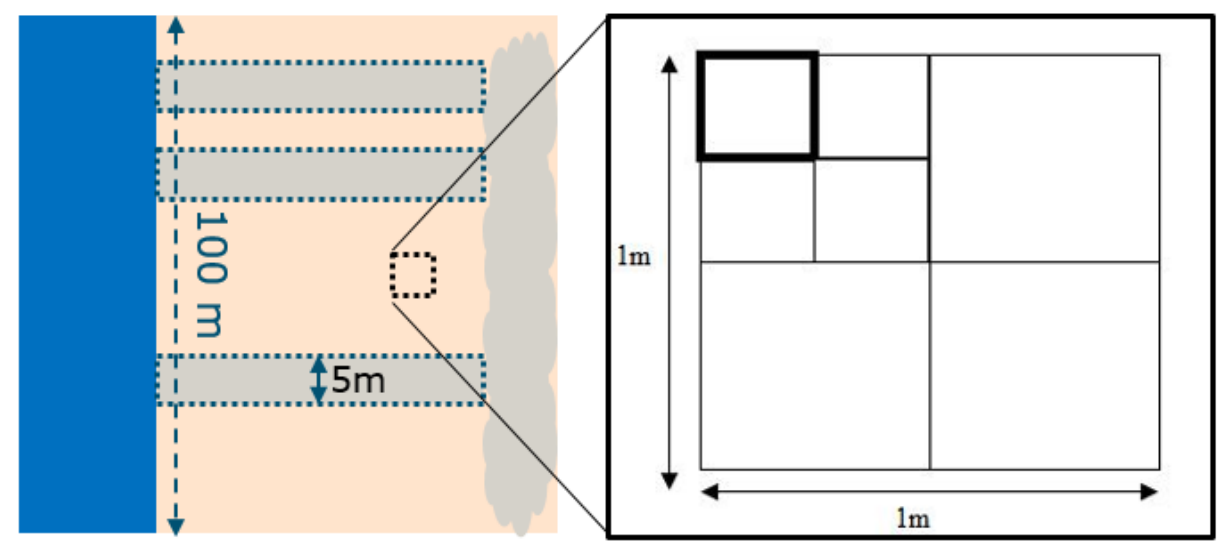

NOAA Protocol

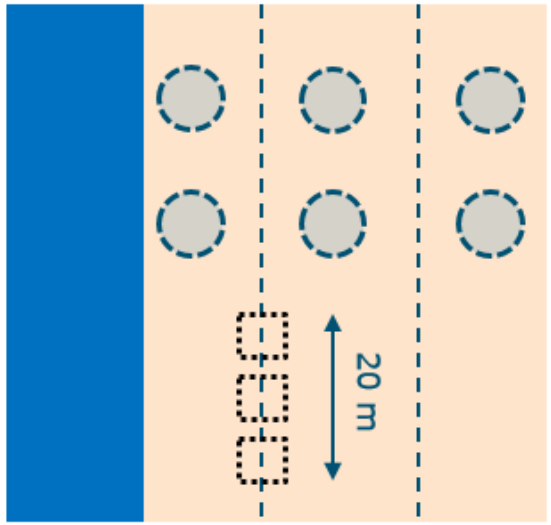

Plastic Pirates

Figure 5 Overview of the compared riverbank litter monitoring protocols.

\subsection{NOAA Protocol}

The American National Oceanic and Atmospheric Administration (NOAA) has developed a protocol to monitor marine debris (Lippiatt et al., 2013). This protocol sets out guidelines for litter identification on water surfaces, at sea, benthic environments, and for shorelines. We will compare the shoreline protocol with the same criteria as used for previous comparisons.

\section{Sampling area}

The sampling area used within the NOAA protocol is similar to other methods analyzed in this report; the micro sized litter uses a slightly larger quadrat $(1 \times 1 \mathrm{~m})$ to scoop up the top $3 \mathrm{~cm}$ of the sand of from a sub quadrant $(25 \times 25 \mathrm{~cm})$ (Figure 5). This sub quadrant is determined by the volunteer with the help of a random number table. However, the sampling area used to analyze macrolitter within the NOAA protocol is different. To quantify macrolitter, it requires researchers to set out transects from the highwater line until the dunes within a 100m stretch of beach (Lipiatt et al., 2013). To do this, a $100 \mathrm{~m}$ long stretch of beach parallel to the water is staked out. A random number table is used to determine where transects ( $5 \mathrm{~m}$ wide) are set out in order to reduce observer bias (Figure 5). This random element could be added to the River-OSPAR method.

\section{Sampling period}

The NOAA protocol prescribes that litter analysis should be performed once per month (once every $28 \pm 3$ days) at each location. Therefore, the measuring frequency is higher compared to both OSPAR methods. A higher measuring frequency allows for a more detailed trend analysis of litter over time. Moreover, the sampling period is shorter compared to the OSPAR methods, since all measurements have to be performed within a 7-day window. 


\section{Types of debris analyzed}

Like the River-OSPAR method, the NOAA protocol considers both macro-sized and micro-sized litter in its analysis.

\section{Item identification category list}

The item category list utilized within the NOAA protocol is shorter than the River-OSPAR item category list. A total of 39 categories are listed, with the possibility to mark non-listed items in the "other category". The items are categorized per material type to make it easier for the user to find the item on the list. As with the River-OSPAR method, a consequence of the reduction in item categories produces the risk that many items are listed as other, which could make analysis more difficult.

\section{Training protocol}

Although it is probable that researchers performing the NOAA protocol will receive training from the organization, this training is not written down in the guide. We therefore assume that the written guide is the only form of training that is provided. Using a written guide as the main source of training is less desirable since researchers will be trained less elaborate when compared to the personal training provided by IVN for the River-OSPAR method.

\section{Summary}

Although the NOAA protocol and River-OSPAR method both analyze macro-sized and micro-sized litter, their methods to do so are fairly different. The NOAA protocol excels in the sampling frequency since it prescribes to sample 6 times more frequently than the River-OSPAR method. Moreover, the randomness that NOAA has implemented within the method in order to reduce observer bias could be interesting for the River-OSPAR method. However, the River-OSPAR method is more robust considering the number of item identification categories, the training protocol, data validation and analysis.

\subsection{Battulga Protocol}

The Battulga protocol is a method developed by Battulga et al. (2019) to quantify macro and microplastics on riverbanks. It has been applied once in the Selenga river basin in Mongolia, where it was applied at 12 sampling sites. We will compare this method with the River-OSPAR method since it characterizes both macro and microplastics, and it does so with an alternative method.

\section{Sampling area}

The Battulga protocol utilizes a sampling area of $10 \times 10 \mathrm{~m}$ for both macro and microplastics. First, macrolitter is removed by hand. The same area is then analyzed for microlitter by trained observers that remove the plastics by hand. The Battulga protocol shows that the sampling area could be reduced to save time, while still gaining relevant insights. This sentiment is mirrored by Dalu et al. (2019), who used a $5 \times 5 \mathrm{~m}$ quadrant to analyze macroplastics on lakeshores in South Africa.

\section{Sampling period}

The Battulga protocol was only applied once. The sampling period therefore gives no new insights.

\section{Types of debris}

The Battulga protocol prescribes the analysis of both macro- and microlitter.

\section{Item identification categories}

Instead of characterizing the identity of litter found in the quadrats, the Battulga protocol categorizes litter based on size, the plastic type (e.g. polystyrene, polypropylene, etc.) and on shape (e.g. fiber, film, foam, fragment, etc.) for both macro- and microlitter. The plastic types were determined using visual observation for macroplastics, and using micro-FTIR spectroscopy for microplastics. This method gives a more in-depth overview of what types of plastic are present in the riverine environment. However, using this characterization method makes source identification rather difficult.

\section{Training protocol}


Since the Battulga protocol is not meant to be applied on a large scale (yet), this category is not relevant for this comparison.

\section{Summary}

The Battulga protocol shows that there are possibilities to use other types of sampling areas in order to characterize macrolitter on riverbanks. However, the item identification categories used within this method are not ideal for source identification of litter. Moreover, the Battulga protocol would need further development in order to be applied on a larger scale.

\subsection{Overview of other citizen science projects}

Citizen science is also applied within various other projects to collect large datasets. Even though these methods are different, lessons learned from these projects can be used to further improve the RiverOSPAR method. For example, Honorato-Zimmer et al. (2019) quantified beach litter with the help of school children. For this they used a similar sampling protocol as Kiessling et al. (2019). Using similar protocols for riverbank and beach litter analysis allows for a direct comparison between the two environments. This comparison could also be made between the Beach- and River-OSPAR methods. Other citizen science driven litter identification projects include the usage of kayaks to paddle down rivers and sampling otherwise difficult to access areas as shown by Cowger et al. (2019), the gathering of microplastic beach sediment samples through volunteers traveling abroad by Lots et al. (2017), and collecting water quality data with the help of trained volunteers (Het Schone Waterexperiment ${ }^{5}$ )

\footnotetext{
${ }^{5}$ https://hetschonewaterexperiment.nl/
} 


\begin{tabular}{|c|c|c|c|c|}
\hline Element & River-OSPAR & Plastic Pirates & $\begin{array}{l}\text { Battulga et al. } \\
\text { (2019) }\end{array}$ & $\begin{array}{l}\text { NOAA protocol } \\
\text { (Lippiatt et al., } \\
2013 \text { ) }\end{array}$ \\
\hline Sampling area & $\begin{array}{l}\text { Macro: } 100 \mathrm{~m} \text { stretch } \\
\text { along river, from } \\
\text { water to dense } \\
\text { vegetation or high } \\
\text { waterline Micro: } \\
50 \times 50 \mathrm{~cm} \text { quadrat, } 3 \\
\mathrm{~cm} \text { deep }\end{array}$ & $\begin{array}{l}\text { Macro: subsamples } \\
\text { in } 3 \text { different zones } \\
\text { Micro: three } 50 \times 50 \\
\text { cm quadrats, spaced } \\
\text { out over } 20 \mathrm{~m}\end{array}$ & $\begin{array}{l}10 \times 10 \text { meter for both } \\
\text { macro and micro }\end{array}$ & $\begin{array}{l}\text { Macro: random } \\
\text { transects from water } \\
\text { to dune, } 5 \mathrm{~m} \text { wide } \\
\text { Micro: randomly } \\
\text { selected } 1 / 16^{\text {th }} \text { of } \\
1 \times 1 \mathrm{~m} \text { quadrat }\end{array}$ \\
\hline $\begin{array}{l}\text { Sampling period and } \\
\text { frequency }\end{array}$ & $\begin{array}{l}\text { Twice annually, } 4 \\
\text { week period }\end{array}$ & $\begin{array}{l}\text { Twice annually, } \\
\text { single day for all } \\
\text { measurements }\end{array}$ & $\begin{array}{l}\text { One-off } \\
\text { measurement }\end{array}$ & $\begin{array}{l}\text { Once per } 28 \pm 3 \\
\text { days }\end{array}$ \\
\hline Types of debris & Macro + Micro & Macro + Micro & Macro + Micro & Macro + Micro \\
\hline $\begin{array}{l}\text { Item identification } \\
\text { category list }\end{array}$ & $\begin{array}{l}\text { Modified OSPAR list } \\
\text { ( } 110 \text { items), } \\
\text { frequently found } \\
\text { items can be added } \\
\text { as a new category }\end{array}$ & $\begin{array}{l}\text { Paper, cigarettes, } \\
\text { plastic, metal, glass, } \\
\text { food leftovers and } \\
\text { others }\end{array}$ & $\begin{array}{l}\text { Material type and } \\
\text { shape }\end{array}$ & $\begin{array}{l}39 \text { categories, listed } \\
\text { per material type, } \\
\text { items not on list } \\
\text { marked as other }\end{array}$ \\
\hline Training protocol & $\begin{array}{l}\text { Personal training } \\
\text { from IVN }\end{array}$ & $\begin{array}{l}\text { To be taught during } \\
\text { a school project }\end{array}$ & Not applicable & Written guide \\
\hline
\end{tabular}

\subsection{Microlitter methods}

Sampling methods for microlitter are fairly standardized across most research (e.g. Klein et al., 2015; Cheung, Cheung \& Fok, 2016; Naido, Glassom \& Smith, 2010). The River-OSPAR method uses a similar approach to gather samples of smaller sized particles. However, the analysis of these samples differs compared to the standardized method applied in other research. Currently, the River-OSPAR method gathers the data using a $50 \times 50 \mathrm{~cm}$ quadrat, from which the top $3 \mathrm{~cm}$ is scooped up using a metal spoon in order to avoid contamination of microplastic from this process. The volunteers then spread this sample out on a white surface in order to count the plastic granulates (pre-processed plastic materials) in the sample. This analysis gives insights in the abundance of these particles on the riverbank.

However, other microlitter research has a more elaborate process to treat and analyze the samples. Treatment of the samples by Klein et al. (2015) include drying at $50^{\circ} \mathrm{C}$, sieving to separate in different size classes, and treatment with hydrogen peroxide to remove natural debris among others. Analysis of the sample includes the weighing of each size class, classification of the shape of each particle, and the determination of plastic types using Fourier transform infrared spectroscopy. Moreover, the size range of the particles that are analyzed by Klein et al. (2015) $(<5 \mathrm{~mm})$ is larger compared to the River-OSPAR method (1-5 mm). This difference is due to the fact microscopes are used by Klein et al. (2015) to count smaller particles than cannot be seen by eye. Last, standard analysis also considers microlitter from non-virgin sources, which expands the scope analysis greatly.

Besides microlitter abundance, this more elaborate treatment and analysis gives insights in plastic types and size of the particles. This could also give an insight in the source of the plastic, since a large fraction of the identified microlitter particles are virgin plastic pellets that have not been transformed into plastic products yet. A downside to this analysis is that it requires significantly more time to analyze and is more expensive. Taking these factors into consideration, SDN could consider applying this more elaborate methodology of treatment and analysis to a subset of samples taken by their volunteers in order to get a deeper understanding of microlitter characteristics in Dutch rivers. 


\section{Analysis River-OSPAR data 2017 - 2019}

\subsection{Dataset}

The current dataset consists of 211 unique locations spread along the Meuse and Waal rivers in The Netherlands. Not all locations have been sampled during the entire sampling period (fall 2017 - spring 2019). Figure 6 indicates the number of observations for each measurement locations. Note that several data points are considered as uncertain, mainly due to incomplete or incorrect metadata (sampling location area codes). The number of observations are presented in Table $\mathbf{1 0 .}$

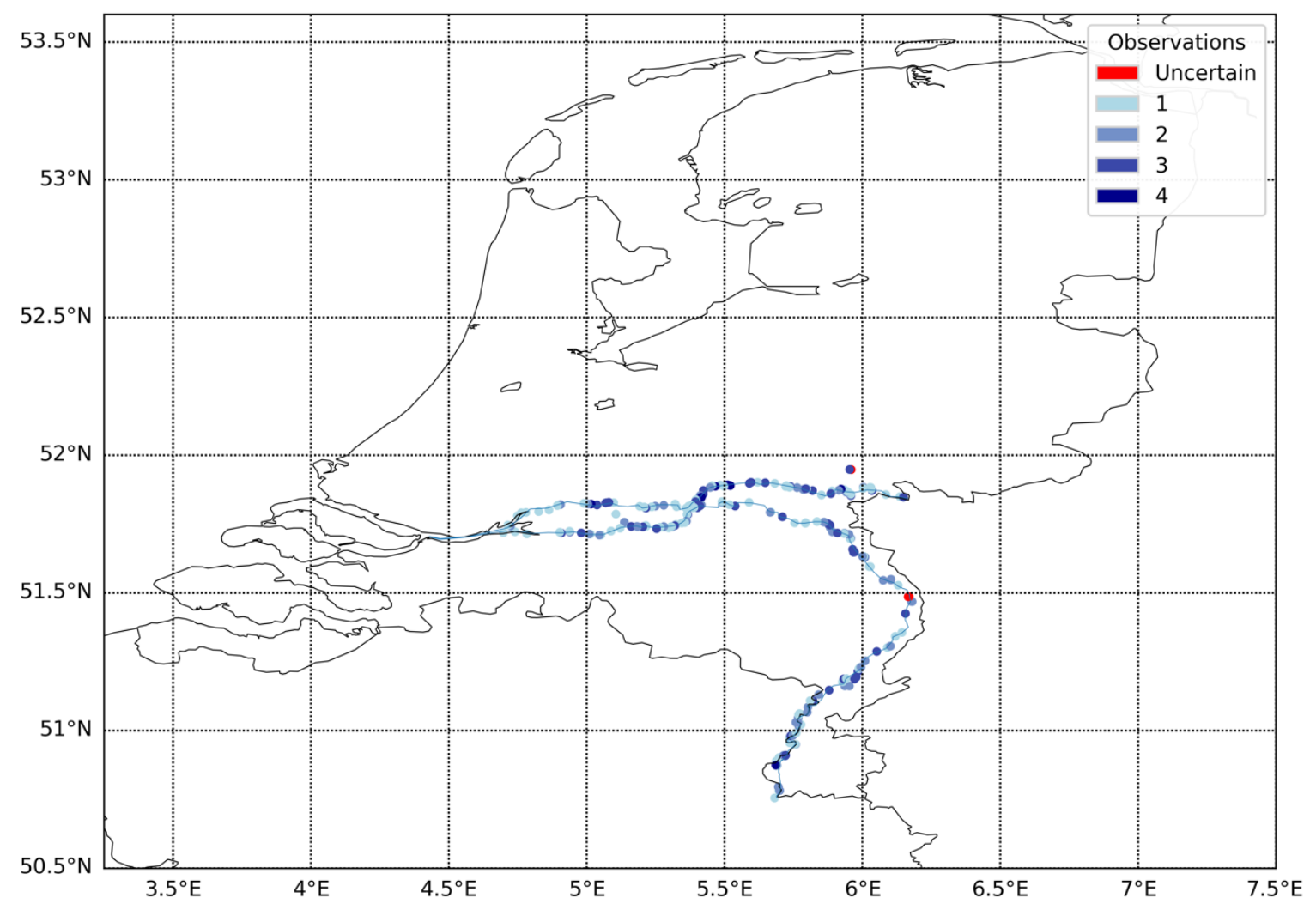

Figure 6 Overview of the available dataset generated between 2017 and 2019 along the Meuse and Waal rivers.

Table 10 Number of locations measured during number of observation rounds

\begin{tabular}{ll} 
Number of observation & Number of locations \\
\hline 1 & 97 \\
\hline 2 & 57 \\
\hline 3 & 47 \\
\hline 4 & 7 \\
\hline Uncertain & 3 \\
\hline
\end{tabular}

\subsection{Variation over time}

Using the complete dataset, summed over space and time, we identified which items showed the largest increase or decrease over time. Figure 8 presents the top 5 items that increased and decreased most between 2017 and 2019. This was done using the coefficients obtained from the negative binomial regression models for all items as explained in chapter 2. (Parts of) fireworks showed the largest increase along the Dutch riverbanks, followed by expanded polystyrene (larger than $50 \mathrm{~cm}$ and smaller than 2.5 $\mathrm{cm}$ ), fishing wire and stirrers. The largest decrease was observed for polystyrene food packaging, tape, shoes, plastic cutlery and plastic bags. In Annex 2 the figure is presented in its expanded form presenting all items that have been found at least a 100 times and change significantly over time $(p<0.05)$. Only nine items show a significant decrease over time while most other items show a slight increase. 


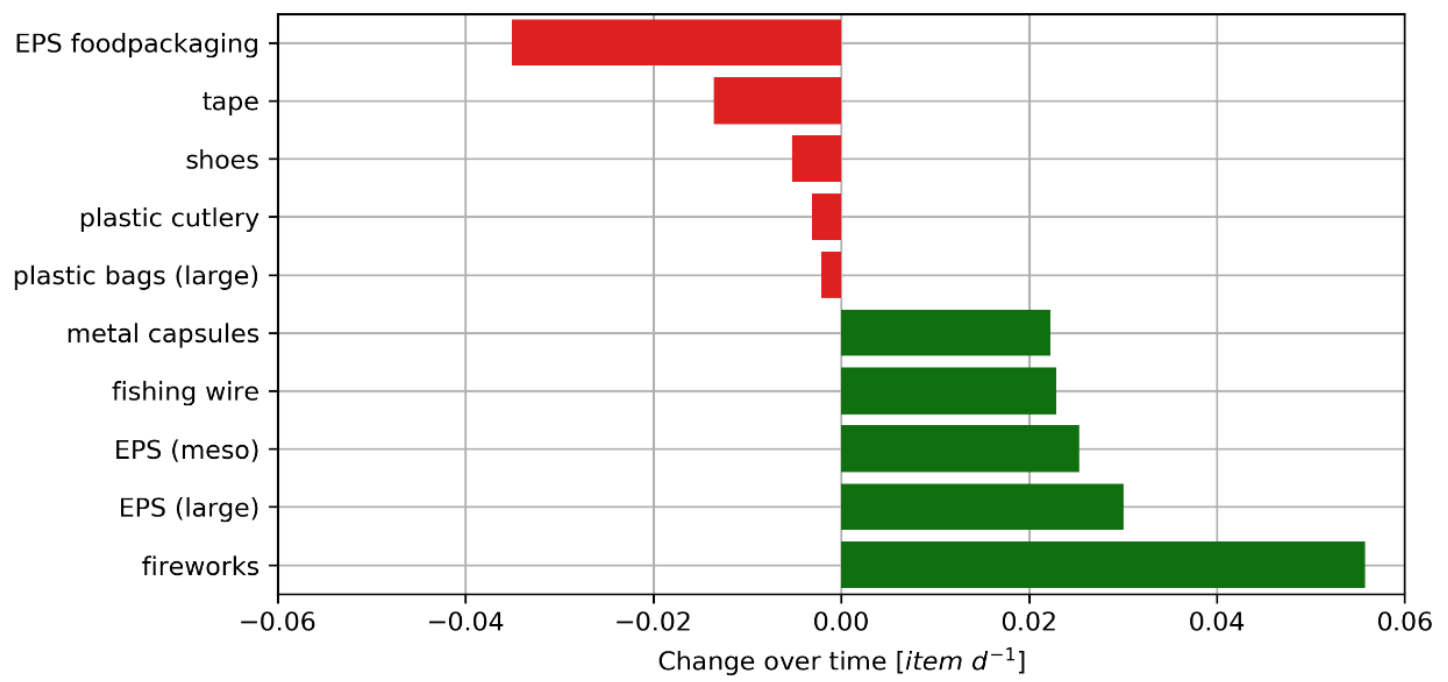

Figure 8 Five most decreasing and increasing items during the measuring period. The coefficients are shown as change of item count per day. A coefficient of 0.01 roughly corresponds with an increase of 4 items year over year.

\subsection{Seasonality}

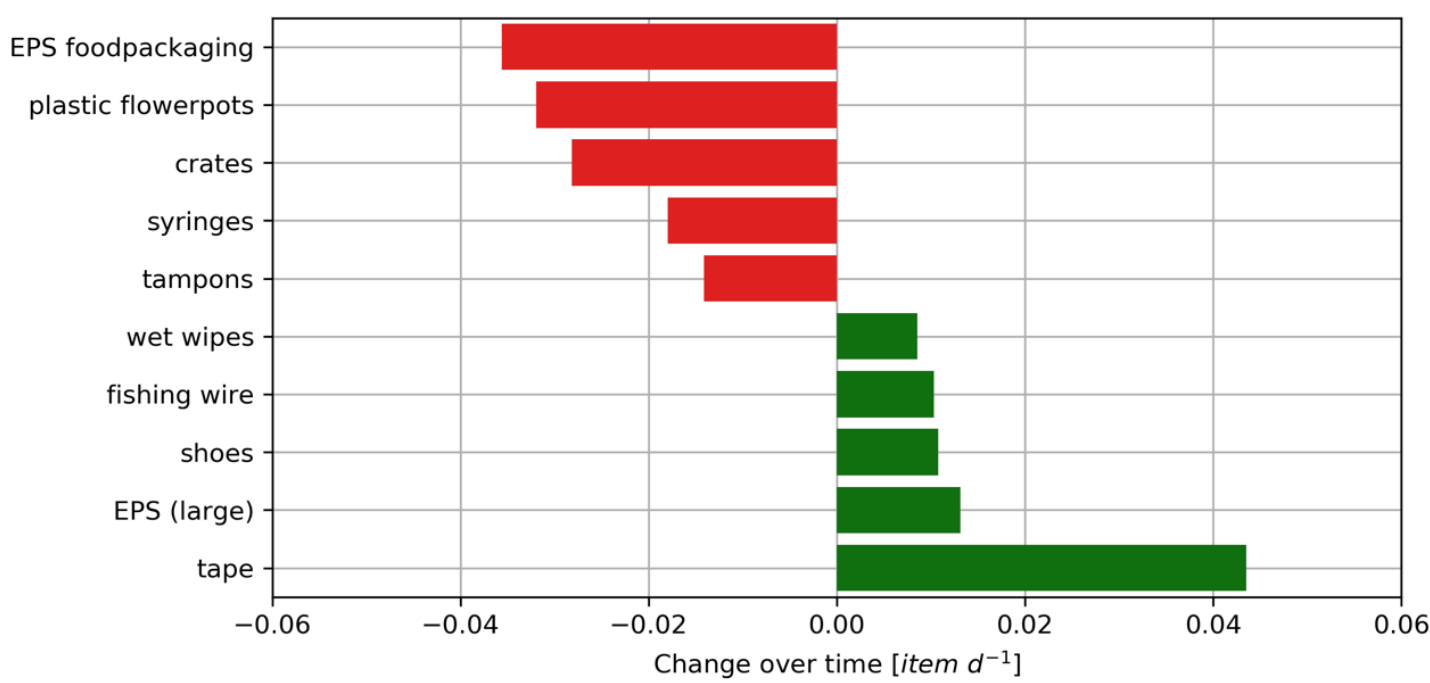

Figure 7 Five most decreasing and increasing items during the season. The coefficients are shown as change over time, and can be interpreted as the decrease of items found during a specific day of the year in comparison with the $1^{\text {st }}$ of January.

In contrast with the previous section, Figure $\mathbf{7}$ shows the seasonal change in the number of items that were found on the river beaches. The expanded version of this figure, covering all items with a significant change during the season is shown in Annex 2. Some interesting observations can be made with this expanded figure; items related to sewage overflows (tampons, toilet freshener) display a negative coefficient. This would create the hypothesis that sewage overflow occurs most often during the winter season. Many items related to recreation on the beaches, such as crown caps, cigarette filters and drinking cans show a positive coefficient. This would confirm that recreation most often happens during spring and summer, before the second measurement round. 


\subsection{Variation along the river}

\subsubsection{Parent categories}

\subsubsection{Meuse}
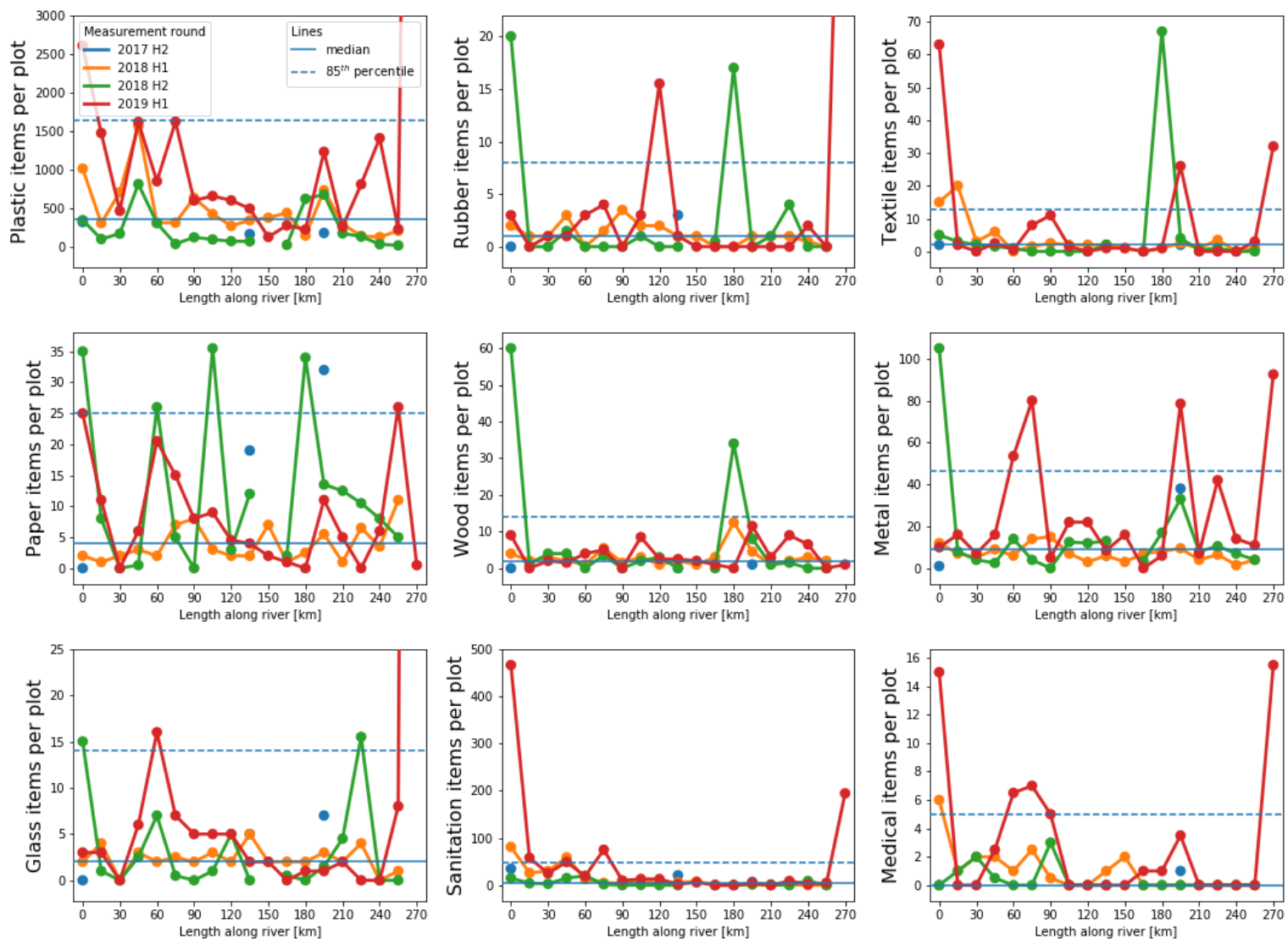

Figure 9 Variation of mean items count per plot segment of the Meuse. Each segment is $15 \mathrm{~km}$ long. The length along the river stretches from the border between Belgium and the Netherlands $(0 \mathrm{~km})$ to the most downstream measurement location $(270 \mathrm{~km})$. The plastic, rubber and glass subplot are clipped to better show the data. The last measurement location showed respectively 19477, 60 and 361 items. The horizontal blue full and dotted line show respectively the median and 85th percentile line (obtained from the full dataset).

To study the variation of the litter density over the river length, the data have been binned into segments of $15 \mathrm{~km}$. For each measurement campaign, profiles along the river length have been made. For the River Meuse, the results for the total sampled plastic items is presented in Figure 9. Here, it can be seen that the sampled litter is generally stable over the river length and between the measurement campaigns between 2017 and 2019. During the last measurement campaign in the spring of 2019, a clear peak was observed at the most downstream measurement location, and around $30 \mathrm{~km}$ upstream of the most downstream location. This could indicate that there has been introduction of additional litter items, from for example the city of Den Bosch. Alternatively, this could indicate that these locations are a (temporary) accumulation zone for litter items. The most downstream measurement location is close to the Biesbosch National Park. Here, the flow is influenced by tidal dynamics, and additional tributaries and distributaries, which could influence the transport of litter items. Another peak was observed around $70 \mathrm{~km}$ downstream of the Belgian border. These locations are located close to Roermond, which may also be an additional source of litter. 


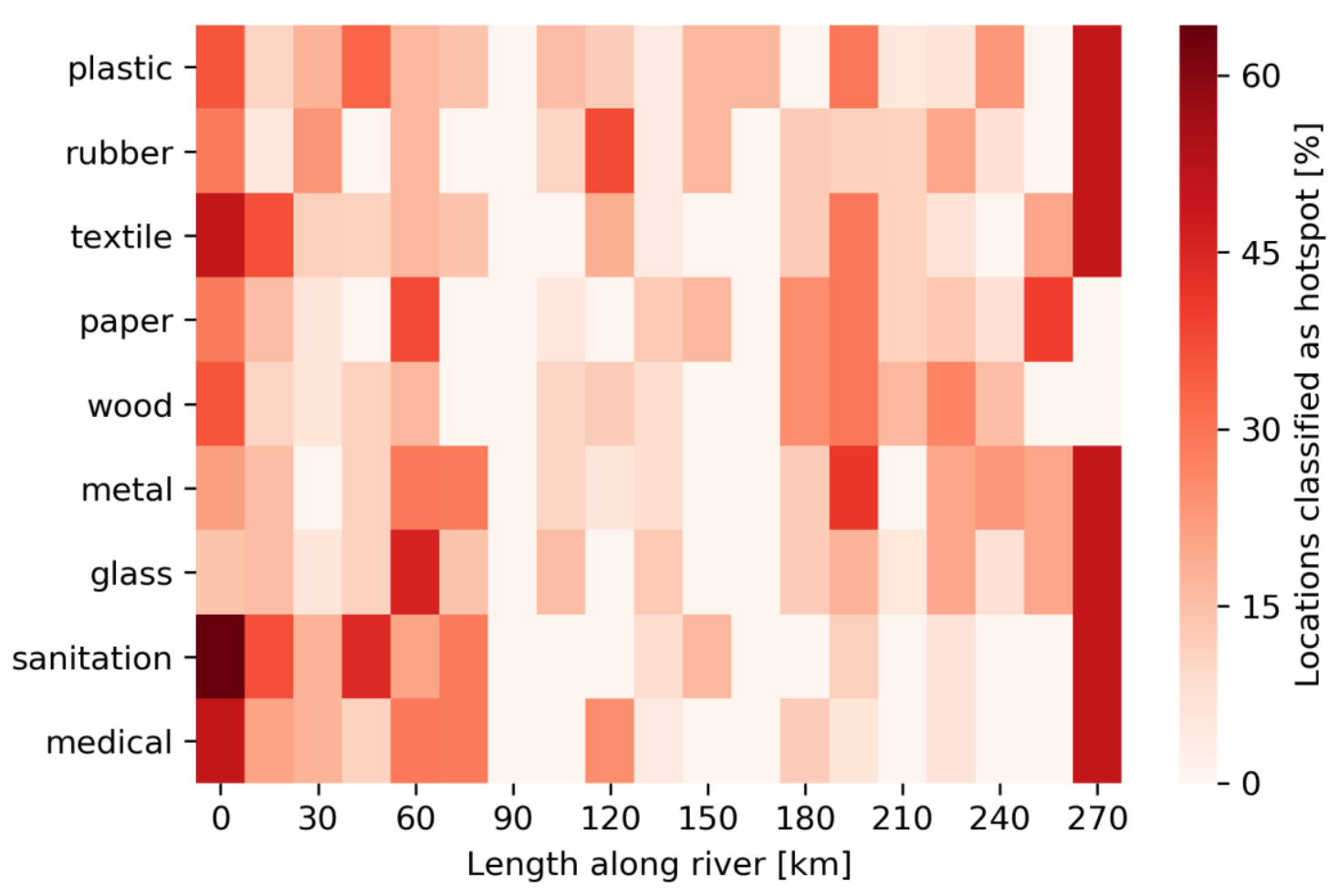

Figure 10 Percentage of sampling locations per river segment that are classified as hotspot for the river Meuse (above $85^{\text {th }}$ percentile per item category).

Figure 10 shows the percentage of the total amount of samples per $15 \mathrm{~km}$ bin that are classified as hotspots. The hotspot threshold per parent category is defined as the $85^{\text {th }}$ percentile of the category of all samples together. This shows very similar patterns as figure 7; the first and last segment are relatively polluted for most item categories while the segments around 90 and 165 kilometers along the river show relatively low amounts of pollution. 


\subsubsection{Waal}
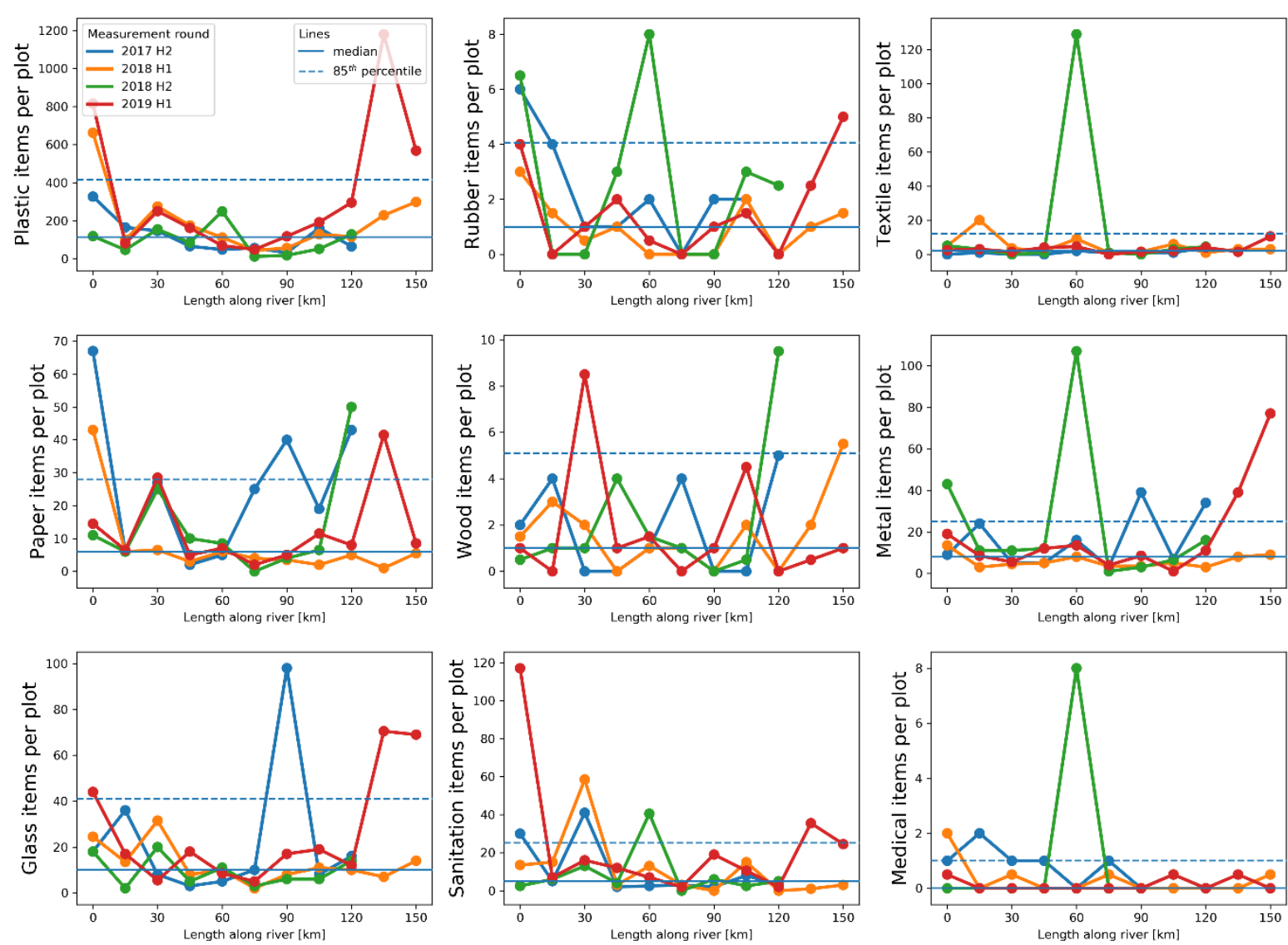

Figure 11 Variation of mean items count per plot segment of the Waal. Each segment is $15 \mathrm{~km}$ long. The length along the river stretches from the border between Germany and the Netherlands $(0 \mathrm{~km})$ to the most downstream measurement location $(150 \mathrm{~km})$. The horizontal blue full and dotted line show respectively the median and $85^{\text {th }}$ percentile line (obtained from the full dataset).

The plastic count per plot along the Waal (Figure 11) shows a different pattern compared to the Meuse (Figure 9). In the Waal, the number of plastic items is relatively high at the most upstream location, directly at the German border. A second peak is observed around $30 \mathrm{~km}$ downstream, which could be related to the input around the city of Nijmegen. In 2019, a high peak was measured around $75 \mathrm{~km}$ downstream, around the city of Tiel. Overall, the plastic items observed decreases in the downstream direction until around $100 \mathrm{~km}$, after which a consistent increase is observed again. Similar to the River Meuse, the locations most downstream are influence by tidal dynamics, tributaries, distributaries, and additional waterways. This influences the transport of litter and could cause (temporary) accumulation zones. 


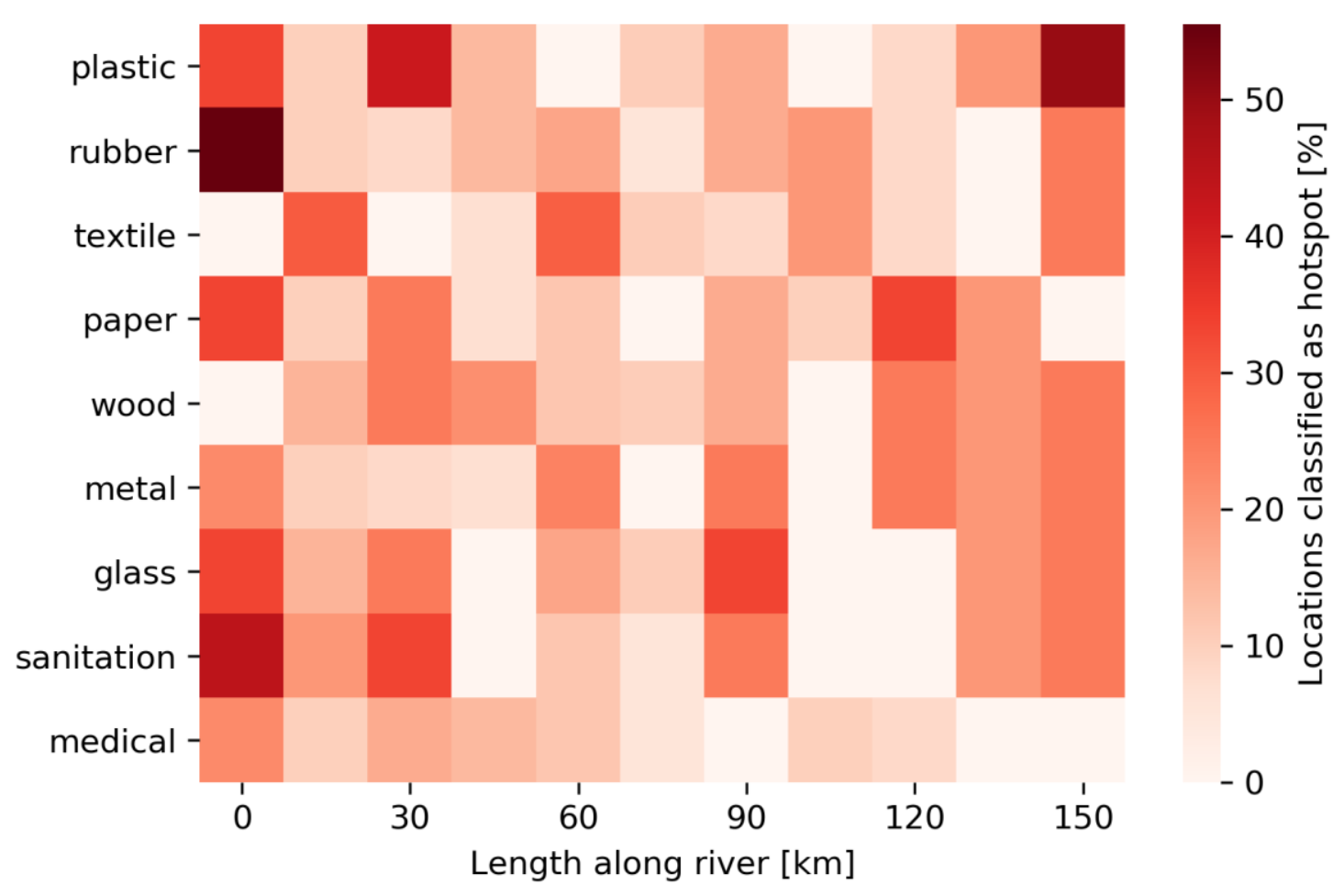

Figure 12 Percentage of sampling locations per river segment that are classified as hotspot for the river Waal (above $85^{\text {th }}$ percentile per item category). It shows the percentage of the sampled locations classified as hotspots, confirming the general trend of higher litter densities along the beginning and end of the river profile. Item categories however differ greatly, hinting at different sources and transport mechanisms being at play in different segments along the river. 


\subsection{Litter sources}

\subsubsection{Meuse}

We explored the spatiotemporal variation in litter sources in the Meuse and Waal rivers using a simple correlation analysis. Several items (see Chapter 2) are associated with one of the four pre-defined litter sources: dumping, recreation, sewer overflow and industry. We determined the correlation between the occurrence of all litter items, to identify the most likely sources. In the Meuse, items from dumping were found most abundant (Figure 13), and therefore mainly show a similar variation as the overall results (Figure 9). The second largest source was found to be recreational, with consistent variation over space across the various measurement campaigns. The abundance of litter from sewerage overflow (Figure 9, lower left) shows an increase for the last measurement campaign. In general there is more variation over the river length. The months prior to the Spring 2019 measurements did not have higher total rainfall (see annex 1 ). However, individual events may have been more extreme, causing local increased sewer overflow and therefore contribute more to the total litter found in the Meuse.
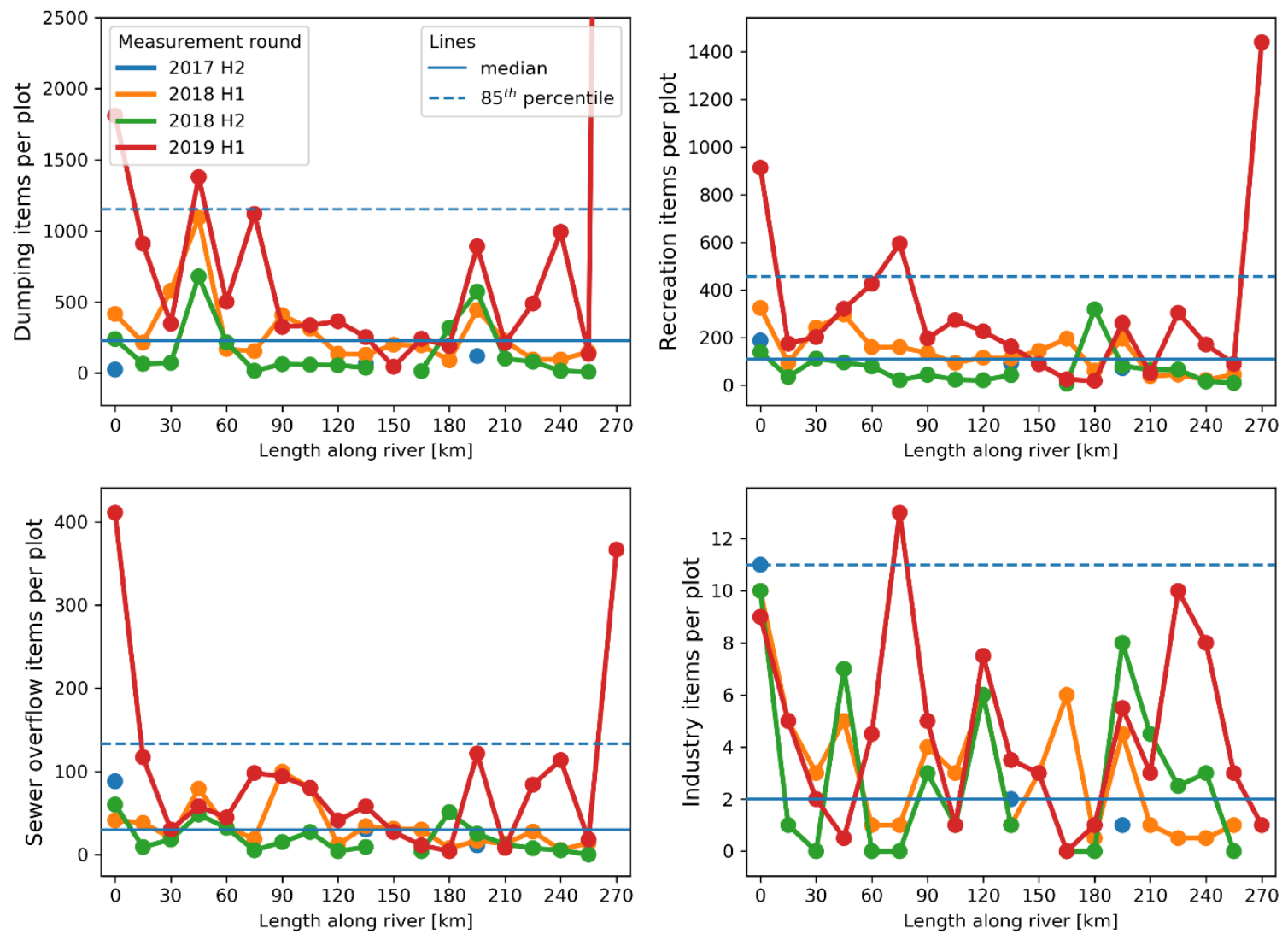

Figure 13 Variation of mean items count per liter source category per plot segment of the Meuse. Each segment is $15 \mathrm{~km}$ long. The length along the river stretches from the border between Belgium and the Netherlands ( 0 $\mathrm{km}$ ) to the most downstream measurement location $(270 \mathrm{~km})$. The dumping subplot is clipped to better show the data. The last measurement location showed 18390 items. The horizontal blue full and dotted line show respectively the median and $85^{\text {th }}$ percentile line (obtained from the full dataset). 


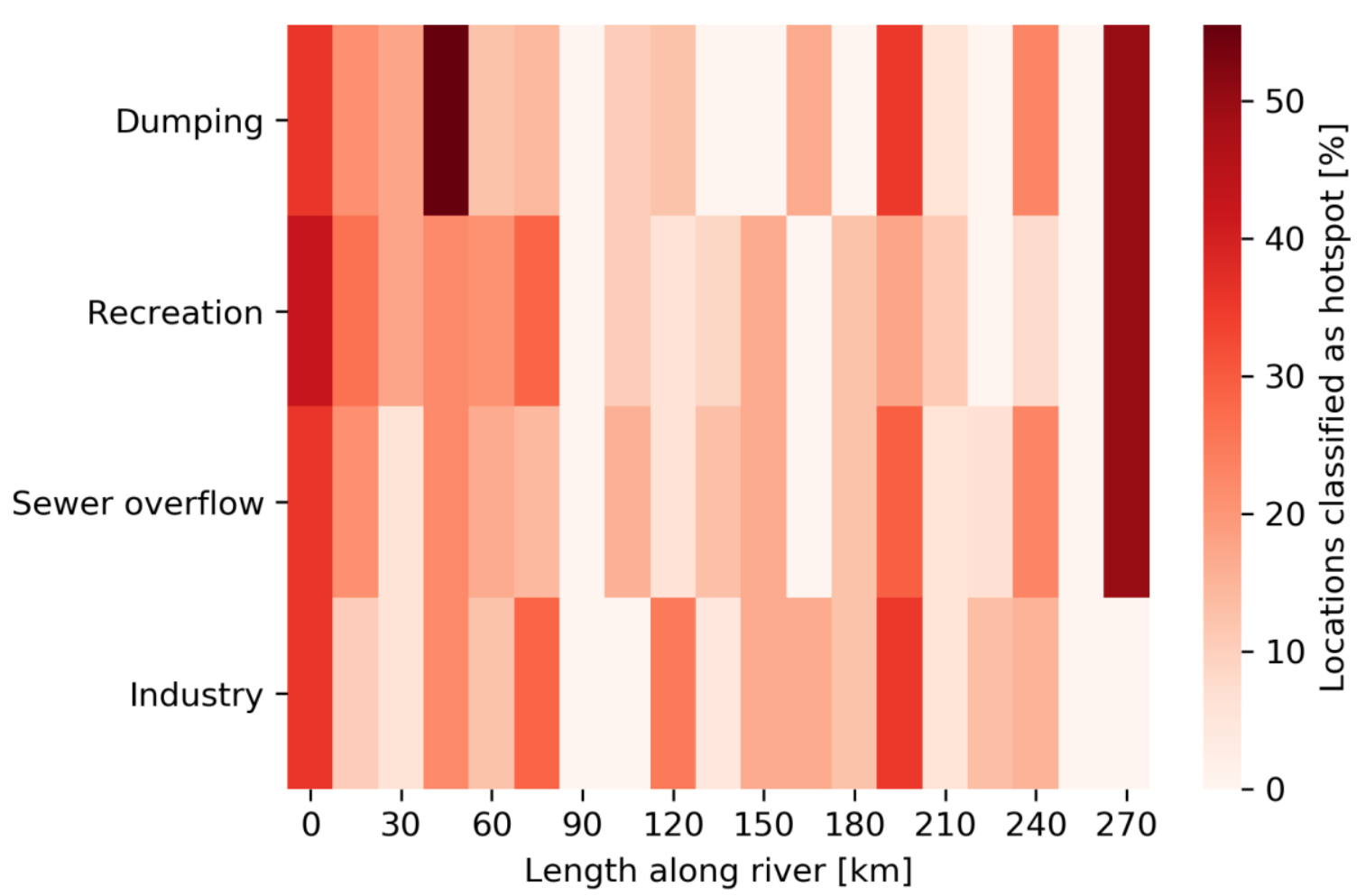

Figure 14 Percentage of sampling locations per river segment that are classified as hotspot for the river Meuse (above $85^{\text {th }}$ percentile per item source category).

The hotspot analysis shows a similar pattern (Figure 14). Recreation as a source seems to be more prominent in the first half of the river length, while sewer overflow and industry as pollution source are more homogeneously spread along the river. Especially dumping and industry sources seem the be very locally sourced, as would be expected since they are distinct point sources. 


\subsubsection{Waal}
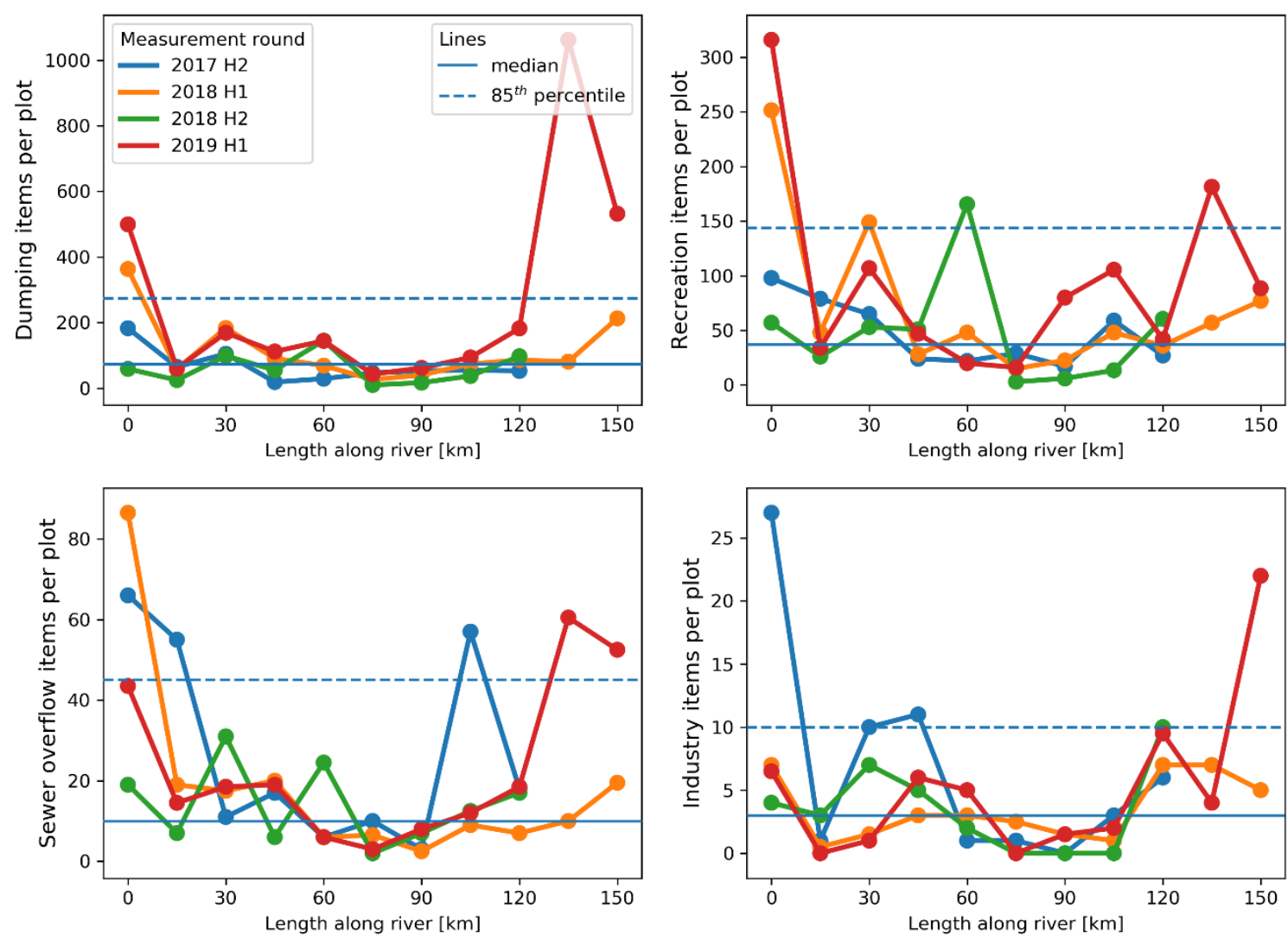

Figure 15 Variation of mean items count per liter source category per plot segment of the Waal. Each segment is $15 \mathrm{~km}$ long. The length along the river stretches from the border between Germany and the Netherlands $(0 \mathrm{~km})$ to the most downstream measurement location $(150 \mathrm{~km})$. The horizontal blue full and dotted line show respectively the median and $85^{\text {th }}$ percentile line (obtained from the full dataset).

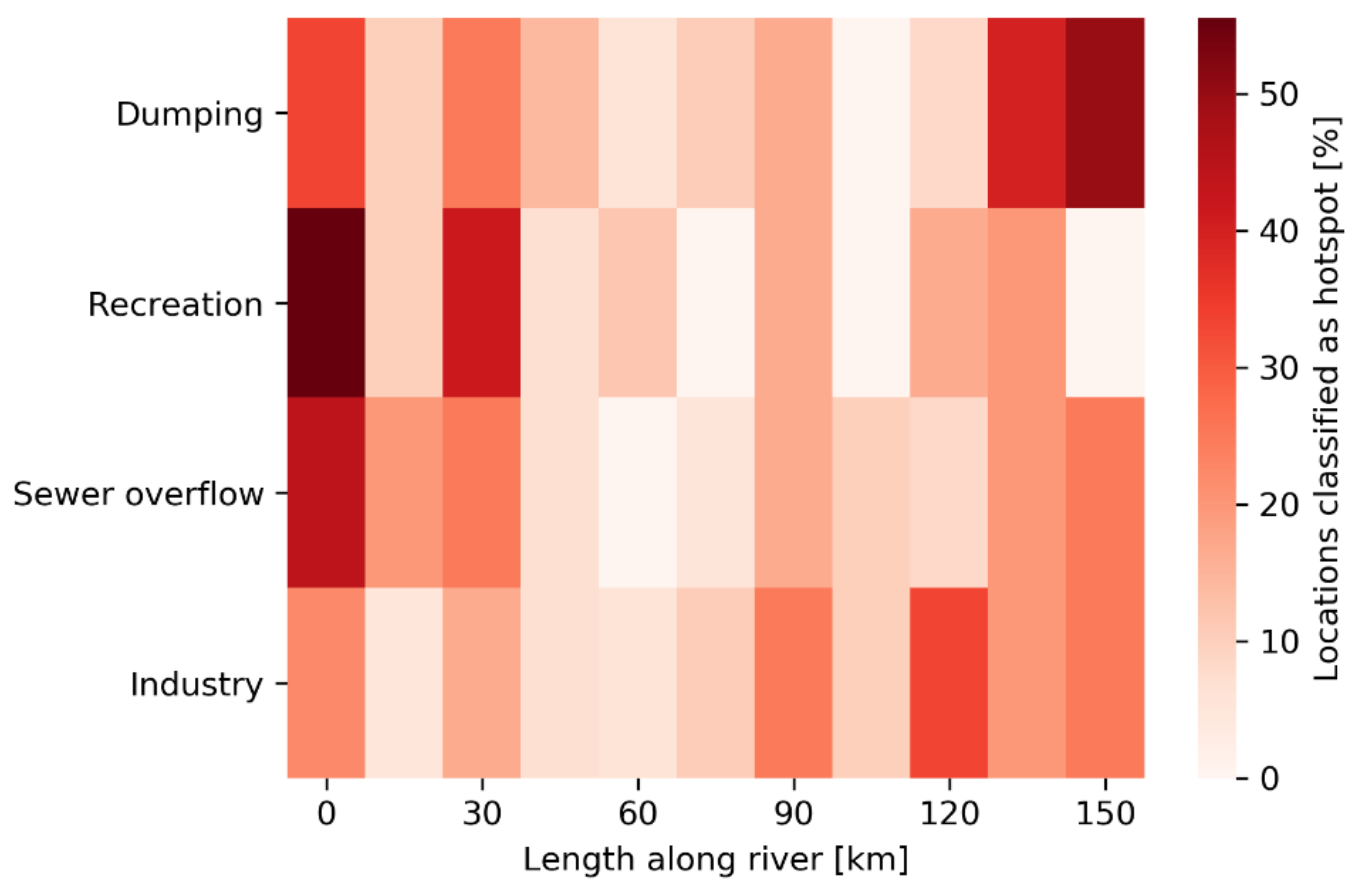

Figure 16 Percentage of sampling locations per river segment that are classified as hotspot for the river Waal (above $85^{\text {th }}$ percentile per item source category). 
The River Waal shows a similar contribution of each source to the total amount of sampled litter (Figure 15, Figure 16). Most abundant are the litter items from dumping, followed by recreational, sewerage overflow and industry. Dumping and sewer overflow show similar pattern; generally ranging from a peak at the German border, a gradual decrease over the length and an increase again between 100 and 150 $\mathrm{km}$ downstream. Recreation and industry contain more clearly separated peaks, hinting at lower mobility of these specific items. Around $30 \mathrm{~km}$ downstream, peaks are observed for each category, suggesting that the city of Nijmegen may be a location with increased introduction of litter items.

\subsubsection{Discussion litter sources}

To interpret the results shown above two things need to be noted. Firstly, industrial items are quite underrepresented. This is mainly caused by the fact that the chosen indicator items for this category are rarely sampled and therefore correlation values are generally quite low. This increases the possibility of categorization in other categories. Right now, many items that are most likely coming from the industries fall in the category of dumping. Secondly, many items are not coming from a single source. Plastic bags for example could be sourced in all four categories but are now sorted in the recreation category. To solve these issues more information about the nature of these items is needed, in which case the item counts can be dynamically allocated to the different source categories. Other ways of dynamically separating River-OSPAR items into more than one source category would be by either applying the method proposed by SDN (adapted from Tudor and Williams) or by using the correlation with all indicator items separately. Thirdly, by analyzing correlation values between the indicator items and the other items, it is assumed that transportation of these items is similar. This assumption, however, will not always hold.

\subsection{Governing transport mechanisms}

\subsubsection{Meuse}
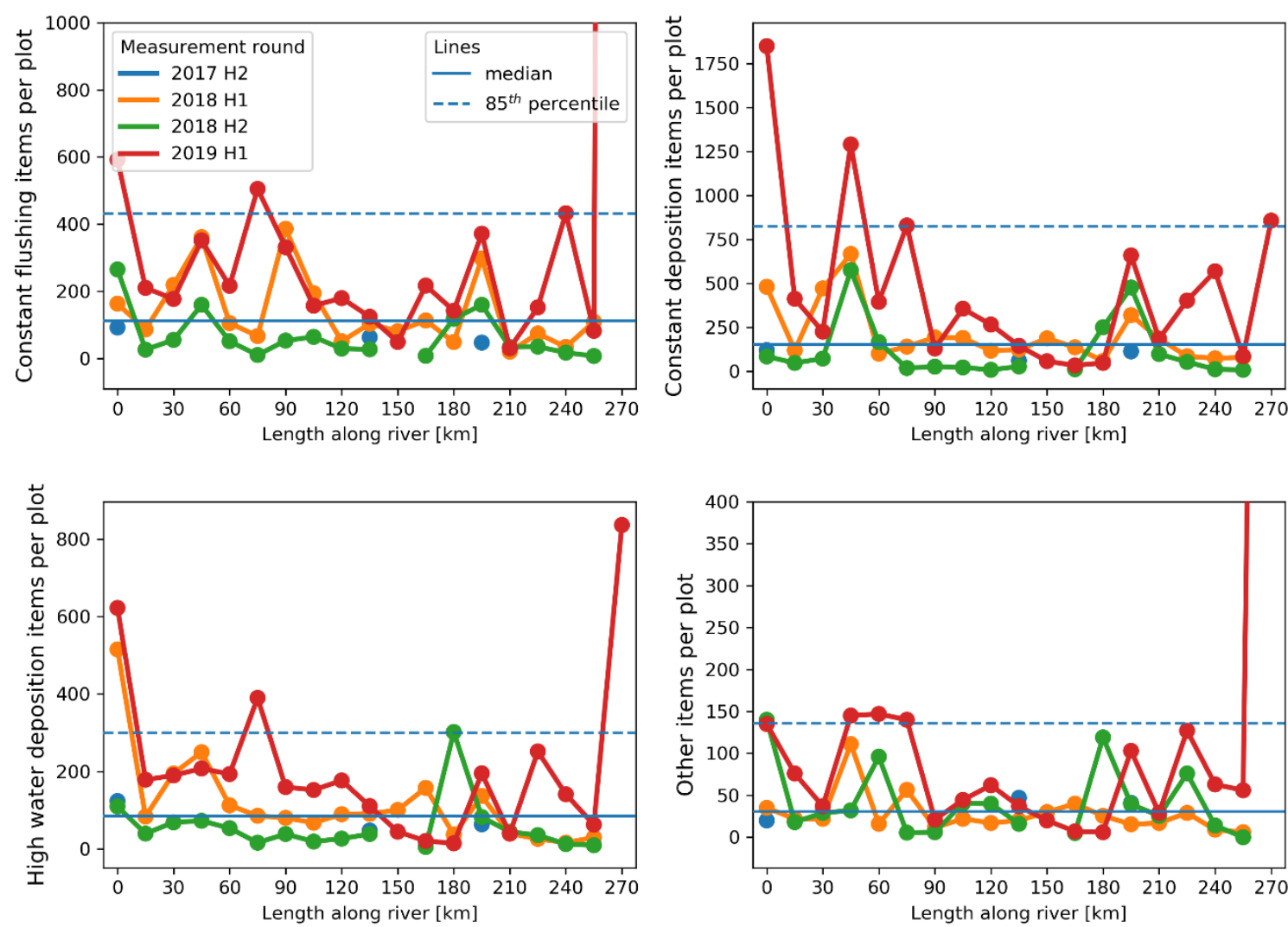

Figure 17 Variation of mean items count per governing transport mechanism category per plot segment of the Meuse. Each segment is $15 \mathrm{~km}$ long. The length along the river stretches from the border between Belgium and the Netherlands $(0 \mathrm{~km})$ to the most downstream measurement location $(270 \mathrm{~km})$. The constant flushing subplot is clipped to better show the data. The last measurement location showed 16098 items. The horizontal blue full and dotted line show respectively the median and $85^{\text {th }}$ percentile line (obtained from the full dataset). 


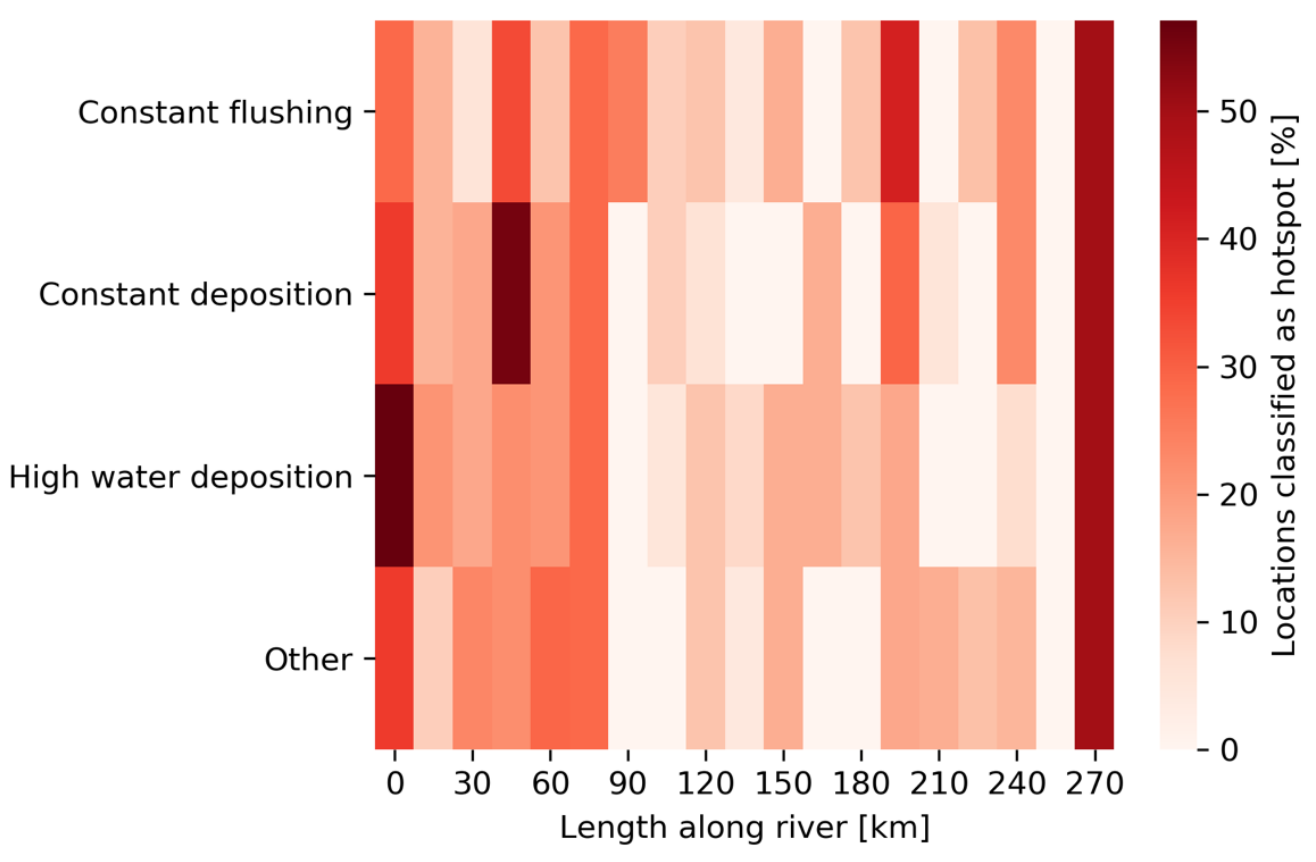

Figure 18 Percentage of sampling locations per river segment that are classified as hotspot for the river Meuse (above $85^{\text {th }}$ percentile per governing transport mechanism category).

In addition to the sources of riverbank litter, we also estimated the main transport mechanisms of item types, see Figure 17 and Figure 18. This was determined using the statistics of the antecedent water level measurements (see Chapter 2). Between 90 and $200 \mathrm{~km}$ downstream of the Belgian border, the main mechanism is "constant flushing", indicating direct introduction of litter on the shores at or close by the monitoring locations. At the locations with increased litter abundance, all mechanisms contribute to this increase. The influence of extreme events ("high water deposition") also seems considerable. Especially around $75 \mathrm{~km}$ and $195 \mathrm{~km}$, a peak of additional litter as a result of extreme events was observed. 


\subsubsection{Waal}
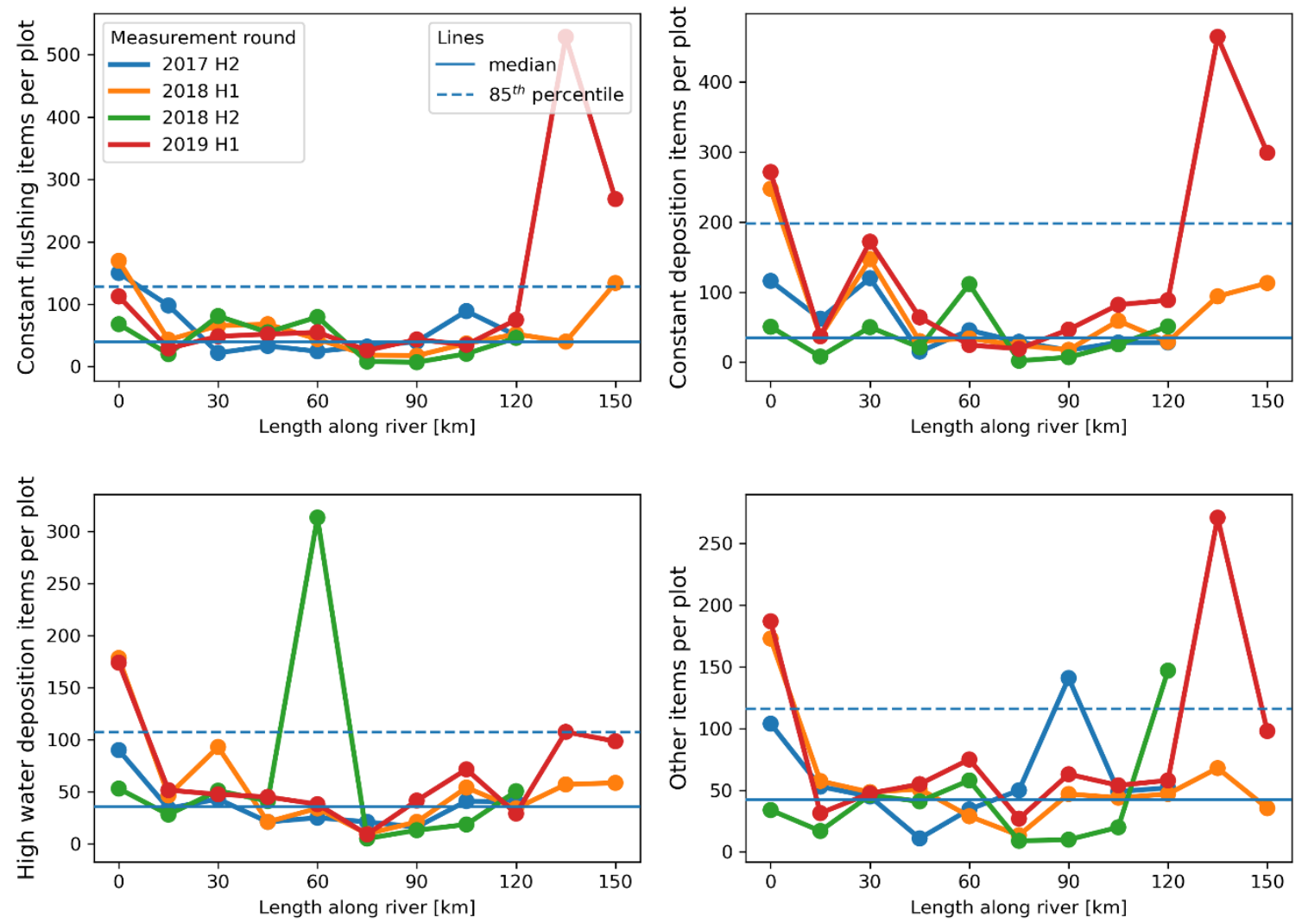

Figure 19 Variation of mean items count per governing transport mechanism category per plot segment of the Waal. Each segment is $15 \mathrm{~km}$ long. The length along the river stretches from the border between Germany and the Netherlands $(0 \mathrm{~km})$ to the most downstream measurement location $(150 \mathrm{~km})$. The horizontal blue full and dotted line show respectively the median and $85^{\text {th }}$ percentile line (obtained from the full dataset). 


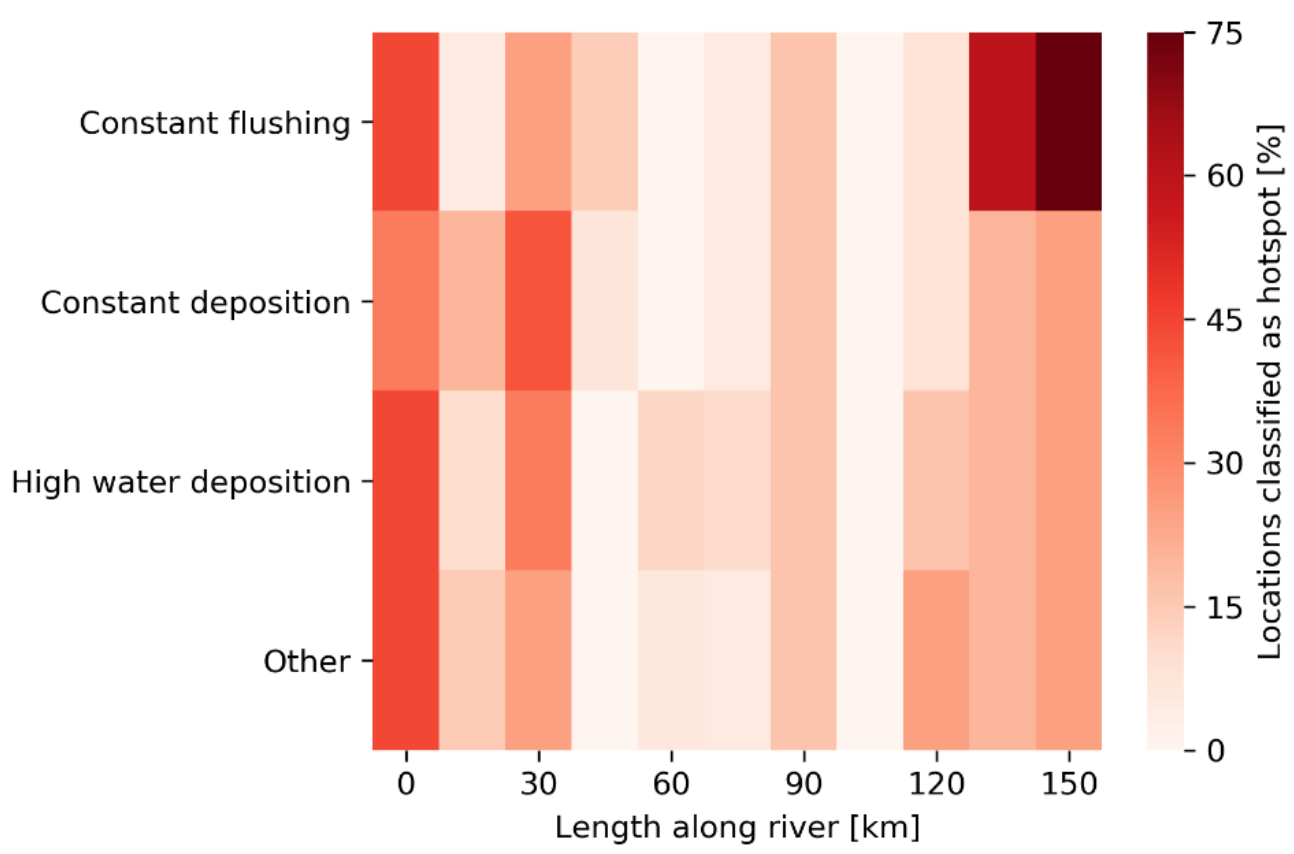

Figure 20 Percentage of sampling locations per river segment that are classified as hotspot for the river Waal (above $85^{\text {th }}$ percentile per governing transport mechanism category).

In the Waal, the main transport mechanism seems to be the "constant deposition", meaning that the plastics found on the riverbanks originate from upstream locations (see Figure 19 and Figure 20). For the Waal, extreme discharge events are less important for the total litter abundance on the riverbanks. The order of magnitude is still similar to the locally sourced litter ("constant flushing").

\subsection{Data quality}

Using the coefficients from the negative binomial regression models, as described in Chapter 2, the difference in reference samples and volunteer samples can be determined. As can be seen in Figure 21 and Annex 2, most items are sampled significantly less by volunteers than was done by SDN, although there are a few exceptions. These values are the best estimates that can be calculated with the current data, but it needs to be considered that the reference samples are very few observations compared to the samples gather by volunteers (roughly $5 \%$ of all samples are done by SDN). In the coming measurement rounds this analysis will become more robust. At the moment, it cannot be statistically

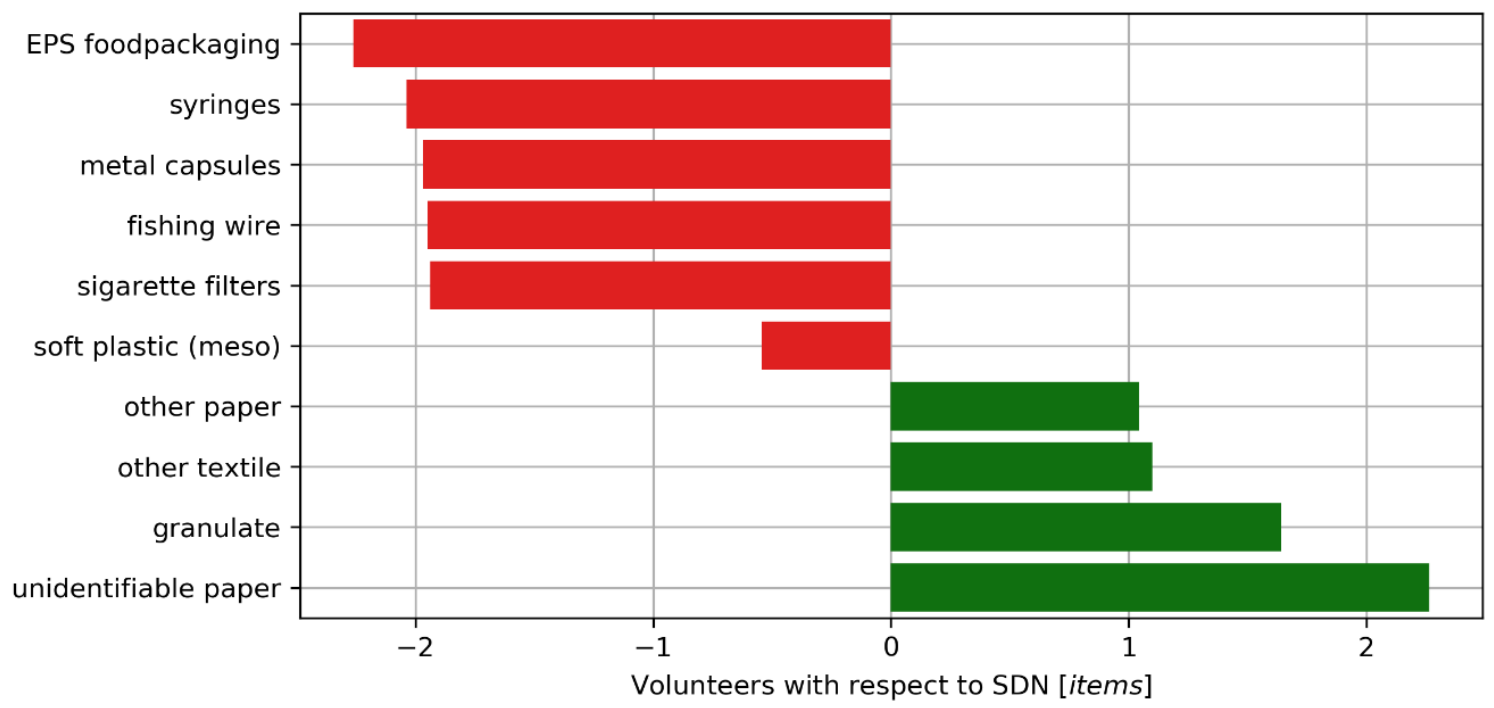

Figure 21 The five items with the highest and lowest change of volunteer sampling in comparison with the reference samples executed by SDN. A version covering all items is presented in Annex 2. 
proven that the reference samples are similar sites as the volunteer samples and not extreme sites, when enough data is present direct statistical tests can be performed to test (per item) if the reference samples are drawn from the same distribution as the volunteer samples. Nevertheless, the presented analysis shows that significant discrepancies are present. Interesting to note that the items sampled significantly more by volunteers in comparison with SDN are unidentifiable objects. This could hint at volunteers not specifically finding less items, but classifying them as unidentifiable while SDN would choose a different category.

\subsection{Discussion}

With the currently available data we analyzed the first trends in space, time and composition of the litter found on the river beaches. With 211 unique locations and almost 400 samples spread over 3 years it gives us an interesting view on the Dutch river system. Since the data was measured in only 4 measurement rounds (and less than 10 locations were sampled every time) direct trend analysis does not yield significant results. Instead, we used the sampling time in a regression model to obtain a first understanding of the temporal trends for each item, with the cautious conclusion that most item categories are increasing over time.

The strength of this measurement campaign lies in its high spatial coverage, making it possible to analyze the composition, sinks and sources across the Netherlands. This information can subsequently be used for policies, targeted cleaning operations and prevention schemes.

The analyses for sources and transport mechanisms both have some uncertainties linked to them. The source analysis is based on the correlation of all items with select indicator items. Currently, the indicator items for 'Industry' are rarely observed and therefore yield relatively low correlation values. At the same time, it needs to be realized that items often do not come from a single source. For example, plastic bags could potentially be attributed to all four sources. This could be resolved in different ways, such as dividing the items dynamically to expert judgement (as proposed by SDN) or by using the currently calculated correlation values to distribute the items proportionally to different sources. Another way to compensate for these uncertainties specific data is needed on the litter composition of all sources; for example sampling sewage overflows and applying the same River-OSPAR checklist. If such data is available, the observed items can be split accordingly to their source category. The transport mechanisms categories are based on model coefficients. These coefficients are significant but the way they are categorized is still simplistic. In the future a more robust categorization scheme can be devised, based on not only water height but also data on precipitation, wind and the side of the river bend.

The main shortcomings of the data are linked to the limited temporal resolution and duration of the project. By continuing the collection of data with the current methodology direct trends in time can be analyzed and benchmarks can be drawn. These benchmarks are important to understand the significance of temporal changes, e.g. cleaning actions. Such benchmarks can for example be calculated with the LitteR (https://cran.r-project.org/web/packages/litteR/index.html) package (based on Schulz et al., 2019) that was developed for creating such benchmarks for the OSPAR protocol. Using this software package requires to fill in the river name instead of the country name, but other than that the software can directly be used without modification.

\subsection{Conclusion}

The conclusion of the data analysis of the first four measurements rounds is that this methodology gives us an elaborate view over the litter composition and distribution over the Netherlands. Many items sampled in this campaign show a significant increase over time. The choice of gathering data with volunteers has provided the chance to obtain a lot of data in a relatively short amount of time. Most items, however, do see a significant discrepancy between plots sampled by volunteers and samples made by professionals at SDN. More data is needed to test these changes more in depth. The spatial distribution of the data gives us insight in so called hotspots, but it cannot yet give decisive information about the locations being sources or accumulation zones. For this but also for establishing benchmarks 
(as can be calculated with the procedure described in Schulz et al, 2019) and observing temporal trends longer timeseries are needed. 


\section{Outlook for future riverbank litter monitoring in the Netherlands}

\subsection{Alternative monitoring methods}

\subsubsection{Learning from similar approaches}

Similar approaches use a variety of researchers to perform fieldwork. The training level of these researchers range from school children (Kiessling et al., 2019) to trained professionals (Battulga et al., 2019). When deciding on who performs the fieldwork, two main aspects should be considered: the accuracy of the data gathered and the amount of locations that can be sampled. Trained professionals will gather more accurate data but will not be able to sample as many locations as for example school children. The River-OSPAR method falls in the middle of this range; using trained volunteers makes it easier to gather enough people to sample many locations, and the training they receive ensures high quality data. We therefore suggest to not alter this component of the River-OSPAR method

Another key factor from similar approaches is the sharing of (interim) findings. Currently, the scope of the Schone Rivieren project is solely on a national level. This while both the Rhine and the Meuse are transboundary rivers. To get a larger picture of the litter problem throughout the whole catchment area of both rivers, we suggest the sharing of results with others. This could be done through for example a scientific paper, but non-public data exchange between other litter identification projects would also suffice. For example, sources of litter could be studied in more detail by comparing what types of litter and how much is found on riverbanks of the Rhine and the Meuse further upstream.

\subsubsection{Citizen science methods}

Several of the methods discussed in Chapters 3 and 4 are based on citizen science-based data collection. The River-OSPAR protocol is an example, as (trained) volunteers are involved in the sampling and collection of data along the Dutch riverbanks. Citizen science is becoming a more prominent and more reliable data source in hydrology, water resources and related fields (Buytaert et al., 2014). One of the benefits of citizen science includes the large potential group of volunteers for sampling, and thereby the potential to collect data all around the world. A challenge is the increased uncertainty of the data due to the level of training, expertise and varying observers. Recent efforts have tried to resolve this, also for the specific field of litter monitoring on and aquatic ecosystems. For example, the Litterati and Marine Debris Tracker apps allows citizen scientists to upload a geotagged image to indicate the time and location of an observed litter item. The newest addition to the list is the CrowdWater app, originally made to collect hydrological data such as water level and soil moisture (Seibert et al., 2019). The CrowdWater app has been extended with a simple module to allow for collecting data on (1) floating plastic items in rivers and (2) plastics on shores and riverbanks. Users can indicate the measurement location, sampling duration, stretch of riverbank, shore or river width, and the number of counted plastic items. More advanced options also allow the citizens to specify the plastic item types (seven categories), and comment on the (absence of) flow velocity and whether the litter items have been removed. 


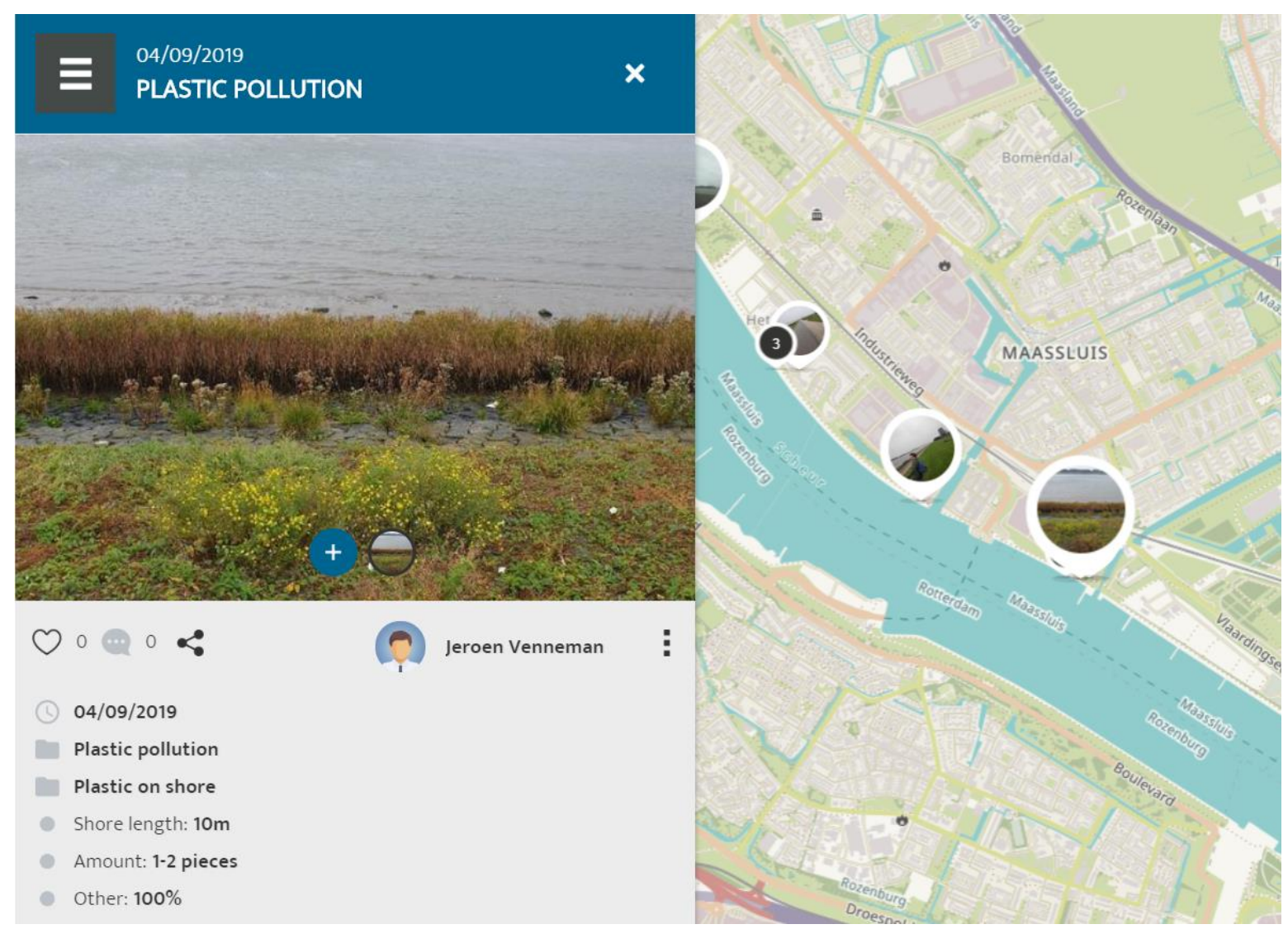

Figure 22 Screenshot of the CrowdWater app for riverbank litter data collection. The example shown illustrates several measurements done along the River Rhine, between Rotterdam and the river mouth.

\subsubsection{UAV-based methods}

Unmanned Aerial Vehicles (UAVs) are also being used more extensively for quantifying litter on land, in river systems and in the ocean. Martin et al. (2018) demonstrated how UAVs can be used to monitor beach litter, using a machine learning algorithm to automatically detect litter items. More recently, Geraeds et al. (2019) used UAVs for the first time to monitor river plastic. The primary goal of this study was to quantify mobile floating plastics, and its variation over the cross-section and over time. However, it was suggested that a similar approach may work well for riverbank litter monitoring. Figure 23 shows two example images for floating plastic items (left) and riverbank plastics (right). From visual inspection, plastic items can be distinguished. Some training may be required for consistent manual detection of litter items. We suggest to further explore the use of using UAVs for riverbank litter monitoring, as it is less labor intensive. The additional benefit is that this method collects raw data more objectively, as the images can be processed again to investigate data outliers. Furthermore, the data analysis can be done again after new processing or machine learning algorithms become available. 

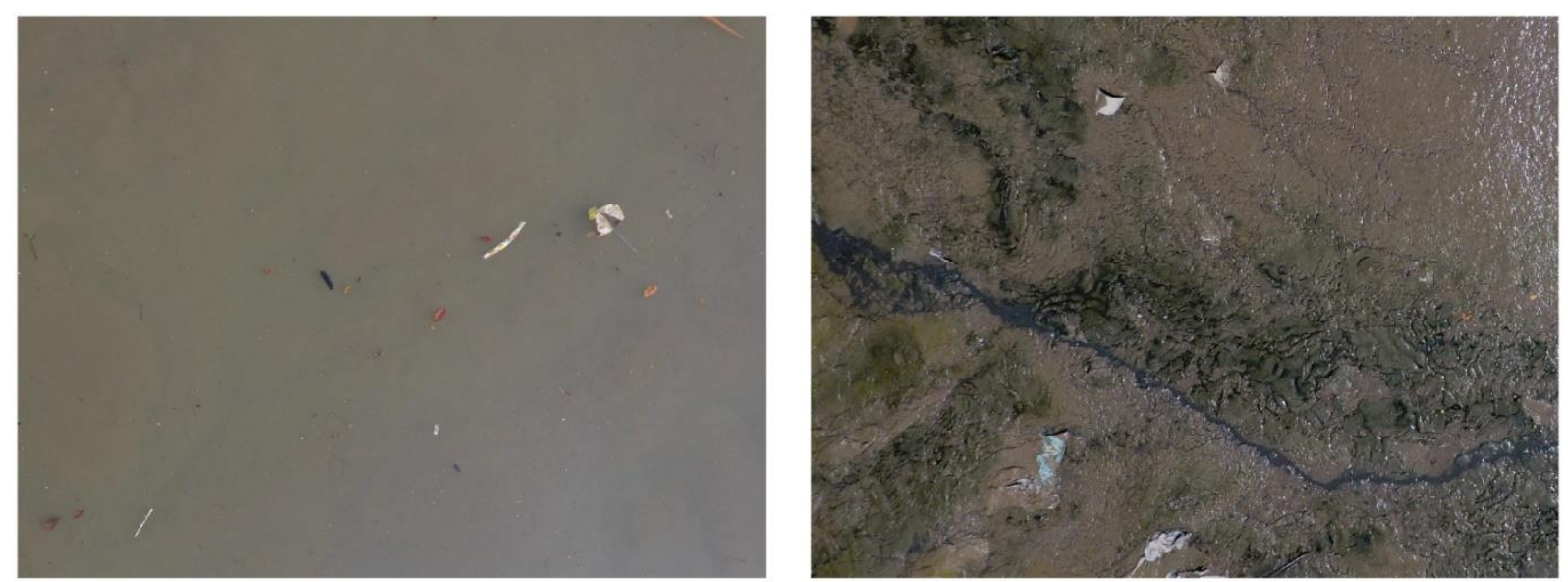

Figure 23

Examples of images collected of floating plastic items (left) and riverbank plastics (right) in the River Klang, Malaysia.

\subsubsection{Remote sensing from space}

It has been hypothesized that remote sensing using satellites may be used for monitoring (plastic) litter in aquatic ecosystems. To date no missions are specifically designed to detect anthropogenic litter. A recent assessment of to what extent remote sensing has potential for litter monitoring concluded that the water environment may be to challenging, as the signal-to-noise ratio is still too high (MartínezVicente et al., 2019). However, shoreline marine detection was considered feasible with specific sensor specifications (hyperspectral optical/(near-)infrared). For river systems, such developments may also yield interesting opportunities for satellite remote sensing of (plastic) litter on shorelines.

\subsubsection{Camera-based monitoring}

To automate (plastic) litter transport, there is an increasing effort to use camera-based monitoring methods. Kylili et al. (2019) presented a first artificial intelligence (AI) based approach to automatically detect and monitor plastic litter items. This could be implemented as well for river systems, by installing camera systems on bridges, for example. This would allow automatic monitoring of floating mobile and riverbank litter along the river length in a simple and cost-effective way. Automated monitoring systems will give new challenges with respect to data infrastructure and analysis. To improve automatic detection of litter on images, images have to be manually analyzed first. Also this can be done with the help of the general public. Platforms such as Zooniverse (https://www.zooniverse.org/) allow manual analysis of images, and preparation of training datasets for artificial intelligence algorithms.

\subsection{Including litter in other river components}

As shown in Figure 1, (plastic) litter is abundant in all components of the river system. There are no generic estimations on what percentage of the total amount of plastic can be found on riverbanks. From observations presented in the literature, it is clear that also other components should be considered for long-term monitoring strategies. Without accurate estimations of the (plastic) waste streams from land to rivers to oceans, it is also more difficult to prioritize and strategize prevention, mitigation and reduction efforts. Here, we suggest several other components that can be taken into account for future national monitoring strategies.

\subsubsection{Floating Litter}

Next to litter on riverbanks, floating litter is one of the most studied components of the plastic waste streams. Floating litter is generally observed through net sampling from bridges or boats (Moore et al., 2011; Hohenblum et al., 2015; van Emmerik et al., 2018) or through visual counting (GonzálezFernández et al., 2017; van Emmerik et al., 2018). Net sampling gives insight in the composition, mass 
and concentration of floating litter. However, it is labor intensive and requires additional infrastructure and equipment, such as nets, laboratories, boats and deployment cranes. The visual counting method comprises of observations from bridges at several segments across the river width. Observations are done for a specific amount of time, generally between 1 and 15 minutes. During this period, all floating (plastic) litter items are counted. This method gives a rapid estimation of the litter transport in items per unit of time, and the variation over time (hours, days, weeks, seasons) and space (river length and across width). All monitoring long-term efforts of floating (plastic) litter to date have been done using the visual counting method (e.g. Crosti et al., 2018; Castro-Jiménez et al., 2019; van Emmerik et al., 2019b). Floating litter observations can also be facilitated through citizen science. The CrowdWater app also allows for floating plastic observations, ideally from bridges. In the first months after its launch, CrowdWater already collected floating plastic observations from several major rivers (Aker, Oslo, Norway; Fyris, Uppsala, Sweden; Sihl, Zurich, Switzerland; Rhine, Rotterdam, Netherlands; Seine, Paris, France; Klang, Kuala Lumpur, Malaysia) that were not or barely measured before. New projects, such as the Plasticspotter (https://www.plasticspotter.nl/) project use citizen science observations to estimate the City of Leiden's contribution to the plastic soup. Such projects may provide relevant blueprints for large-scale monitoring efforts in Dutch rivers.

\subsubsection{Litter in sediments}

River sediment acts as a (temporary) accumulation zone for plastic debris. Unfortunately, this component remains understudied, especially in Dutch rivers. Once in the sediment, larger plastic items may break down in microplastics, making it more challenging to remove them from the system. Also, litter trapped in sediments may be flushed during extreme flood events. In the UK, a $70 \%$ decrease of microplastic concentration in river sediments was observed after the 2015/16 floods (Hurley et al., 2018). The remobilized plastics are likely to have been flushed out of the river system, into the ocean. Sediments in Dutch rivers may be studied on large scale during dredging activities.

\subsubsection{Litter in other components of the river system}

Finally, other components, such as (plastic) litter in riparian vegetation and biota, remain understudied. For Dutch rivers, it is not clear how (plastic) litter is distributed over the various components. Not all components can be monitored using citizen science. On the other hand, citizen science may be a powerful method to get a good first-order impression of the extent of litter spread across river systems. This may specifically be helpful to study the (temporary) accumulation of litter in riparian vegetation.

\subsection{Link to other data sources}

Other data sources could be coupled with the data set of the Schone Rivieren project in the future to get more insights in litter transport behavior in rivers. We have identified several potential data sources that could be utilized. These data sources and their possible uses are further elaborated upon within this chapter.

\subsubsection{Municipal waste data}

Several point sources of litter can be identified within the literature. Wastewater treatment plants have most often been identified as a source of microplastics and larger litter (Browne et al., 2011; McCormick et al., 2014; Morrit et al., 2014). However, sewage storm drains and storm water runoff have been documented as being a source of litter as well (Redford et al., 1997; de Jesus Pinon-Coling et al., 2019). Linking municipal data sets on sewage storm drains could therefore create useful insights on litter sources and transport in rivers.

\subsubsection{Waterboard (Waterschap) infrastructure data}

Weirs, sluices, dams and other barriers within the river can influence litter transport in rivers. These obstacles can act as (temporary) depositional zones for litter or as sinks due to manual removal (e.g. 
clearing of debris at pumping stations). The effects of these man-made structures on riverine litter transport are currently not a widely studied topic, it could therefore be interesting to couple datasets on the locations of these structures within the Netherlands with the Schone Rivieren dataset. Moreover, the possibilities of coupling data on the quantity and the types of litter removed at these locations could be explored.

\subsubsection{Land-based litter}

Land-based litter datasets such as the ones collected through volunteers using the Litterati app could be used to gain further insights of litter transport within the environment. For example, the items that are frequently found in the riverine environment could be compared to land-based data in order to examine which items are more prone to be transported to the riverine environment.

\subsubsection{Land use data}

Cowger et al. (2019) have shown that land use data can be used to predict the composition and source of riverine litter. By comparing data on land use of the area in the vicinity to the river with field data gathered through citizen science, they were able to predict what types of litter was present in the riverine environment. This technique could also be used to predict what types of litter can be found where in the river and could aid with identifying potential litter hotspots on riverbanks.

\subsubsection{Riverbank cleaning efforts}

Another interesting angle to explore are the riverbank cleanups that are currently being performed on Dutch riverbanks. Data on these efforts could be used in twofold: first, these cleanup efforts could influence the results of the Schone Rivieren project since they actively remove litter. Knowing when and where these efforts are undertaken could therefore aid in more accurately describing litter transport behavior. A second use could be derived through having a centralized method for these cleanup efforts in which litter is not only removed, but also analyzed on composition similar to the River-OSPAR method. By doing so, these cleanup efforts could form an extra data source for further analysis.

\subsection{Database and data management}

Data management starts with the volunteers filling out the raw data in the online data form supplied by SDN. This form utilizes the same item category list to register litter as the one used in the field by the volunteers. A potential risk with this process is that the act of copying raw data into an online form is prone to human errors. The ability to skip this step (by for example using an app such as Open Data Kit Collect $^{6}$ to log data in the field) would reduce this risk of human error. Besides data on litter, the online form also allows for the logging of additional data such as the names and other information of the volunteers, the date at which the analysis was performed, the length and width of the transect that was analyzed, at which side of the river the transect was located, unlisted items, and whether any abnormalities occurred that could have influenced the results. Additional data that is currently not being logged but that could be useful for further analysis include the exact GPS location(s) of the transect, time at which the analysis was performed, and whether the transect is located on the straight part, at the inside, or outside of a bend in the river. The latter could be useful to take into consideration since these factors can influence litter deposition. Once the form is filled in, the volunteer clicks on send, which automatically sends the data to SDN for analysis in an excel spreadsheet format.

The current procedure is probably the most straightforward method for volunteers. The data management steps afterwards might be improved, however, to add an extra layer of checks into the workflow. Currently, each sampling location has its own unique code, linking the observations to the

\footnotetext{
${ }^{6}$ https://docs.opendatakit.org/collect-intro/
} 
GPS locations, and site information. This could lead to area codes occurring several times during each measurement round, which did indeed occur. Most of these instances have been resolved during the duration of this project, but some persist. To prevent such errors during future measurement rounds it might be advisable to convert this excel file to a relational database such as Microsoft Access or MySQL. This would resolve several, minor issues at the same time. For example, the date format would be homogeneous, typing errors in for example area codes would be spotted automatically and the observational data would become integer values, removing extra, unnecessary spaces. Another positive result of implementing such as system would be that all the volunteer information can be removed from all tables, except a dedicated table for all privacy sensitive information. When sharing the data, this dedicated table could simply be removed while keeping the rest of the information intact without much effort. A possible database schema is presented in Figure 24.

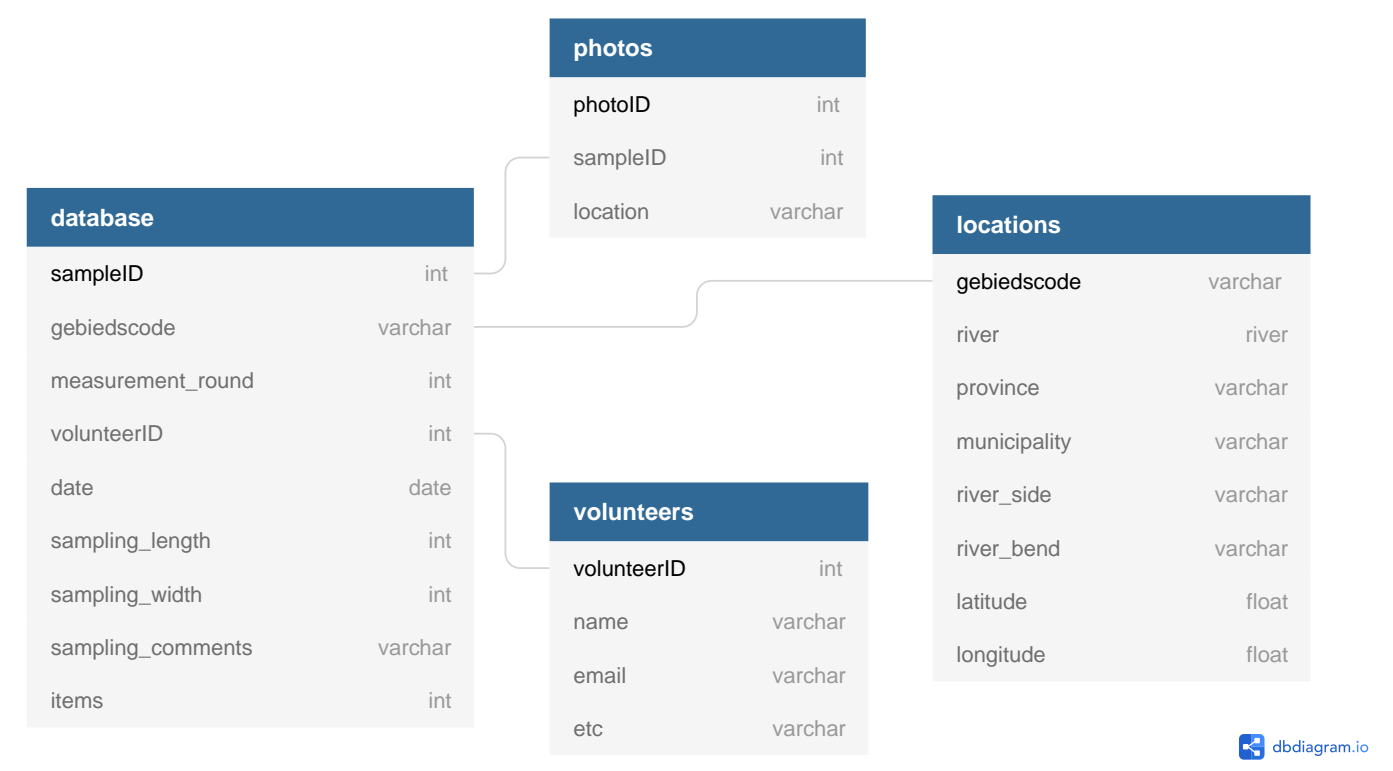

Figure 24 proposed database schema to create a robust and scalable system. When sharing the database with third parties the privacy sensitive 'volunteer' table can be excluded. The photo table is addition to make it possible to include more photos per observation. 'Items' in the 'database' table represents the River-OSPAR checklist. If it needs to be possible for more volunteers to work on one observation an additional relational table between the 'database' and 'volunteers' table should be inserted. 


\title{
7 Conclusions and recommendations
}

\subsection{Answers to the research questions}

\section{To what extent is the River-OSPAR method suitable to get insights in:}

\author{
a. the type and composition of waste in Dutch rivers; \\ b. the sources of riverbank waste; \\ c. what portion of this waste originates from land-based sources.
}

The River-OSPAR method uses a detailed item list for data collection, with over 100 specific items and 10 parent categories. Data collection using this method therefore gives detailed information about the type and composition of riverbank waste. Most other protocols do not give such detailed information, and generally stick to general parent categories (e.g. plastic, wood, glass). As most item categories are similar to the Beach-OSPAR protocol, the River-OSPAR data can potentially also be used for direct comparison of litter item type and composition between rivers and beaches. The River-OSPAR protocol is the most detailed protocol for characterizing litter item type and composition for riverbank litter.

Sources of riverbank waste were explored in terms of source mechanism (dumping, industry, recreational, sewer overflow) and geographical source. The data analysis using the available observations demonstrated that several combinations of items have a high correlation. Assuming the source of specific items (e.g. rubber care tires comes from dumping) therefore provides a reasonable estimation of the source of other items. The current dataset, and the correlation method, have limitations as not all items show a high enough correlation with other items. This can be caused by insufficient observations, or the fact that some litter items do not have a single clear source. Geographical sources were explored through a hotspot analysis. Several hotspots were identified along the rivers, but not all of them were consistent in time. Overlap with urban areas explained several of the hotspots, such as peaks close to cities like Nijmegen, Roermond and Maastricht. However, the dataset is not long enough to provide conclusive statements on to what extent geographical sources of riverbank waste can be identified.

For each item category a reasonable assumption can be made on whether they come from land-based or river-based sources. For other protocols, such as the Plastic Pirates method, this is not possible as the litter categories are too general. Therefore, the River-OSPAR method is suited well to study to what extent litter is land-sourced.

The main recommendation for further improvement is the inclusion of mass and size statistics per litter item category. The current data only includes data on occurrence (number of items). To better analyze sources and quantify the fraction litter that is land-based, translation of items into mass would give additional insights. Quantifying litter in mass would also allow to better link observed litter to production and waste handling statistics, and those are also reported in mass rather than items. We recommend to encourage volunteers to include simple analysis of the sampling items during an observation round. Using household mass scales and measuring tape, volunteers can measure the length, width and mass of the items they collect. Volunteers can do this for the first 50 items they observe.

2. What is the reliability, validity and representativeness of the available River-OSPAR data? Specific aspects to consider are:
a. the number of measurement locations along the Meuse and Waal rivers;
b. the measurement frequency;
c. the training of volunteers and the practical execution of the monitoring by volunteers;
d. the data quality and reference measurements, the data processing, management and statistical analysis;
e. the categorization of waste types. 
The number of measurement locations along the Meuse and Waal rivers is high, especially for the last measurement round. In our analyses we lumped the observations into segments of $15 \mathrm{~km}$ length for more statistical robustness. On average, 5 to 6 measurements were done per $15 \mathrm{~km}$ segment during the last observation round. This yields good results with respect to identifying hotspots along the rivers, but for better accuracy the measurements could be increased to around 10 measurements per $15 \mathrm{~km}$. We do recommend several improvements. First, we recommend extending the measurement locations all the way to the river mouth and other outlets to the ocean. Despite the more complex dynamics, this will allow further investigations of where (plastic) litter from Dutch riverbanks ends up. From the data it seems like the Biesbosch National Park may be an accumulation zone, and it would be valuable to have additional measurements West of the park for comparison. Second, the current dataset is insufficiently described to study the influence of the curvature of the river on the litter density. Both 'left' and 'right' riverbanks were observed, but it is more important to know whether a location is in the inner curve, outer curve or on a straight segment of the river, as flow velocity and litter distribution may vary accordingly. In general, the number of measurement locations provides a valuable and insightful dataset, but can be optimized further.

The measurement frequency is relatively low and does not allow for detailed temporal analyses. Also, the individual measurements are spread over a one-month period (even longer in practice). Observed variations may therefore also be attributed to variation in litter input or changes in river flow regime or antecedent weather conditions. We recommend to reconsider the measurement frequency and either implement a "dynamic" monitoring plan or a stricter low frequency measurement period. Dynamic monitoring would mean that each location should be measured once a year, but the exact timing is not important. Because of the high number of measurement locations, data from neighboring locations can be compared to explore variations over time. For example, if every week four locations are measured (spread more or less evenly over the river length), this would yield data that allows studying temporal variations on a smaller time scale. Alternatively, the measurement period should be made considerably shorter (1-2 weeks maximum). In addition, we recommend increasing the frequency to four times per year. This would fit with the OSPAR monitoring guidelines, and allows for better investigation of the seasonal variation.

A discrepancy was found between volunteer observations and reference measurements. Volunteers generally find less items than the professionals. Since the number of reference measurements is limited, the reference measurements may have been done at locations that have higher item densities. Alternatively, we expect that this bias is caused by the fact that it takes time to develop a trained eye to spot litter items. We also recommend to plan reference measurements at the same locations as the normal measurements. Before collecting the items, both volunteers and professionals should sample the area independently without item collection. Only such measurements will give insights in the actual bias of volunteers and professionals. The training of volunteers is considered very good. The in-person training is expected to be clearer than the remote training of other protocols (e.g. Plastic Pirates). Also, working with volunteers is more cost-effective than sampling by (paid) professionals (NOAA protocol). Therefore, the River-OSPAR protocol combines the best of other existing methods. In general, RiverOSPAR works with well-trained volunteers, but further efforts are necessary to quantify and reduce the potential monitoring bias.

The quality of data management and processing can be improved. The original database contained errors with location IDs, excluding large portions of the dataset for analysis. We recommend to ask volunteers to report the GPS locations of the measurements, so that it can always be checked where measurements were taken. We also recommend to make the raw data available, to allow for better quality check of the data. We also recommend to store the collected data in a more robust an accurate database. Especially for management of long-term monitoring efforts, a robust database is required.

The current categorization gives very detailed data. Although it is a lot of work to categorize the sampled items in over 100 categories, the data give good insights in the potential sources and pathways. We suggest to consider developing a mobile application to facilitate easier data collection, and to allow better data quality checks of the raw data. The current protocol is considered good, but data collection and storage can be optimized using new technology. 
3. Can the currently available data be used for trend analyses on the composition, sources, land-based portion and quantities of the (plastic) waste? If not, what methodological changes have to be implemented to facilitate these? If yes, can the observed trends be used to design policy?

The current dataset is suited very well for spatial trend analyses. Because of the geographical extent of the available data, hotspots in litter density can be identified clearly. Two types of hotspots were found: occasional peaks and consistent peaks. The occasional peaks occurred only once during the four measurement campaigns, and are more likely to be related to peak inflow or transport in the period prior to the measurement. Several consistent peaks were found around urban areas, such as Nijmegen, Roermond and Maastricht. These peaks indicate that around these locations, geographical sources can be found. Next observation rounds, and/or an increased observation frequency, will help verifying whether these hotspots are indeed consistent. The data also clearly show that on the Meuse riverbanks more litter items are found than on the Waal shorelines. The main recommendation is to extent the spatial coverage by including measurement locations until the river mouth(s). This will shed additional light on the distribution and accumulation of litter along the complete Meuse-Rhine delta. The data as such can already support decision-making with respect to planning prevention and clean up strategies. The hotspots give clear indication on what river segments should receive priority.

The temporal dimension of the current dataset is limited. Most findings based on the dataset are therefore uncertain. Despite the limited temporal extent, the data does show that the average litter density is higher in the spring compared to the fall. This may be explained by the seasonal variation in river discharge. The peak discharge for the Rhine and Meuse are in the first quarter of the year, and the lower discharge normally occurs during summer. After high discharge, items are deposited, resulting in higher litter density values. Note that these findings are supported by only two years of data, and may still vary spatially. Our main recommendation is to collect longer time series to further explore the temporal dimension of riverbank litter on Dutch riverbanks. This may be accelerated by increasing the measurement frequency from twice to four times per year.

Determination of litter sources is currently mainly based on assumptions regarding a subset of item sources. Using a correlation analyses, other items are linked to the items with assumed sources. The results of this analyses are as good as the original assumptions, which can only be checked with more data. Also, several items only have a correlation too weak to be linked to a specific source. For the more infrequently found items, this will always remain difficult. More data is needed to further explore the correlation with other items. The current analyses may also be expanded with other statistical analyses, such as a Principal Component Analysis (PCA), although for this dataset this yielded no useful results yet. We recommend to repeat the analyses done in this evaluation after each new data collection round, to explore new correlations, especially for items that show weak correlations to date.

Several methodological adjustments may give additional insights, and better support the findings that the data yielded to date. The main limited is, as mentioned, the lack of temporal frequency to answer most questions. This also limits the possibilities of creating a benchmark or reference value. It is still unclear whether the spatial variation can be attributed to natural variation or not. The low temporal resolution is also the reason why analysis tools such as LitteR are not useful yet, as longer time series are required for useful analyses. We therefore recommend to increase the temporal frequency of the observations, either by spreading the measurements over the entire year (measuring each location once or twice, but not during the same period) or by increasing the number of measurements from two to four. We recommend furthermore to include additional statistics about the sampled items, such as item mass and size. The current dataset only allows expressing the data in terms of item density, meaning that a granulate or fragment has the same numerical value as a car tire or mattress. By including information on mass, the data can be converted to mass density, which in turn can be related to mass data on (plastic) production, waste collection and recycling. Once of the other remaining unknowns is the distribution of litter within the sampling area. Especially the distribution along the axis from the water line to the vegetation is interesting, as this may give additional clues on the degree of mobility. Litter close to the water line are more likely to be remobilized, in contrast to the item further away. Several other protocols (e.g. Plastic Pirates) do collect such data. Finally, we recommend to make the collected data publicly available as soon as possible. By comparing data in Dutch rivers to similar data 
in Belgium and Germany, additional insights in the sources of items found along the Dutch rivers can be gained. Adjusting the method is finding a new balance between many variables. Unfortunately, not everything can be measured, and additional efforts added to the protocol will come at the costs of others. We emphasize the importance of collecting mass statistics on litter items and increasing the measurement frequency. This could be done by either reducing the sampling area length (e.g. $50 \mathrm{~m}$ instead of $100 \mathrm{~m}$ ).

The current dataset can be used to develop policy in two directions. First, prevention measures can be planned based on the geographical hotspots found in the data. Additional analyses can be done to pinpoint the exact hotspots in more detail. However, the data suggest that mainly urban areas with direct river access are represented in the peaks in litter density. Second, the abundance of items may be used to plan policy to reduce the unsound disposal of specific items. The most abundant items are fragments and granulates, which are more difficult to tackle with policy, but may be a focus of clean-up activities. Other frequently found items may be subject to further study on how they end up in the riverine environment.

\section{What changes have been implemented in the River-OSPAR method in comparison to the international OSPAR Beach Litter monitoring protocol? What are the consequences for the intercomparison of data obtained from the two methods?}

From the comparative review it can be concluded that the Beach-OSPAR and the River-OSPAR are relatively similar. Some alterations have been made to the River-OSPAR method in order to make it fit for the riverine environment. Most of these alterations have been made in the spirit of the Beach-OSPAR method. For example, the sampling unit was altered to something that closely resembles the BeachOSPAR unit but is based on the riverbank environment.

However, some fundamental characteristics were changed in the River-OSPAR method. Some of these changes enriched the River-OSPAR method such as the inclusion of the analysis of plastic pellets, since this greatly expands the scope of method. Moreover, the in-person training protocol or the volunteers enhances the method since it ensures reliable and accurate results. However, the alterations that were made to the frequency of sampling are less ideal since this reduces the temporal resolution of the data. Moreover, the item category list was slightly altered compared to the Beach-OSPAR protocol, which could make the intercomparison of certain items between the two methods more difficult.

The consequences of the alterations to the methods on the intercomparison of data are threefold. First, it is difficult to compare the additional data gathered on plastic pellets since the presence of plastic pellets on Dutch beaches is noted, but analyzed with the same detail as with the River-OSPAR method. However, it would be interesting to explore options to add this more in-depth analysis to the BeachOSPAR protocol. Second, the lower frequency of sampling in the River-OSPAR method causes the two datasets to be compared with different temporal scales. An increase in frequency would result in a more accurate comparison on seasonal variations in litter accumulation on riverbanks and beaches. Last, the item category list has been altered slightly. Most items that were removed from the list were beach specific, so the effects of these alterations are minor. Moreover, some item categories were added, or existing categories were split up for a more detailed analysis.

\section{What changes/improvements are required to obtain a reliable, valid and representative estimation of riverbank (plastic) waste for the whole of the Netherlands? What are the costs for the realization of a national riverbank waste monitoring strategy?}

For the whole of the Netherlands we consider the IJssel, Nederrijn, Scheldt and all Meuse-Rhine delta outlets. The comparative literature review examined how the River-OSPAR method compares with other litter identification protocols that are currently being used in other parts of the world, and to identify elements that could be used to further improve the River-OSPAR method. First, the River-OSPAR protocol was compared with the Plastic Pirates protocol that is being applied in Germany, since it is most similar to each other. This comparison identified differences between the two methods, most notably the variations in sampling area and the identification categories. Elements from PPM that could be used 
to further improve the River-OSPAR method include the usage of the circular sampling area for microlitter since it is applicable on more substrata (including ones with high vegetation density). Moreover, the PPM shows the possible merits of using different sampling areas, for example, the location of litter could be analyzed through the identification of different zones on the riverbank. Because of this, a more in-depth analysis was performed on sampling areas used in the literature.

From this review it can be concluded that a wide range of sampling areas are currently being used. Ideally these sampling areas would be homogenized to allow for comparison between different programs and rivers. Moreover, other sampling areas, such as the one used by the PPM, offer a reduction in time required for the analysis and give more insights in the distribution of litter types over the riverbank. However, as identified in the comparison with other citizen science projects, it would be ideal to use a similar methodology for litter identification in both riverine and coastal systems. Last, the microlitter analysis used within the River-OSPAR is limited when compared to established methods for microplastic analysis in the literature. These protocols are time consuming and more expensive, but offer a more indepth insight in microliter composition, and possibly sources of this litter. SDN could therefore decide to analyze a sub-set of the samples collected during the research to gain further data on microlitter.

A valuable addition to the River-OSPAR method would be the inclusion of mass of the items collected by the volunteers. Although none of the other protocols reviewed within the comparative literature study include this element in their method, the addition of data on mass per item category would allow for more detailed analysis of litter transport within Dutch rivers.

All aforementioned improvements to the River-OSPAR method, except for the proposed microlitter analysis, should not significantly increase the costs for the analysis of riverbank litter. The microlitter analysis is more expensive, but it could be decided to only analyze a subsample in order to reduce costs. The exact costs are highly dependent on the organization that is hired for the microlitter analysis, we will therefore not give an exact price range for this.

Additional recommendations for improving riverbank litter estimations include exploring the use of camera- and UAV-based monitoring systems. UAVs can easily be used to cover large areas. They can be used for getting a rapid, overall estimation of the litter on riverbanks in the whole of the Netherlands. Moreover, UAVs can be used to monitor peaks found from the conventional data collection. Rather than mobilizing volunteers, or waiting until the next observation round, the hotspots can be further observed directly. This may also be useful to monitor the impact of prevention or clean up strategies. Cameras on the other hand offer a way for permanent data collection at specific locations. Such data may give insights in the response of litter to high and low river flow. It may also show the variation in response of specific litter items.

\section{What other data sources can be coupled with the data from the Schone Rivieren project to get more insight. For example:}

\section{a. sewerage outlets and discharge of wastewater treatment plants; \\ b. locations of hydraulic infrastructure; \\ c. other riverbank cleaning efforts; \\ d. land-based litter data.}

The inclusion on of data sources on sewerage outlets and points of discharge of wastewater treatment plants could be valuable since these are both known point sources of both micro- and macrolitter. Geospatial data on these point sources could be used to determine the effects they have on litter quantity in the river environment. Moreover, data on the locations of hydraulic structures within Dutch rivers could be linked to the current dataset to gain a deeper understanding of the transport mechanisms of litter in the riverine environment. Structures such as dams, weirs, and pumping station can act as a sink or as a point where litter is removed from the aquatic system by humans. Other (decentralized) riverbank cleaning efforts could similarly influence litter quantities in the riverine system. It would therefore be useful to gather data on the quantity of litter that is removed by other cleaning efforts. Lastly, land-based litter datasets such as the ones collected through volunteers using the Litterati app could be used to gain further insights of litter transport within the environment. For example, the items 
that are frequently found on riverbanks could be compared to land-based data in order to examine which items are more prone to be transported to the riverine environment.

\subsection{Additional recommendations}

We recommend to include monitoring floating litter items in Dutch rivers. Floating items are a major part of the total abundance of litter in riverine systems. Also, this gives more insight in the pathways of litter items, and potential sources and sinks. Floating litter items can either be monitored by professionals or volunteers, and it can either be done using the manual visual counting method or automated methods using cameras and drones. A way forward may be including bridges along the Dutch rivers as sampling locations. Instead of shoreline plastic, floating litter items are counted during a measurement. The available literature does illustrate that frequent measurements (multiple times per month to multiple times per day) are required for accurate estimations. Especially in complex areas with tidal and human influence on litter item transport, frequent observations are key.

Given today's available technology, we recommend implementing new tools for data collection and data management. UAVs can be used to frequent and accurate data collection, with the additional benefit that raw data is saved more objectively. Hotspots can be reanalyzed by other researchers or processed with new algorithms, unlike analogue raw measurements. Mobile apps can also facilitate easier and more subjective data management. Rather than using paper tally sheets in the field, simple applications can allow rapid insertion of new data points. These raw data can be made available publicly, to allow for frequent quality control and cross-referencing with other data.

Finally, we recommend to invest in international harmonization of data collected methods. The BeachOSPAR is a good example of how observations are done equally all over the world, facilitating rapid and accurate data comparison. To date, riverbank plastic data is collected using many different protocols. Also in the Netherlands, riverbank litter is an international challenge, with input coming from Germany and Belgium (and beyond). For fair analyses of the data and optimal planning of prevention and cleanup strategies, harmonized data across borders is crucial. 


\section{References}

Battulga, B., Kawahigashi, M., \& Oyuntsetseg, B. (2019). Distribution and composition of plastic debris along the river shore in the Selenga River basin in Mongolia. Environmental Science and Pollution Research, 26(14), 14059-14072.

Blettler, M. C., Ulla, M. A., Rabuffetti, A. P., \& Garello, N. (2017). Plastic pollution in freshwater ecosystems: macro-, meso-, and microplastic debris in a floodplain lake. Environmental monitoring and assessment, 189(11), 581.

Blettler, M. C., Abrial, E., Khan, F. R., Sivri, N., \& Espinola, L. A. (2018). Freshwater plastic pollution: Recognizing research biases and identifying knowledge gaps. Water research, 143, 416-424.

Browne, M. A., Crump, P., Niven, S. J., Teuten, E., Tonkin, A., Galloway, T., \& Thompson, R. (2011). Accumulation of microplastic on shorelines woldwide: sources and sinks. Environmental science \& technology, 45(21), 9175-9179.

Bruge, A., Barreau, C., Carlot, J., Collin, H., Moreno, C., Maison, P., 2018. Monitoring Litter Inputs from the Adour River (Southwest France) to the Marine Environment. Journal of Marine Science and Engineering 6, 24. https://doi.org/10.3390/jmse6010024

Buytaert W, Zulkafli Z, Grainger S, Acosta L, Alemie TC, Bastiaensen J, De Bièvre B, Bhusal J, Clark J, Dewulf A, Foggin M, Hannah DM, Hergarten C, Isaeva A, Karpouzoglou T, Pandeya B, Paudel D, Sharma K, Steenhuis T, Tilahun S, Van Hecken G and Zhumanova M (2014) Citizen science in hydrology and water resources: opportunities for knowledge generation, ecosystem service management, and sustainable development. Front. Earth Sci. 2:26. doi: 10.3389/feart.2014.00026

Carson, H.S., Lamson, M.R., Nakashima, D., Toloumu, D., Hafner, J., Maximenko, N., McDermid, K.J., 2013. Tracking the sources and sinks of local marine debris in Hawai'i. Marine Environmental Research 84, 76-83. https://doi.org/10.1016/j.marenvres.2012.12.002

Castro-Jiménez, J., González-Fernández, D., Fornier, M., Schmidt, N., \& Sempere, R. (2019). Macrolitter in surface waters from the Rhone River: Plastic pollution and loading to the NW Mediterranean Sea. Marine Pollution Bulletin, 146, 60-66.

Cheung, P. K., Cheung, L. T. O., \& Fok, L. (2016). Seasonal variation in the abundance of marine plastic debris in the estuary of a subtropical macro-scale drainage basin in South China. Science of The Total Environment, 562, 658-665.

Cowger, W., Gray, A. B., \& Schultz, R. C. (2019). Anthropogenic litter cleanups in Iowa riparian areas reveal the importance of near-stream and watershed scale land use. Environmental Pollution, 250, 981989.

Crosti, R., Arcangeli, A., Campana, I., Paraboschi, M., \& González-Fernández, D. (2018). 'Down to the river': amount, composition, and economic sector of litter entering the marine compartment, through the Tiber river in the Western Mediterranean Sea. Rendiconti Lincei. Scienze Fisiche e Naturali, 29(4), 859-866.

Dalu, T., Malesa, B., \& Cuthbert, R. N. (2019). Assessing factors driving the distribution and characteristics of shoreline macroplastics in a subtropical reservoir. Science of the Total Environment, $696,133992$.

Dris, R., Imhof, H., Sanchez, W., Gasperi, J., Galgani, F., Tassin, B., Laforsch, C., 2015. Beyond the ocean: contamination of freshwater ecosystems with (micro-)plastic particles. Environ. Chem. 12, 539550. https://doi.org/10.1071/EN14172 
Gasperi, J., Dris, R., Bonin, T., Rocher, V., Tassin, B., 2014. Assessment of floating plastic debris in surface water along the Seine River. Environmental Pollution 195, 163-166. https://doi.org/10.1016/j.envpol.2014.09.001

Geraeds, M., van Emmerik, T., de Vries, R. and bin Ab Razak, M.S., 2019. Riverine plastic litter monitoring using unmanned aerial vehicles (UAVs). Remote Sensing, 11(17), p.2045.

González-Fernández, D., \& Hanke, G. (2017). Toward a harmonized approach for monitoring of riverine floating macro litter inputs to the marine environment. Frontiers in Marine Science, 4, 86.

Hanke G., Walvoort D., van Loon W., Addamo A.M., Brosich A., del Mar Chaves Montero M., Molina Jack M.E., Vinci M., Giorgetti A. (2019). EU Marine Beach Litter Baselines

Hoellein, T., Rojas, M., Pink, A., Gasior, J., \& Kelly, J. (2014). Anthropogenic litter in urban freshwater ecosystems: distribution and microbial interactions. PloS one, 9(6), e98485.

Hohenblum, P. et al. (2015). Plastik in der Donau-Untersuchung zum Vorkommen von Kunststoffen in der Donau in Österreich. Im Auftrag des Bundesministeriums für Land-und Forstwirtschaft, Umwelt-und Wasserwirtschaft und der Ämter der Landesregierungen Oberösterreich, Niederösterreich und Wien, Wien.

Honorato-Zimmer, D., Kruse, K., Knickmeier, K., Weinmann, A., Hinojosa, I. A., \& Thiel, M. (2019). Inter-hemispherical shoreline surveys of anthropogenic marine debris-A binational citizen science project with schoolchildren. Marine pollution bulletin, 138, 464-473.

Hurley, R., Woodward, J., \& Rothwell, J. J. (2018). Microplastic contamination of river beds significantly reduced by catchment-wide flooding. Nature Geoscience, 11(4), 251.

de Jesus Piñon-Colin, T., Rodriguez-Jimenez, R., Rogel-Hernandez, E., Alvarez-Andrade, A., \& Wakida, F. T. (2019). Microplastics in stormwater runoff in a semiarid region, Tijuana, Mexico. Science of The Total Environment, 135411.

Jiang, J. Q. (2018). Occurrence of microplastics and its pollution in the environment: A review. Sustainable Production and Consumption, 13, 16-23.

Kiessling, T., Knickmeier, K., Kruse, K., Brennecke, D., Nauendorf, A., Thiel, M., 2019. Plastic Pirates sample litter at rivers in Germany - Riverside litter and litter sources estimated by schoolchildren. Environmental Pollution 245, 545-557. https://doi.org/10.1016/j.envpol.2018.11.025

Klein, S., Worch, E., \& Knepper, T. P. (2015). Occurrence and spatial distribution of microplastics in river shore sediments of the Rhine-Main area in Germany. Environmental science \& technology, 49(10), 6070-6076.

Klein, Sascha, Eckhard Worch, and Thomas P. Knepper. "Occurrence and spatial distribution of microplastics in river shore sediments of the Rhine-Main area in Germany." Environmental science \& technology 49.10 (2015): 6070-6076.

Kylili, K., Kyriakides, I., Artusi, A. and Hadjistassou, C., 2019. Identifying floating plastic marine debris using a deep learning approach. Environmental Science and Pollution Research, pp.1-9.

Lippiatt, S., Opfer, S., \& Arthur, C. (2013). Marine debris monitoring and assessment: recommendations for monitoring debris trends in the marine environment.

Lots, F. A., Behrens, P., Vijver, M. G., Horton, A. A., \& Bosker, T. (2017). A large-scale investigation of microplastic contamination: Abundance and characteristics of microplastics in European beach sediment. Marine pollution bulletin, 123(1-2), 219-226. 
Martin, C., Parkes, S., Zhang, Q., Zhang, X., McCabe, M.F. and Duarte, C.M., 2018. Use of unmanned aerial vehicles for efficient beach litter monitoring. Marine pollution bulletin, 131, pp.662-673.

Martínez-Vicente, Víctor, et al. "Measuring Marine Plastic Debris from Space: Initial Assessment of Observation Requirements." Remote Sensing 11.20 (2019): 2443.

McCormick, A., Hoellein, T. J., Mason, S. A., Schluep, J., \& Kelly, J. J. (2014). Microplastic is an abundant and distinct microbial habitat in an urban river. Environmental science \& technology, 48(20), $11863-$ 11871.

Morritt, D., Stefanoudis, P. V., Pearce, D., Crimmen, O. A., \& Clark, P. F. (2014). Plastic in the Thames: a river runs through it. Marine Pollution Bulletin, 78(1-2), 196-200.

McIlgorm, A., Campbell, H.F., Rule, M.J., 2011. The economic cost and control of marine debris damage in the Asia-Pacific region. Ocean \& Coastal Management 54, 643-651. https://doi.org/10.1016/j.ocecoaman.2011.05.007

Mihai, F.-C. (2018). Rural plastic emissions into the largest mountain lake of the Eastern Carpathians. Royal Society Open Science 5, 172396. https://doi.org/10.1098/rsos.172396

Moore, C. J., Lattin, G. L., \& Zellers, A. F. (2011). Quantity and type of plastic debris flowing from two urban rivers to coastal waters and beaches of Southern California. Revista de Gestão Costeira IntegradaJournal of Integrated Coastal Zone Management, 11(1), 65-73.

Naidoo, T., Smit, A. J., \& Glassom, D. (2016). Plastic ingestion by estuarine mullet Mugil cephalus (Mugilidae) in an urban harbour, KwaZulu-Natal, South Africa. African Journal of Marine Science, 38(1), 145-149.

Ó Conchubhair, D., Fitzhenry, D., Lusher, A., King, A.L., Emmerik, T. van, Lebreton, L., Ricaurte-Villota, C., Espinosa, L., O'Rourke, E., 2019. Joint effort among research infrastructures to quantify the impact of plastic debris in the ocean. Environ. Res. Lett. 14, 065001. https://doi.org/10.1088/17489326/ab17ed

OSPAR Commission, 2010. Guideline for monitoring marine litter on the beaches in the OSPAR maritime area. OSPAR Commission: London, UK, p.84.

Rech, S., Macaya-Caquilpán, V., Pantoja, J.F., Rivadeneira, M.M., Campodónico, C.K., Thiel, M., 2015. Sampling of riverine litter with citizen scientists - findings and recommendations. Environ Monit Assess 187, 335. https://doi.org/10.1007/s10661-015-4473-y

Redford, D. P., Trulli, H. K., \& Trulli, W. R. (1997). Sources of plastic pellets in the aquatic environment. In Marine Debris (pp. 335-343). Springer, New York, NY.

Sarkar, D. J., Sarkar, S. D., Das, B. K., Manna, R. K., Behera, B. K., \& Samanta, S. (2019). Spatial distribution of meso and microplastics in the sediments of river Ganga at eastern India. Science of the Total Environment, 694, 133712.

Schmidt, C., Krauth, T., Wagner, S., 2017. Export of Plastic Debris by Rivers into the Sea. Environ. Sci. Technol. 51, 12246-12253. https://doi.org/10.1021/acs.est.7b02368

Schulz, Marcus, Dennis J.J. Walvoort, Jon Barry, David M. Fleet \& Willem M.G.M. van Loon, 2019. Baseline and power analyses for the assessment of beach litter reductions in the European OSPAR region. Environmental Pollution 248:555-564

Schwarz, A. E., Ligthart, T. N., Boukris, E., \& van Harmelen, T. (2019). Sources, transport, and accumulation of different types of plastic litter in aquatic environments: A review study. Marine Pollution Bulletin, 143, 92-100. 
Seibert J, Strobl B, Etter S, Hummer P and van Meerveld HJ (2019) Virtual Staff Gauges for CrowdBased Stream Level Observations. Front. Earth Sci. 7:70. doi: 10.3389/feart.2019.00070

Thompson, R.C., Olsen, Y., Mitchell, R.P., Davis, A., Rowland, S.J., John, A.W.G., McGonigle, D., Russell, A.E., 2004. Lost at Sea: Where Is All the Plastic? Science 304, 838-838. https://doi.org/10.1126/science.1094559

van Emmerik, T. and Schwarz., A. (2020). Plastic debris in rivers. WIREs Water 7:e1398. https://doi.org/10.1002/wat2.1398

van Emmerik, T., Kieu-Le, T. C., Loozen, M., van Oeveren, K., Strady, E., Bui, X. T., ... \& Schwarz, A. (2018). A methodology to characterize riverine macroplastic emission into the ocean. Frontiers in Marine Science, 5, 372.

van Emmerik, T., Tramoy, R., van Calcar, C., Alligant, S., Treilles, R., Tassin, B., \& Gasperi, J. (2019a). Seine plastic debris transport tenfolded during increased river discharge. Frontiers in Marine Science, 6 , 642.

van Emmerik, T., Strady, E., Kieu-Le, T. C., Nguyen, L., \& Gratiot, N. (2019b). Seasonality of riverine macroplastic transport. Scientific Reports, 9(1), 1-9.

Martínez-Vicente, V., Clark, J. R., Corradi, P., Aliani, S., Arias, M., Bochow, M., et al. (2019). Measuring marine plastic debris from space: Initial assessment of observation requirements. Remote Sensing, 11(20), 2443.

Williams, A.T., Simmons, S.L., 1997. Movement patterns of riverine litter. Water Air Soil Pollut. 98, 119139. https://doi.org/10.1007/BF02128653 


\section{Annex 1 Hydrometeorological analysis}

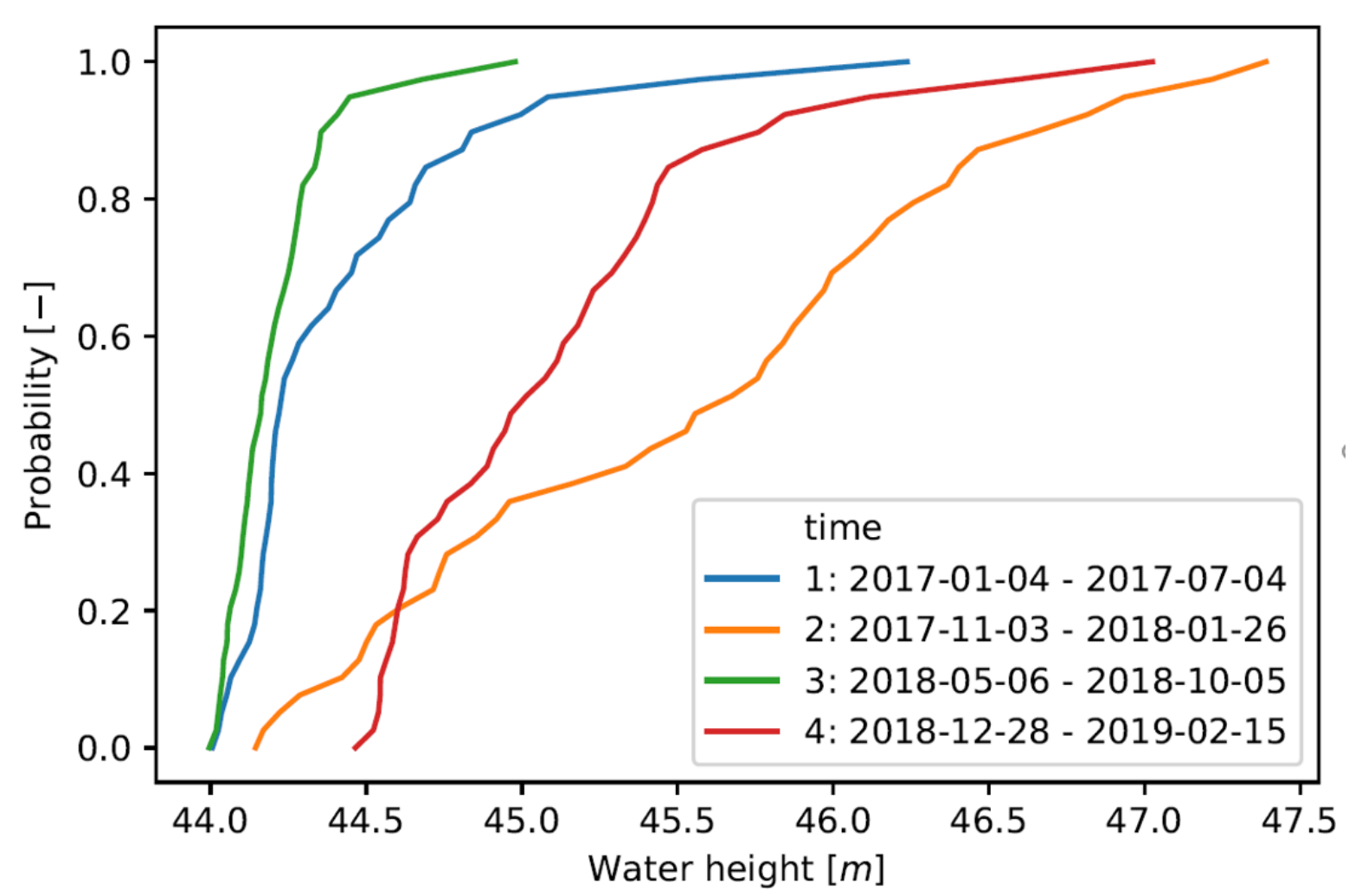

Figure 25 Probability of exceedance for water height in the Meuse.

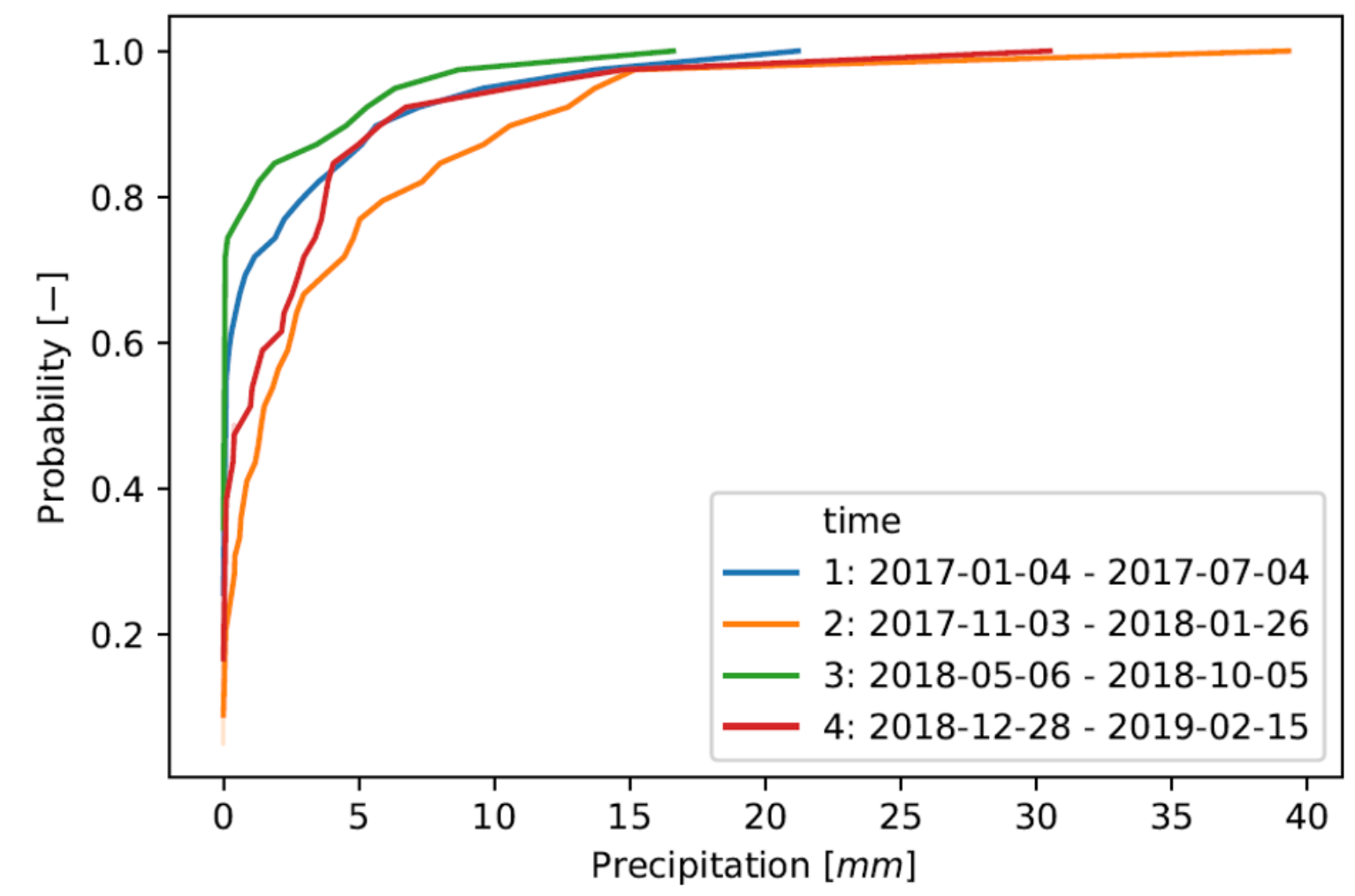

Figure 26 Probability of exceedance for precipitation at De Bilt station. 


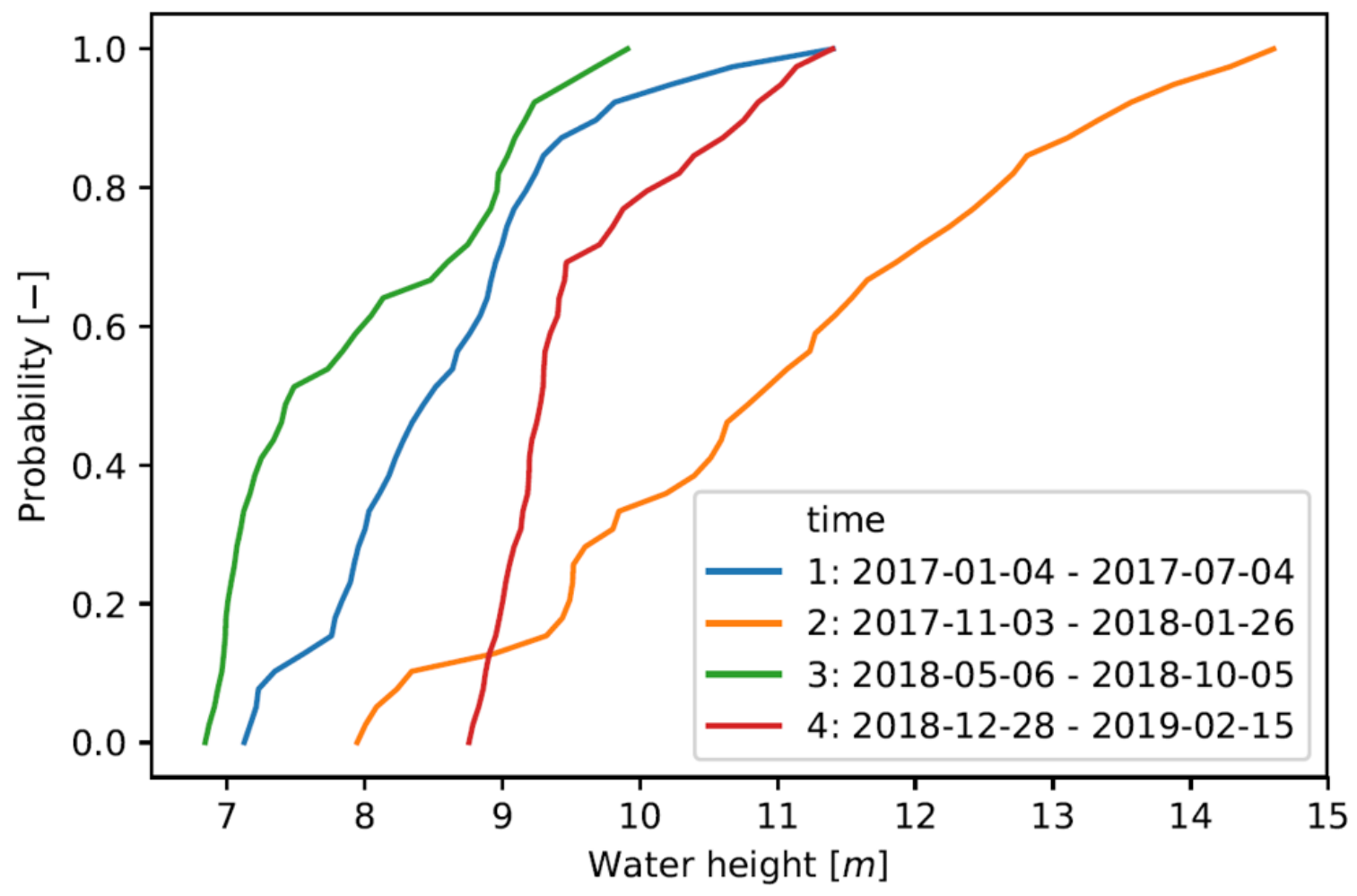

Figure 27 Probability of exceedance for water height in the Waal.

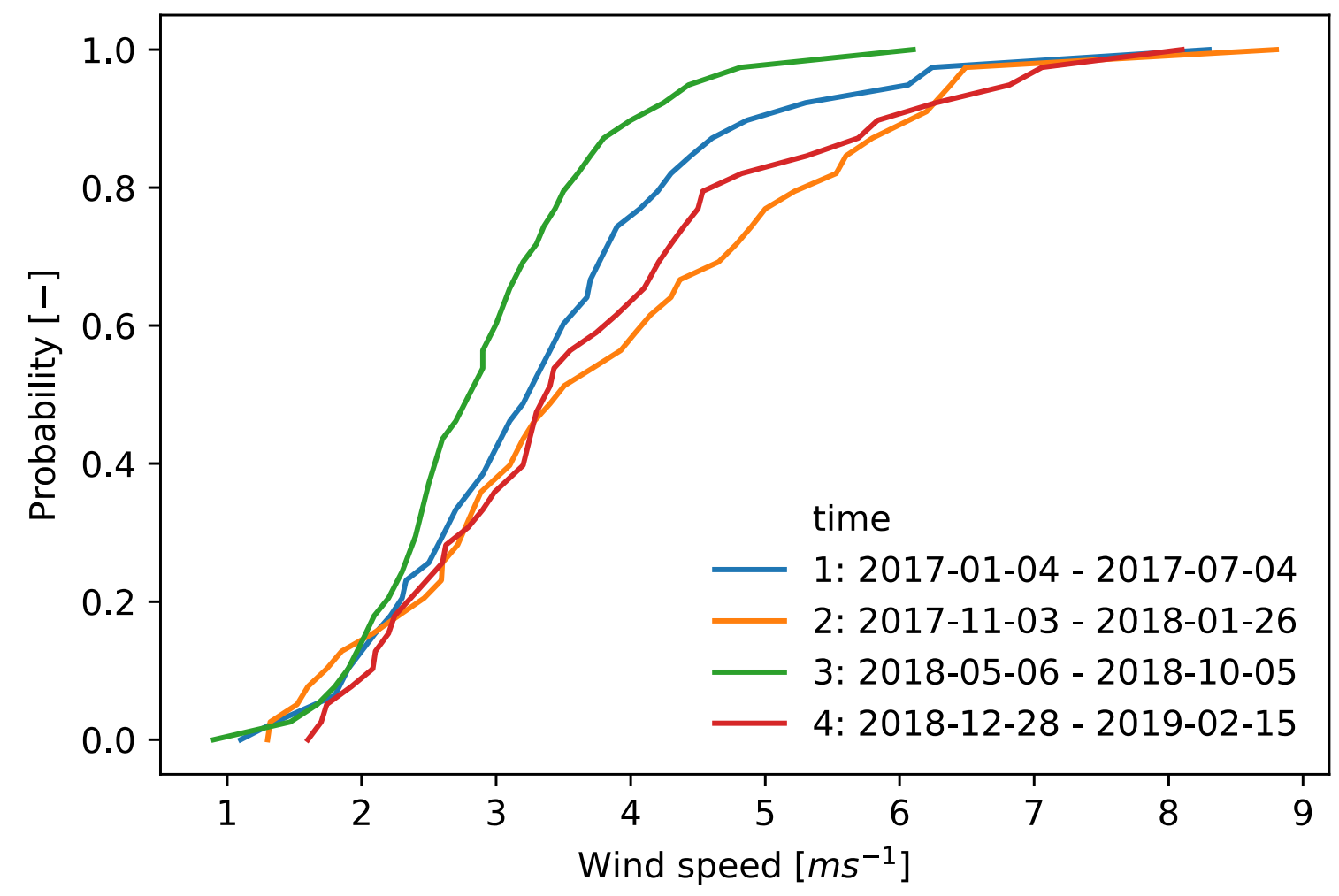

Figure 28 Probability of exceedance for wind speed at De Bilt station. 


\section{Annex 2 Extended figures}

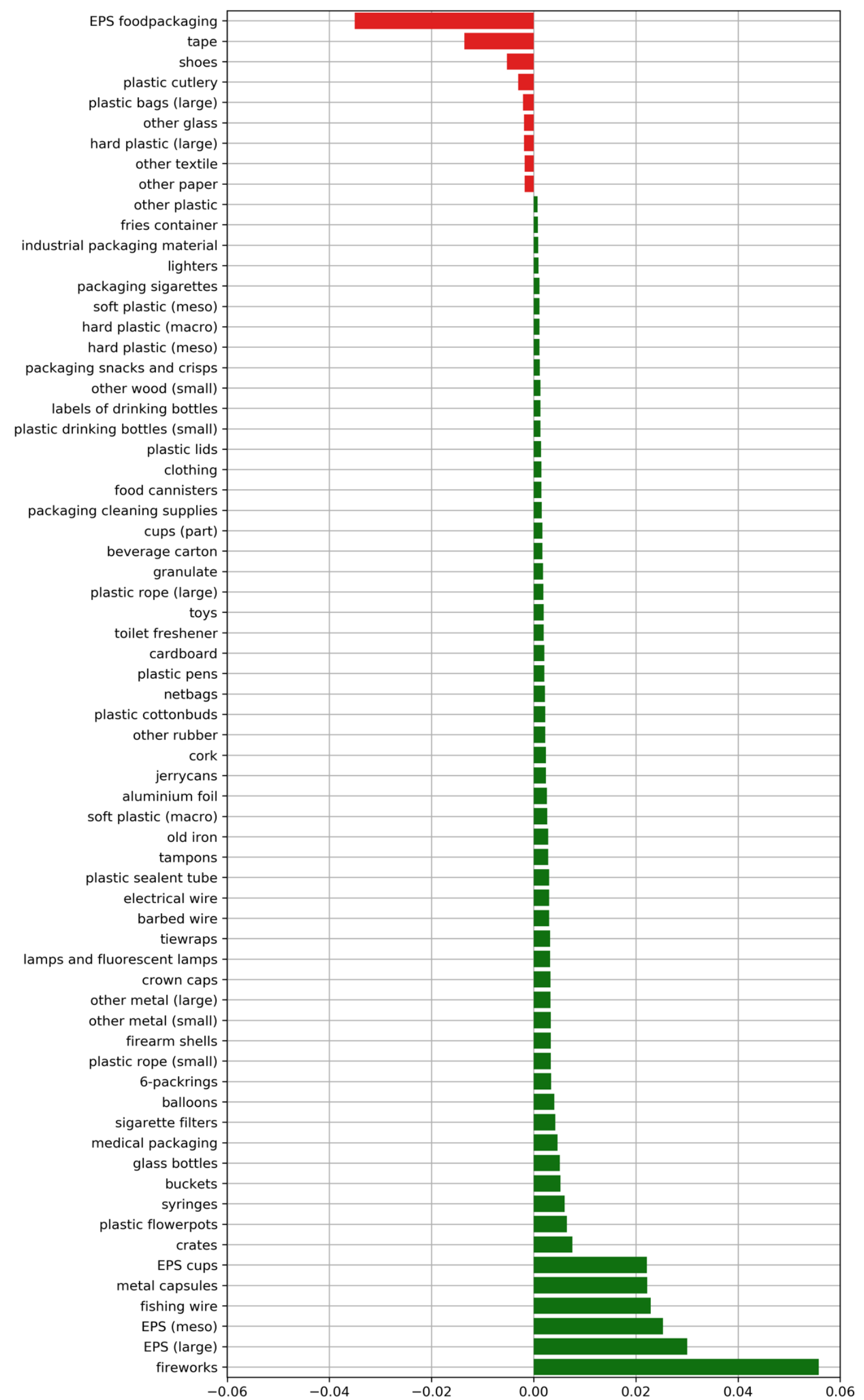

Figure 29 Significant change over time for the River-OSPAR items that were found at least a hundred times. 


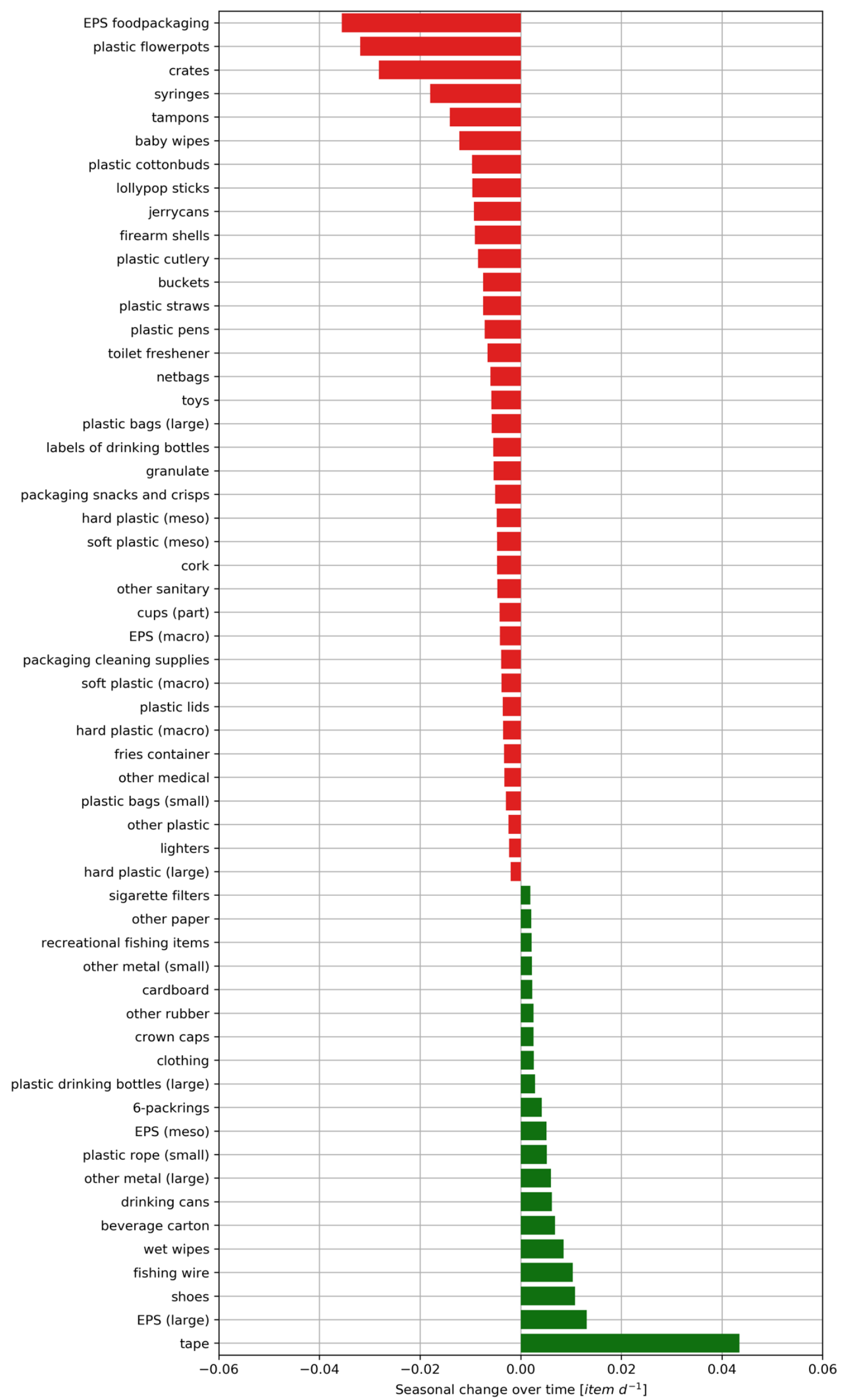

Figure 30 Significant change over time during the season. It displays the increase and decrease of items found in comparison with the $1^{\text {st }}$ of January. 


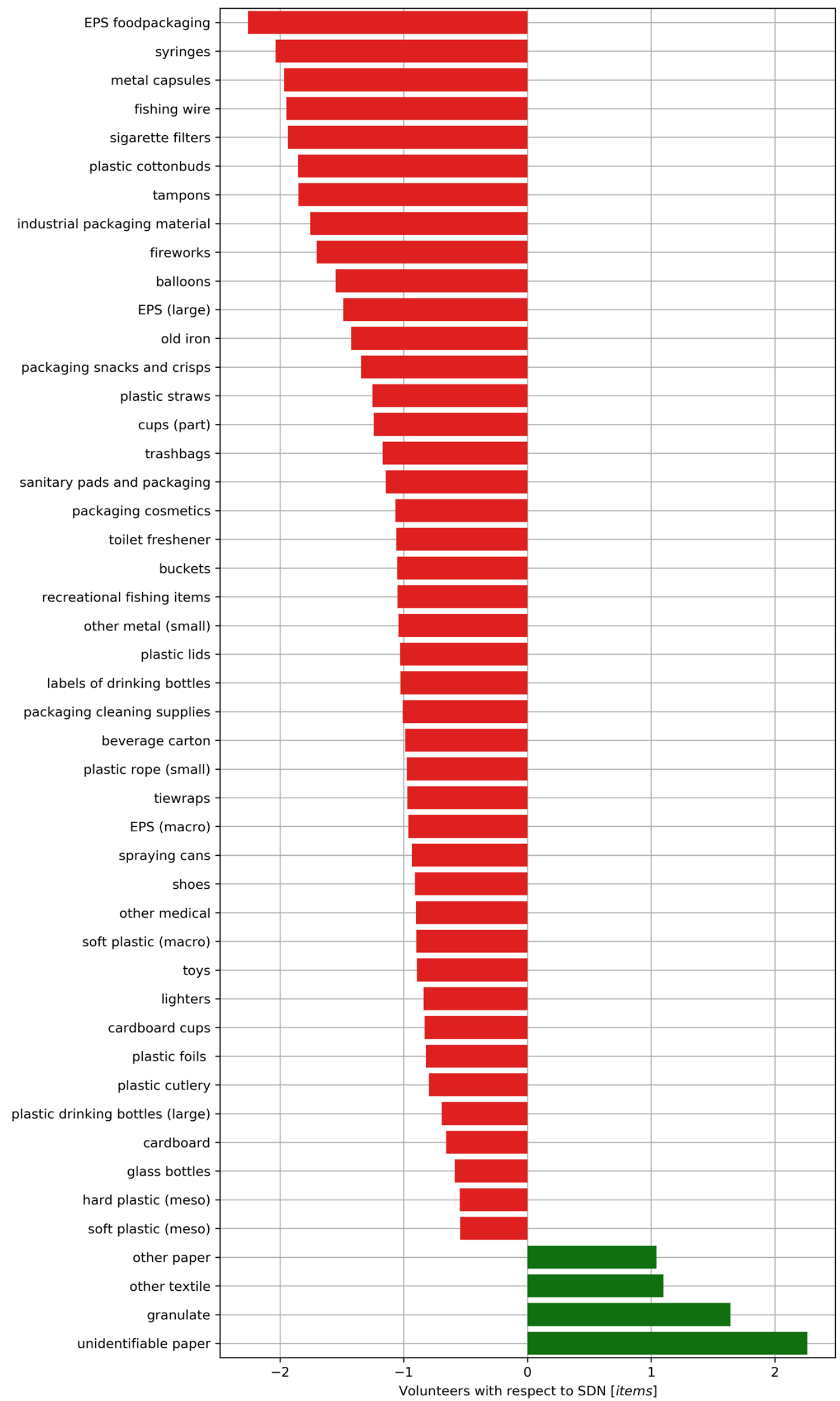

Figure 31 Discrepancy of items sampled by volunteers in respect to SDN. 


\section{Annex 3 Item category lists}

\section{Beach-OSPAR}

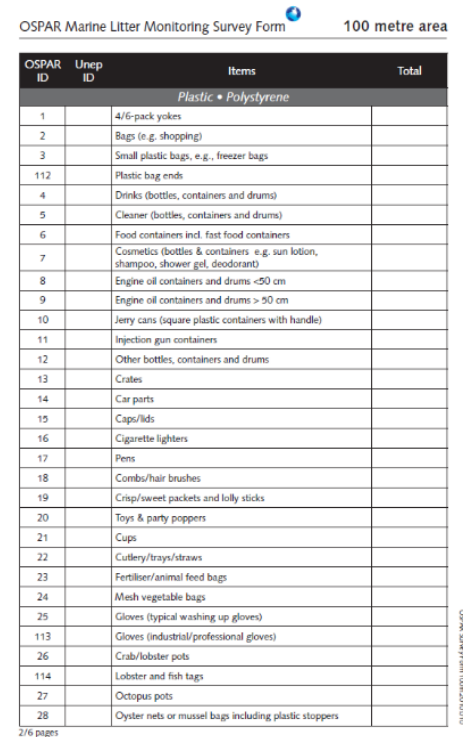

100 metre area $\quad$ OSPAR Marine Litter Monitoring Sunvey Form

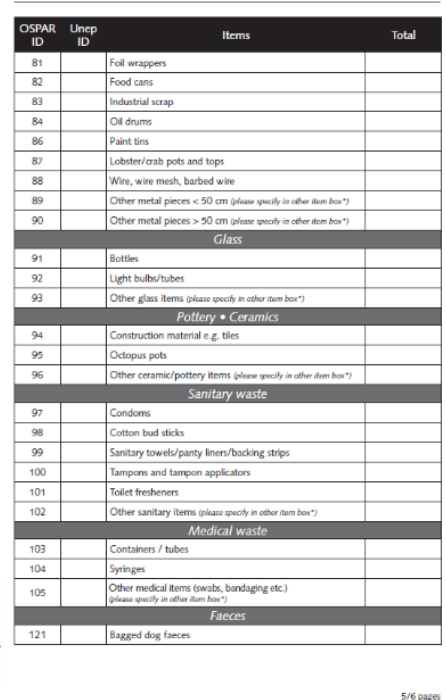

100 metre area $\quad$ OSPAR Marne Utter Monitoring Survey Form

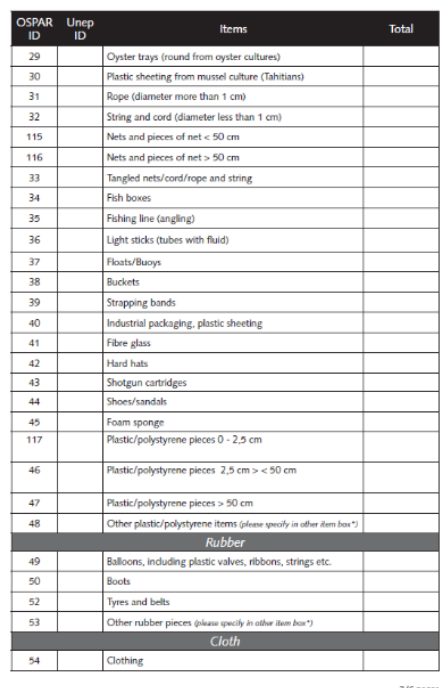

OSPAR Marne Litter Monitoting Survey Form ${ }^{\circ} \quad 100$ metre area

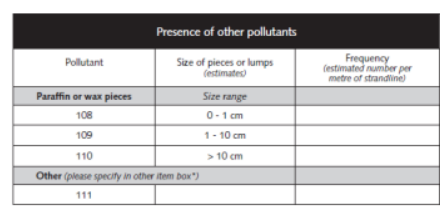

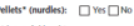
$100 \mathrm{~m}$

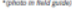

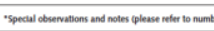

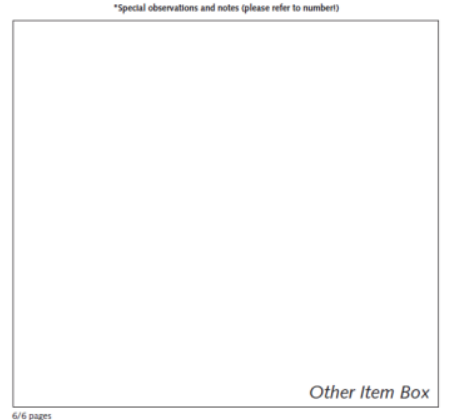

100 metre area
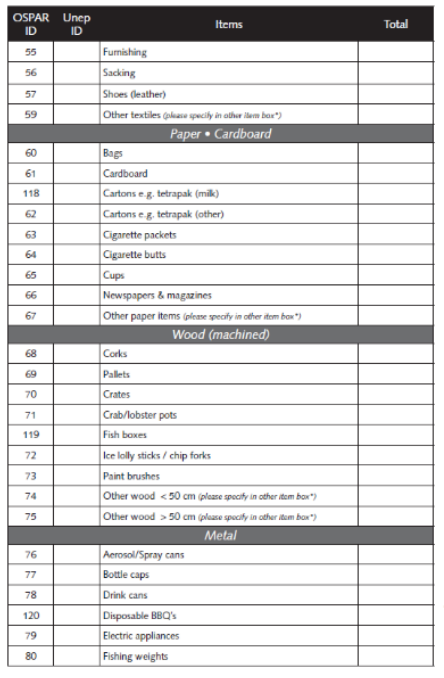

4 46neses

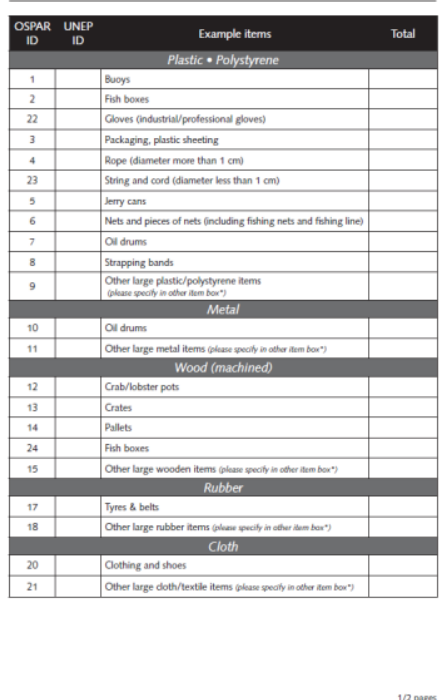




\section{River-OSPAR}
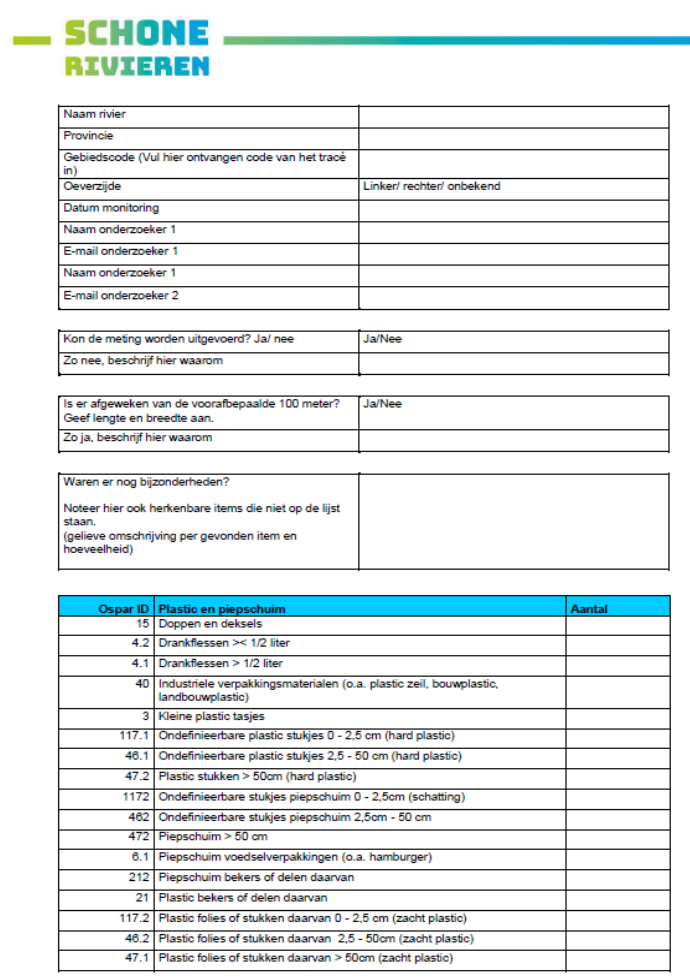

www.schonerivieren.org

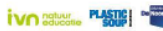

\section{- SCHONE RIUIEREN}

${ }^{53} \begin{aligned} & \text { Overig nubber (indien herkenbas, noteer omschrijuing per gevonden item } \\ & \text { in opmektingen veld) }\end{aligned}$
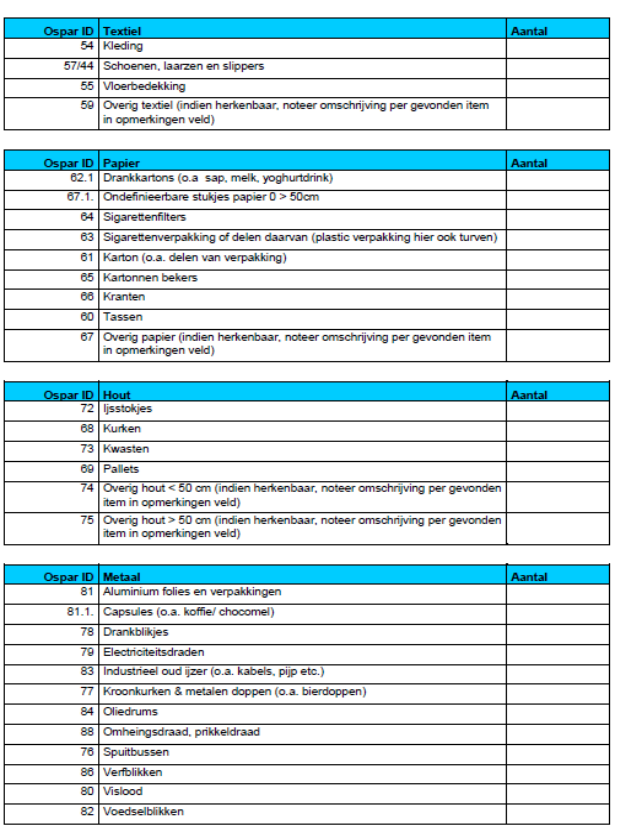

www.schonerivieren.org

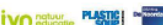

\section{SCHONE RIUIEREN}
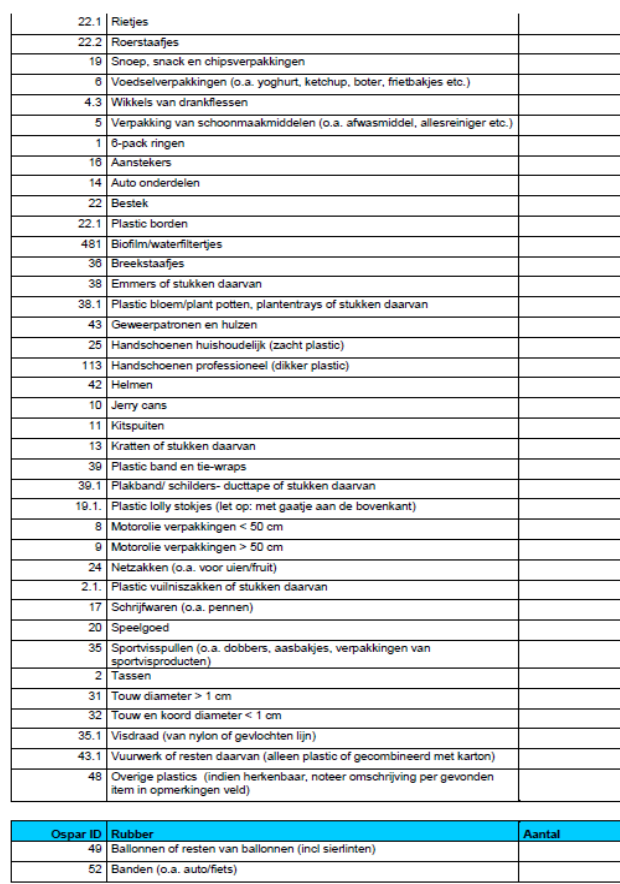

www.schonerivieren.org

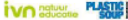

\section{- SEHONE \\ RTUrEREN}

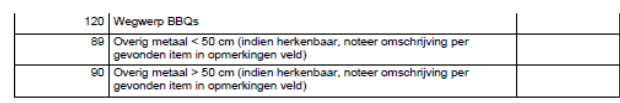
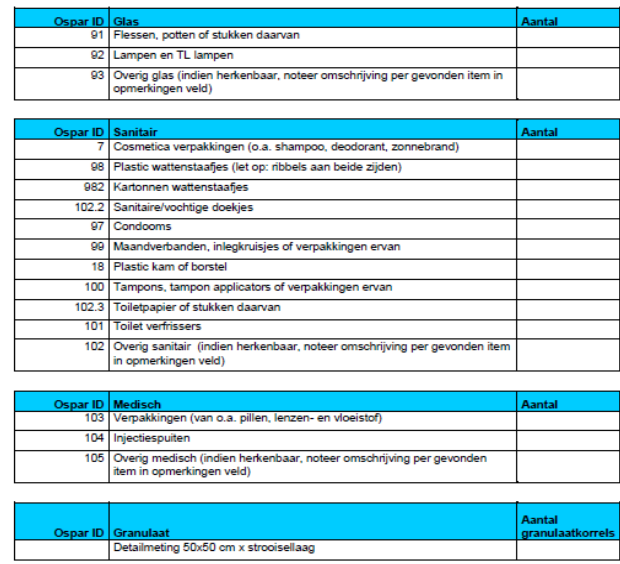


\begin{tabular}{|c|c|c|c|}
\hline \multirow{3}{*}{$\begin{array}{l}\text { SHORELINE DEBRIS } \\
\text { Survey Data Sheet }\end{array}$} & Organization & & \begin{tabular}{|l|} 
Name of organization responsible for \\
data collection
\end{tabular} \\
\hline & Surveyor name & & $\begin{array}{l}\text { Name of person responsible for filling in } \\
\text { this sheet }\end{array}$ \\
\hline & Phone number & & Phone contact for surveyor \\
\hline \multirow{2}{*}{$\begin{array}{l}\text { Complete this form during } \\
\text { EACH transect }\end{array}$} & Email address & & Email contact for surveyor \\
\hline & \begin{tabular}{|l|} 
Date \\
\end{tabular} & & Date of this survey \\
\hline \multicolumn{4}{|c|}{ ANCILLARY INFORMATION } \\
\hline Shoreline name & & & $\begin{array}{l}\text { Name for section of shoreline (e.g." } \\
\text { beach name, park) }\end{array}$ \\
\hline Transect \# and photo ID & & & $\begin{array}{l}\text { Transect } \# \text { (1-20) and dipital photo } \\
\text { number of transect }\end{array}$ \\
\hline \multirow{2}{*}{$\begin{array}{l}\text { Coordinates of start of } \\
\text { shoreline site }\end{array}$} & Latitude & Longitude & \multirow{2}{*}{ 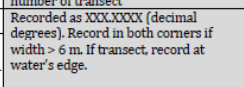 } \\
\hline & & & \\
\hline \multirow{2}{*}{$\begin{array}{l}\text { Coordinates of end of } \\
\text { shoreline site }\end{array}$} & Latitude & Longitude & \multirow{2}{*}{$\begin{array}{l}\text { Recorded as DXXx.xodxx (decimal } \\
\text { degrees). Record in both comers if } \\
\text { width }>6 \mathrm{~m} \text {. If transect, record at back } \\
\text { of shoreline. }\end{array}$} \\
\hline & & & \\
\hline Width of beach & & & $\begin{array}{l}\text { Width of beach at time of survey from } \\
\text { water's edge to back of shoreline }\end{array}$ \\
\hline Time start/end & Start & End & $\begin{array}{l}\text { Time at the beginning and end of the } \\
\text { survey }\end{array}$ \\
\hline Time of low tide & & & $\begin{array}{l}\text { Time of the most recent or upcoming } \\
\text { low tide. }\end{array}$ \\
\hline Season & & & $\begin{array}{l}\text { Spring, summer, fall, winter, tropical } \\
\text { wetect }\end{array}$ \\
\hline Date of last survey & & & $\begin{array}{l}\text { Date on which the last survey was } \\
\text { conducted }\end{array}$ \\
\hline Storm activity & & & $\begin{array}{l}\text { Describe significant storm activity } \\
\text { within the previous week (date(s), high } \\
\text { winds, etc) }\end{array}$ \\
\hline Current weather & & & $\begin{array}{l}\text { Describe weather on sampling day, } \\
\text { including wind speed and \% cloud } \\
\text { coverage }\end{array}$ \\
\hline Number of persons & & & $\begin{array}{l}\text { Number of persons conducting the } \\
\text { survey }\end{array}$ \\
\hline Large items & YES & No & $\begin{array}{l}\text { Duvey you note large items in the large } \\
\text { Did you } \\
\text { debissection? }\end{array}$ \\
\hline $\begin{array}{l}\text { Debris behind back } \\
\text { barrier? }\end{array}$ & YES & NO & $\begin{array}{l}\text { Is there ectebris behind the back barrier } \\
\text { of the site (if yes, do not include it in } \\
\text { tallies below) }\end{array}$ \\
\hline Photo ID \#s & & & $\begin{array}{l}\text { The digital identification number(s) of } \\
\text { debris photos taken during this transect. }\end{array}$ \\
\hline
\end{tabular}
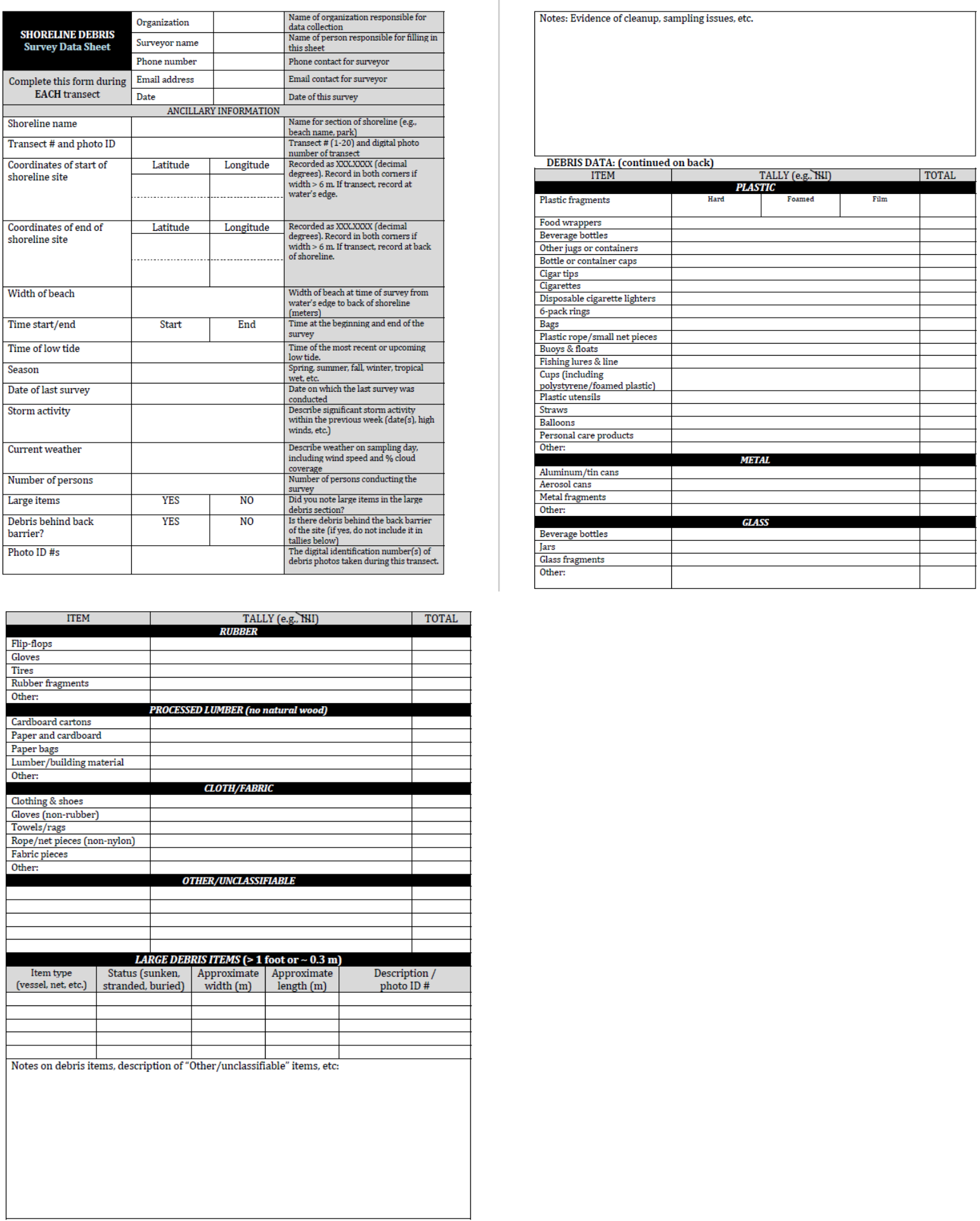


\section{Annex 4 Item source classification}

\begin{tabular}{|c|c|}
\hline plastic_6_packringen & dumping \\
\hline plastic_piepschuim_0_2_5cm & dumping \\
\hline plastic_piepschuim_2_5_50cm & dumping \\
\hline $\begin{array}{l}\text { plastic_piepschuim_voedselverpakkin } \\
\text { gen }\end{array}$ & dumping \\
\hline plastic_plastic_folies_groterdan_50cm & dumping \\
\hline plastic_hard_plastic_groterdan_50cm & dumping \\
\hline plastic_bestek & dumping \\
\hline plastic_kitspuiten & dumping \\
\hline plastic_kunststof_band_tiewraps & dumping \\
\hline plastic_visdraad & dumping \\
\hline plastic_roerstaafjes_new & dumping \\
\hline rubber_ballonnen & dumping \\
\hline textiel_schoeisel & dumping \\
\hline hout_kurk & dumping \\
\hline hout_overig_hout_keinderdan_50cm & dumping \\
\hline hout_overig_hout_groterdan_50cm & dumping \\
\hline metaal_aluminiumfolie & dumping \\
\hline metaal_kroonkurken & dumping \\
\hline metaal_omheinigsdraad_prikkeldraad & dumping \\
\hline glas_flessen_pottten & dumping \\
\hline sanitair_overig_sanitair & dumping \\
\hline medisch_verpakkingen & dumping \\
\hline $\begin{array}{l}\text { plastic_plastic_stukjes_2_5_50cm_za } \\
\text { cht_plastic }\end{array}$ & dumping \\
\hline $\begin{array}{l}\text { plastic_plastic_stukjes_0_2_5cm_zac } \\
\text { ht_plastic }\end{array}$ & dumping \\
\hline plastic_piepschuim_groterdan_50cm & dumping \\
\hline granulaat_korrels & dumping \\
\hline plastic_kratten & dumping \\
\hline plastic_netzakken & dumping \\
\hline $\begin{array}{l}\text { plastic_verpakking_van_schoonmaak } \\
\text { middelen }\end{array}$ & dumping \\
\hline plastic_wikkels_van_drankflessen & dumping \\
\hline $\begin{array}{l}\text { plastic_drankflessen_kleinerdan_halve } \\
\text { liter }\end{array}$ & dumping \\
\hline plastic_aanstekers & dumping \\
\hline $\begin{array}{l}\text { plastic_drankflessen_groterdan_halvel } \\
\text { iter }\end{array}$ & dumping \\
\hline plastic_geweerpatronen & dumping \\
\hline $\begin{array}{l}\text { plastic_touw_diameter_kleinerdan_1c } \\
\mathrm{m}\end{array}$ & dumping \\
\hline $\begin{array}{l}\text { plastic_touw_diameter_groterdan_1c } \\
\mathrm{m}\end{array}$ & industry \\
\hline
\end{tabular}

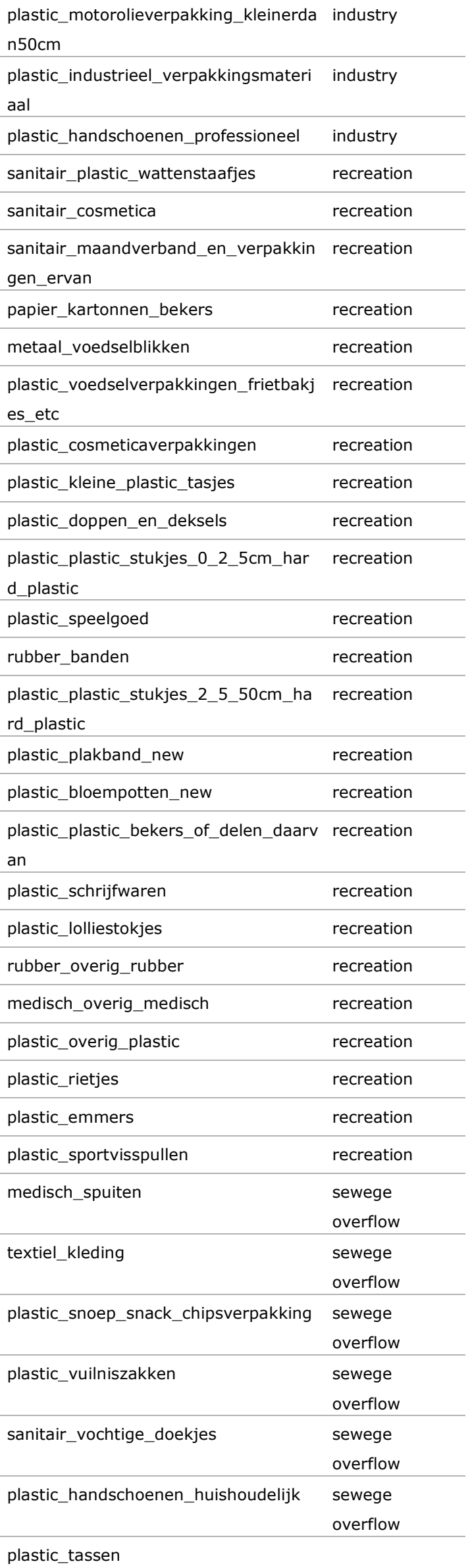




\begin{tabular}{|c|}
\hline plastic_jerrycans \\
\hline plastic_auto_onderdelen \\
\hline plastic_breekstaafjes \\
\hline plastic_helmen \\
\hline plastic_schoenen \\
\hline plastic_piepschuim_bekers \\
\hline plastic_biofilm_waterfiltertjes \\
\hline plastic_vuurwerk \\
\hline plastic_borden_new \\
\hline textiel_vloerbedekking \\
\hline textiel_overig_textiel \\
\hline papier_tassen \\
\hline papier_karton \\
\hline papier_sigarettenverpakking \\
\hline papier_sigarettenfilters \\
\hline papier_kranten \\
\hline papier_papier_overig \\
\hline papier_drankkarton \\
\hline papier_ondefinieerbaar \\
\hline hout_pellets \\
\hline hout_ijsstokjes \\
\hline hout_kwasten \\
\hline metaal_capsules \\
\hline metaal_drankblikjes \\
\hline metaal_elektriciteitsdraad \\
\hline metaal_oud_ijzer \\
\hline metaal_oliedrum \\
\hline metaal_spuitbussen \\
\hline metaal_verfblik \\
\hline metaal_vislood \\
\hline metaal_wegwerpbarbecues \\
\hline metaal_overig_metaal_kleinerdan_50cm \\
\hline metaal_overig_metaal_groterdan_50cm \\
\hline glas_lampen_tl_lampen \\
\hline glas_overig_glas \\
\hline sanitair_kartonnen_wattenstaafjes \\
\hline sanitair_condooms \\
\hline sanitair_plastic_kam_borstel \\
\hline sanitair_tampons_en_tamponapplicators \\
\hline sanitair_tissues_wc_papier \\
\hline sanitair_toiletverfrissers \\
\hline
\end{tabular}




\section{Annex 5 Transport mechanism classification}

\begin{tabular}{|c|c|}
\hline $\begin{array}{l}\text { plastic_plastic_stukjes_2_5_50cm_zacht_ } \\
\text { plastic }\end{array}$ & $\begin{array}{l}\text { constant } \\
\text { flushing }\end{array}$ \\
\hline \multirow[t]{2}{*}{ plastic_touw_diameter_groterdan_1cm } & constant \\
\hline & flushing \\
\hline \multirow[t]{2}{*}{ plastic_sportvisspullen } & constant \\
\hline & flushing \\
\hline \multirow[t]{2}{*}{ metaal_overig_metaal_kleinerdan_50cm } & constant \\
\hline & flushing \\
\hline \multirow[t]{2}{*}{ metaal_voedselblikken } & constant \\
\hline & flushing \\
\hline \multirow[t]{2}{*}{ metaal_verfblik } & constant \\
\hline & flushing \\
\hline \multirow[t]{2}{*}{ metaal_kroonkurken } & constant \\
\hline & flushing \\
\hline \multirow[t]{2}{*}{ plastic_handschoenen_professioneel } & constant \\
\hline & flushing \\
\hline \multirow[t]{2}{*}{ metaal_oud_ijzer } & constant \\
\hline & flushing \\
\hline \multirow[t]{2}{*}{ hout_overig_hout_groterdan_50cm } & constant \\
\hline & flushing \\
\hline \multirow[t]{2}{*}{ hout_kwasten } & constant \\
\hline & flushing \\
\hline \multirow[t]{2}{*}{ plastic_snoep_snack_chipsverpakking } & constant \\
\hline & flushing \\
\hline \multirow[t]{2}{*}{ rubber_ballonnen } & constant \\
\hline & flushing \\
\hline \multirow[t]{2}{*}{ plastic_plakband_new } & constant \\
\hline & flushing \\
\hline \multirow[t]{2}{*}{ plastic_visdraad } & constant \\
\hline & flushing \\
\hline \multirow[t]{2}{*}{ rubber_banden } & constant \\
\hline & flushing \\
\hline \multirow[t]{2}{*}{ glas_lampen_tl_lampen } & constant \\
\hline & flushing \\
\hline \multirow[t]{2}{*}{ plastic_roerstaafjes_new } & constant \\
\hline & flushing \\
\hline \multirow[t]{2}{*}{ plastic_plastic_bekers_of_delen_daarvan } & constant \\
\hline & flushing \\
\hline \multirow[t]{2}{*}{ sanitair_plastic_kam_borstel } & constant \\
\hline & flushing \\
\hline \multirow[t]{2}{*}{ papier_kranten } & constant \\
\hline & flushing \\
\hline \multirow[t]{2}{*}{ rubber_overig_rubber } & constant \\
\hline & flushing \\
\hline \multirow[t]{2}{*}{ plastic_auto_onderdelen } & constant \\
\hline & flushing \\
\hline plastic_kratten & constant \\
\hline & flushing \\
\hline plastic_jerrycans & constant \\
\hline & flushing \\
\hline textiel_vloerbedekking & constant \\
\hline & flushing \\
\hline glas_flessen_pottten & other \\
\hline
\end{tabular}

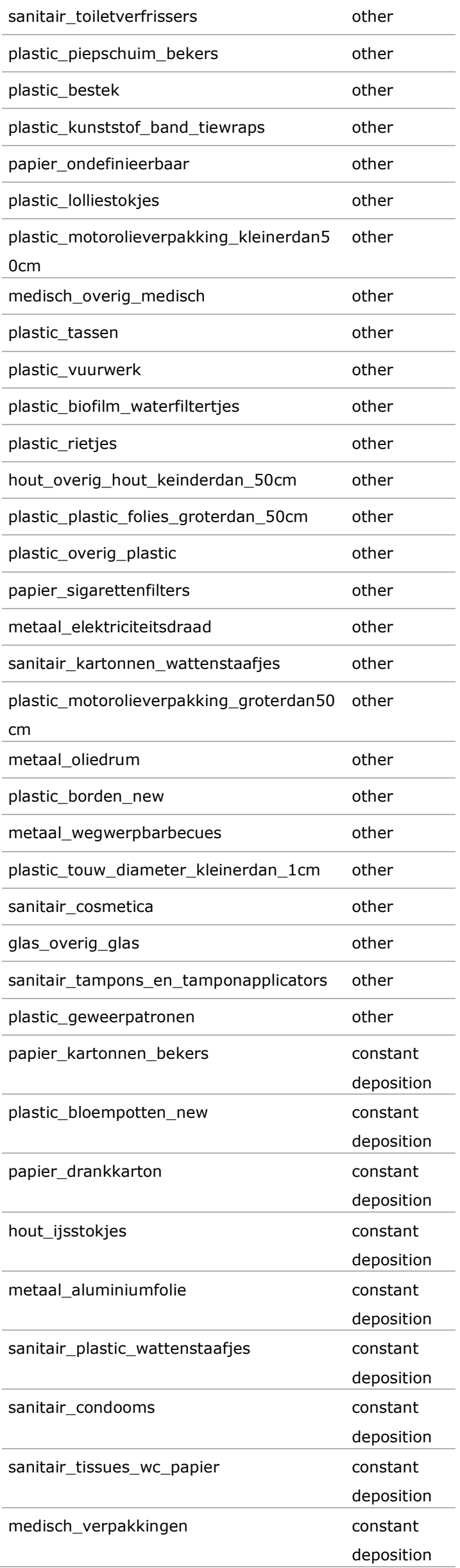




\begin{tabular}{|c|c|}
\hline papier_papier_overig & $\begin{array}{l}\text { constant } \\
\text { deposition }\end{array}$ \\
\hline papier_sigarettenverpakking & $\begin{array}{l}\text { constant } \\
\text { deposition }\end{array}$ \\
\hline granulaat_korrels & $\begin{array}{l}\text { constant } \\
\text { deposition }\end{array}$ \\
\hline papier_tassen & $\begin{array}{l}\text { constant } \\
\text { deposition }\end{array}$ \\
\hline plastic_emmers & $\begin{array}{l}\text { constant } \\
\text { deposition }\end{array}$ \\
\hline plastic_aanstekers & $\begin{array}{l}\text { constant } \\
\text { deposition }\end{array}$ \\
\hline plastic_cosmeticaverpakkingen & $\begin{array}{l}\text { constant } \\
\text { deposition }\end{array}$ \\
\hline plastic_schoenen & $\begin{array}{l}\text { constant } \\
\text { deposition }\end{array}$ \\
\hline $\begin{array}{l}\text { plastic_plastic_stukjes_2_5_50cm_hard_ } \\
\text { plastic }\end{array}$ & $\begin{array}{l}\text { constant } \\
\text { deposition }\end{array}$ \\
\hline $\begin{array}{l}\text { plastic_plastic_stukjes_0_2_5cm_zacht_p } \\
\text { lastic }\end{array}$ & $\begin{array}{l}\text { constant } \\
\text { deposition }\end{array}$ \\
\hline plastic_netzakken & $\begin{array}{l}\text { constant } \\
\text { deposition }\end{array}$ \\
\hline plastic_piepschuim_2_5_50cm & $\begin{array}{l}\text { constant } \\
\text { deposition }\end{array}$ \\
\hline plastic_piepschuim_voedselverpakkingen & $\begin{array}{l}\text { constant } \\
\text { deposition }\end{array}$ \\
\hline plastic_piepschuim_0_2_5cm & $\begin{array}{l}\text { constant } \\
\text { deposition }\end{array}$ \\
\hline plastic_piepschuim_groterdan_50cm & $\begin{array}{l}\text { constant } \\
\text { deposition }\end{array}$ \\
\hline plastic_hard_plastic_groterdan_50cm & $\begin{array}{l}\text { constant } \\
\text { deposition }\end{array}$ \\
\hline plastic_drankflessen_groterdan_halveliter & $\begin{array}{l}\text { constant } \\
\text { deposition }\end{array}$ \\
\hline plastic_kitspuiten & $\begin{array}{l}\text { constant } \\
\text { deposition }\end{array}$ \\
\hline plastic_schrijfwaren & $\begin{array}{l}\text { constant } \\
\text { deposition }\end{array}$ \\
\hline $\begin{array}{l}\text { plastic_drankflessen_kleinerdan_halvelite } \\
r\end{array}$ & $\begin{array}{l}\text { constant } \\
\text { deposition }\end{array}$ \\
\hline $\begin{array}{l}\text { plastic_verpakking_van_schoonmaakmid } \\
\text { delen }\end{array}$ & $\begin{array}{l}\text { high water } \\
\text { deposition }\end{array}$ \\
\hline $\begin{array}{l}\text { plastic_voedselverpakkingen_frietbakjes_ } \\
\text { etc }\end{array}$ & $\begin{array}{l}\text { high water } \\
\text { deposition }\end{array}$ \\
\hline plastic_wikkels_van_drankflessen & $\begin{array}{l}\text { high water } \\
\text { deposition }\end{array}$ \\
\hline sanitair_vochtige_doekjes & $\begin{array}{l}\text { high water } \\
\text { deposition }\end{array}$ \\
\hline sanitair_overig_sanitair & $\begin{array}{l}\text { high water } \\
\text { deposition }\end{array}$ \\
\hline plastic_doppen_en_deksels & $\begin{array}{l}\text { high water } \\
\text { deposition }\end{array}$ \\
\hline plastic_kleine_plastic_tasjes & $\begin{array}{l}\text { high water } \\
\text { deposition }\end{array}$ \\
\hline plastic_speelgoed & $\begin{array}{l}\text { high water } \\
\text { deposition }\end{array}$ \\
\hline
\end{tabular}

\begin{tabular}{|c|c|}
\hline medisch_spuiten & $\begin{array}{l}\text { high water } \\
\text { deposition }\end{array}$ \\
\hline $\begin{array}{l}\text { sanitair_maandverband_en_verpakkingen } \\
\text { _ervan }\end{array}$ & $\begin{array}{l}\text { high water } \\
\text { deposition }\end{array}$ \\
\hline plastic_handschoenen_huishoudelijk & $\begin{array}{l}\text { high water } \\
\text { deposition }\end{array}$ \\
\hline plastic_helmen & $\begin{array}{l}\text { high water } \\
\text { deposition }\end{array}$ \\
\hline plastic_breekstaafjes & $\begin{array}{l}\text { high water } \\
\text { deposition }\end{array}$ \\
\hline textiel_overig_textiel & $\begin{array}{l}\text { high water } \\
\text { deposition }\end{array}$ \\
\hline textiel_schoeisel & $\begin{array}{l}\text { high water } \\
\text { deposition }\end{array}$ \\
\hline textiel_kleding & $\begin{array}{l}\text { high water } \\
\text { deposition }\end{array}$ \\
\hline plastic_vuilniszakken & $\begin{array}{l}\text { high water } \\
\text { deposition }\end{array}$ \\
\hline hout_kurk & $\begin{array}{l}\text { high water } \\
\text { deposition }\end{array}$ \\
\hline hout_pellets & $\begin{array}{l}\text { high water } \\
\text { deposition }\end{array}$ \\
\hline metaal_overig_metaal_groterdan_50cm & $\begin{array}{l}\text { high water } \\
\text { deposition }\end{array}$ \\
\hline metaal_capsules & $\begin{array}{l}\text { high water } \\
\text { deposition }\end{array}$ \\
\hline $\begin{array}{l}\text { plastic_plastic_stukjes_0_2_5cm_hard_pl } \\
\text { astic }\end{array}$ & $\begin{array}{l}\text { high water } \\
\text { deposition }\end{array}$ \\
\hline metaal_omheinigsdraad_prikkeldraad & $\begin{array}{l}\text { high water } \\
\text { deposition }\end{array}$ \\
\hline metaal_spuitbussen & $\begin{array}{l}\text { high water } \\
\text { deposition }\end{array}$ \\
\hline papier_karton & $\begin{array}{l}\text { high water } \\
\text { deposition }\end{array}$ \\
\hline metaal_vislood & $\begin{array}{l}\text { high water } \\
\text { deposition }\end{array}$ \\
\hline plastic_industrieel_verpakkingsmateriaal & $\begin{array}{l}\text { high water } \\
\text { deposition }\end{array}$ \\
\hline metaal_drankblikjes & $\begin{array}{l}\text { high water } \\
\text { deposition }\end{array}$ \\
\hline plastic_6_packringen & $\begin{array}{l}\text { high water } \\
\text { deposition }\end{array}$ \\
\hline
\end{tabular}




\section{Annex 6 Supporting files}

Python files

- ospar.py

- the main functions used in the Jupyter notebooks

Jupyter notebooks

- 01_dubious_locations.ipynb

- Checking the quality of the database and locations

- 02_ospar_analysis.ipynb

- Integrating RWS and KNMI in the database

- 03_ospar_spatial_analysis.ipynb

- Creating figures and the statistical models

Excel files

- table_final.xlsx

- Coefficients of the statistical models as used in chapter 5 
Wageningen University

P.O. Box 47

6700 AA

Wageningen

The Netherlands

$\mathrm{T}+31(0) 317480700$

www.wur.nl

Wageningen University

Report
The mission of Wageningen University \& Research is "To explore the potential of nature to improve the quality of life". Under the banner Wageningen University \& Research, Wageningen University and the specialised research institutes of the Wageningen Research Foundation have joined forces in contributing to finding solutions to important questions in the domain of healthy food and living environment. With its roughly 30 branches, 5,000 employees and 10,000 students, Wageningen University \& Research is one of the leading organisations in its domain. The unique Wageningen approach lies in its integrated approach to issues and the collaboration between different disciplines. 